NBER WORKING PAPER SERIES

\title{
DISTINGUISHING CONSTRAINTS ON FINANCIAL INCLUSION AND THEIR IMPACT ON GDP, TFP, AND THE DISTRIBUTION OF INCOME
}

\author{
Era Dabla-Norris \\ Yan Ji \\ Robert M. Townsend \\ D. Filiz Unsal \\ Working Paper 20821 \\ http://www.nber.org/papers/w20821 \\ NATIONAL BUREAU OF ECONOMIC RESEARCH \\ 1050 Massachusetts Avenue \\ Cambridge, MA 02138 \\ January 2015, Revised December 2019
}

\begin{abstract}
Previously circulated as "Distinguishing Constraints on Financial Inclusion and Their Impact on GDP and Inequality."We thank Abhijit Banerjee, Adrien Auclert, Francisco Buera, Stijn Claessens, Dean Corbae, Joseph Kaboski, Hanno Lustig, David Marston, Benjamin Moll, Rafael Portillo, Yongs Shin, Alp Simsek, Iv an Werning, and seminar participants at ESWC 2015, the IMF Workshop on Macroeconomic Policy and Inequality, and the MIT Macro and Development seminar for very helpful comments. We thank Songyuan Teng for excellent research assistance. This paper forms part of a research project on macroeconomic policy in low-income countries supported by the U.K.'s Department for International Development (DFID). The views here belong to the authors and not to the DFID. Townsend gratefully acknowledges research support from the Eunice Kennedy Shriver National Institute of Child Health and Human Development (NICHD) (grant number R01 HD027638), the Centre for Economic Policy Research (CEPR), and DFID (grant number MRG002-1255).
\end{abstract}

NBER working papers are circulated for discussion and comment purposes. They have not been peer-reviewed or been subject to the review by the NBER Board of Directors that accompanies official NBER publications.

(C) 2015 by Era Dabla-Norris, Yan Ji, Robert M. Townsend, and D. Filiz Unsal. All rights reserved. Short sections of text, not to exceed two paragraphs, may be quoted without explicit permission provided that full credit, including $\odot$ notice, is given to the source. 
Distinguishing Constraints on Financial Inclusion and Their Impact on GDP, TFP, and the Distribution of Income

Era Dabla-Norris, Yan Ji, Robert M. Townsend, and D. Filiz Unsal

NBER Working Paper No. 20821

January 2015, Revised December 2019

JEL No. C54,E23,E44,E69,O11,O16,O57

\section{ABSTRACT}

A general equilibrium model featuring multiple realistic sources of financial frictions is developed to study how different constraints interact in equilibrium. We highlight, distinguish, and evaluate their differential impacts and rich interactions. The economic impact of financial inclusion policies in an economy depends not only on which constraint is alleviated, but also on the tightness of other constraints. Policy instruments should target the most binding constraint, which likely varies across countries. Moreover, there are important tradeoffs between financial inclusion, GDP, and the distribution of income. The transitional dynamics also differ from those in steady states. Policy makers should consider both.

Era Dabla-Norris

International Monetary Fund

700 19th Street Northwest

Washington, DC 20431

EDABLANORRIS@imf.org

Yan Ji

Room 5005, Department of Finance

Lee Shau Kee Business Building

Hong Kong University of Science

and Technology

Clear Water Bay, Kowloon, Hong Kong

Hong Kong

China

jiy@ust.hk
Robert M. Townsend

Department of Economics, E52-538

MIT

50 Memorial Drive

Cambridge, MA 02142

and NBER

rtownsen@mit.edu

D. Filiz Unsal

International Monetary Fund

700 19th Street Northwest

Washington, DC 20431

dunsal@imf.org 


\section{Introduction}

The development of a financial system is multi-faceted in nature. In general, the stage of financial development and the extent of financial inclusion in a country are mainly reflected in the breadth (ability of firms to access credit), depth (the amount of collateral required for borrowing), and efficiency (ability of financial intermediaries to provide services at low cost) of its financial system. These three characteristics can be proxied by the fraction of firms with credit, the loan-to-collateral ratio, and one minus the interest rate spread. More developed financial systems are usually associated with greater breadth, depth, and efficiency. However, there are significant cross-country difference, and the correlations among the three measures are not high (see Figure 1).
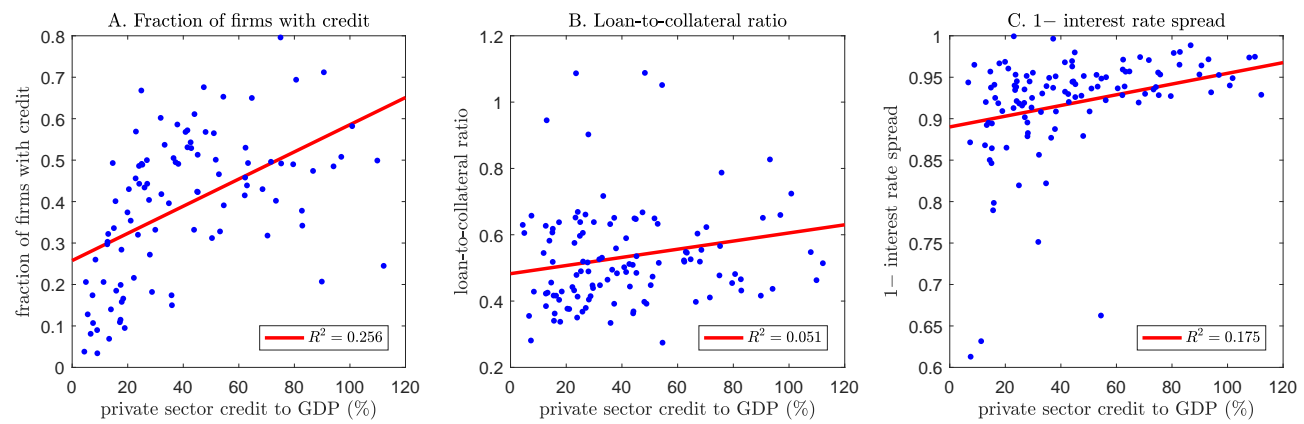

Note: Data is from the World Bank's Enterprise Surveys and World Development Indicators. The breadth, depth, and efficiency of a country's financial system can be measured by the fraction of firms with credit, the loan-to-collateral ratio, and one minus the interest rate spread, respectively. Among the 139 countries in our sample, the correlation is 0.11 between the measures of breadth and depth, 0.09 between the measures of depth and efficiency, and 0.37 between the measures of efficiency and breadth.

Figure 1: Ratio of private credit to GDP versus various financial system indicators.

For this reason, policy instruments to foster financial inclusion will necessarily vary across countries. Instead of deriving optimal policies based on specific objectives and cost functions, the goal of this paper is to highlight, distinguish, and systematically examine the tradeoffs between various policy instruments as an essential first step in policy design. Reduced-form empirical techniques, however, are less likely to offer revealing answers, because different constraints have nonlinear interactions with each other and economy-wide policies inevitably have general-equilibrium effects. These challenges lend themselves to a structural approach followed in this paper. 
We develop a general equilibrium model of heterogeneous agents with multiple sources of financial frictions to study the equilibrium interactions among different financial constraints and their implications on GDP, TFP, and the distribution of income. Our model has two key implications. First, policy instruments should target the most binding constraint, which likely varies across countries. Likewise, assuming there is only one generic type of constraint across all countries can give inaccurate predictions of an economy's response to lowering that constraint. For example, relaxing the collateral constraint may significantly boost GDP in one country, but may not be as effective in other countries, where financial inclusion is constrained by a high borrowing cost. Second, there are important tradeoffs between financial inclusion, GDP, and the distribution of income. Further, short-run transitional effects may differ from outcomes in long-run steady states, which may be years away. ${ }^{1}$ For example, policies that increase GDP may lead to high income inequality and the extent of these tradeoffs can vary over time after implementation. We provide a roadmap for policy makers so that they know what they are likely to face in the future, thereby allowing them to build in some commitment if possible or to choose another path if not.

Our model is built on the workhorse model of occupational choice in the macro-development literature (see, e.g., Banerjee and Newman, 1993; Gine and Townsend, 2004; Buera and Shin, 2011, 2013). In the model, agents are heterogeneous in wealth and entrepreneurial productivity, and can choose to be workers or entrepreneurs. Workers supply labor for wages in return. Entrepreneurs use capital and labor for production.

Our major deviation from standard models is that we make the more realistic assumption that agents face multiple sources of financial constraints rather than a single one. First, agents who borrow from financial intermediaries incur a credit entry cost. This cost captures the fixed transaction costs, documentation requirements, and other access barriers. Second, the amount of loans obtained is constrained by a collateral constraint as in Jermann and Quadrini (2009, 2012). Finally, the interest rate charged by loans is higher than the deposit rate, reflecting

\footnotetext{
${ }^{1}$ In Appendix C.5, we study the transitional dynamics after implementing financial inclusion policies.
} 
an informational or intermediation cost. Existing studies have emphasized the quantitative importance of each type of financial friction. For example, Greenwood and Jovanovic (1990) and Townsend and Ueda (2006) study the credit entry cost. Buera, Kaboski and Shin (2011) and Buera and Shin (2013) focus on the collateral constraint. Greenwood, Sanchez and Wang $(2010,2013)$ quantify the importance of the intermediation cost. These three types of financial constraints distort the allocation of capital and entrepreneurial productivity. They naturally give rise conceptually to three policy instruments, each alleviating a specific type of constraint.

Real-world counterparts of these constraints are easy to find. For example, the existing literature has documented that the distance to a bank branch matters for credit access, suggesting that policies to promote branch opening in rural locations with unbanked populations could help reduce the credit entry cost in our model. ${ }^{2}$ During the global financial crisis of 2007 - 2008, many countries relaxed the collateral constraint by widening the range of securities that could be accepted as collateral with the aim of boosting lending to firms and households. Finally, financial inclusion can lead to increased competition among financial institutions, accelerating investment in financial technology, thereby improving intermediation efficiency and lowering the intermediation cost. ${ }^{3}$

In order to assess and quantify the interactions and tradeoffs of policy instruments, we calibrate the model using data from the World Bank's Enterprise Surveys and World Development Indicators for a number of countries. We choose the model's key parameters to match the data moments reflecting the key characteristics of a financial system, in particular the percentage of firms with credit, the collateral-to-loan ratio, and the interest rate spread,

\footnotetext{
${ }^{2}$ Many developing countries have implemented such policies to increase credit access. For example, after nationalizing a bank in 1969, the Indian government launched an ambitious social banking program that sought to improve the access of the rural poor to formal credit and savings opportunities (see Burgess and Pande, 2005). Also see Assuncao, Mityakov and Townsend (2012), Alem and Townsend (2013), Gilje, Loutskina and Strahan (2016), Aguirregabiria, Clark and Wang (2017), Celerier and Matray (2017), and Nguyen (2017).

${ }^{3}$ For example, from 1985 to 1994, the Thai banking sector became more capital-intensive, substituting physical capital for labor. The average cost of raising funds decreased from $14.40 \%$ in 1985 to $5.61 \%$ in 1994 for large banks (see Okuda and Mieno, 1999).
} 
as well as other moments such as the real interest rate, the gross savings as a percentage of GDP, and the firm employment distribution.

Our lead illustrative example is taken from the Philippines, although we also consider other countries. We first examine the steady-state implications of alleviating different financial constraints on GDP and TFP by conducting counterfactual experiments. Policies that relax the collateral constraint away from its calibrated value have a larger impact on increasing GDP and TFP than policies that reduce the credit entry cost or the intermediation cost. Moreover, the model implies that the increase in GDP and TFP is attributed to different margins depending on which policy instrument is used. Specifically, when the credit entry cost is reduced, GDP and TFP will initially increase mostly through the intensive margin; that is, the few entrepreneurs who already have access to finance will expand their scale of production. This is because most entrepreneurs do not have sufficient wealth to pay the upfront cost and are excluded from the credit market. When the credit entry cost is further lowered, however, GDP and TFP will increase through the extensive margin; that is, productive but wealth-constrained entrepreneurs who were previously excluded from the credit market will start to gain access to finance. By contrast, when the collateral constraint is relaxed, both intensive and extensive margins will contribute significantly to the increase in GDP and TFP. When the intermediation cost is lowered, the increase in GDP and TFP is attributed only to the extensive margin. More generally, the model structure provides these decompositions in theory with formulas, which are also quantified in the data, as are the general equilibrium effects on wages and interest rates.

We further study the equilibrium interactions of these financial constraints. In partial equilibrium, our analytical results reveal that when multiple constraints are relaxed simultaneously, the effect is amplified through the intensive margin but dampened through the extensive margin. This implies that policies that alleviate multiple constraints could, in principle, yield a larger or a smaller effect than policies targeting individual constraints, depending on whether the overall interaction effect between different constraints is positive or 
negative. For example, if the interaction effect through the intensive margin dominates, policy makers should develop a more balanced financial system, as different financial constraints are complements in constraining GDP. In this case, policies that alleviate the most binding financial constraint would be most effective. On the other hand, if the interaction effect through the extensive margin dominates, policy makers should focus on alleviating a single constraint while ignoring all other constraints.

Using the calibrated model, we conduct a sequence of counterfactual experiments to study the equilibrium interactions between financial constraints. We find that the interaction effect between different constraints is positive, suggesting that effective financial inclusion policies should be designed to develop a well-rounded financial system by alleviating the currently most binding constraint. As noted earlier, policies that are effective in increasing GDP in one country may not be equally effective in others. Therefore, identifying the most binding constraint is important for designing financial policies.

In terms of the distributional implications, we find that policies that relax different constraints tend to bring differential benefits to agents, depending on their wealth and productivity. Although reducing the credit entry cost benefits every agent in the economy, the welfare of some agents will fall when the collateral constraint is relaxed or when the intermediation cost is reduced due to general equilibrium effects.

To demonstrate how our model can be harnessed to help identify the bottleneck constraint in a financial system, we separately calibrate the model to six representative countries. Three of them, Pakistan, Bangladesh, and Brazil, have relatively extreme financial constraints. For example, only $6.7 \%$ of firms in Pakistan have access to credit; the average collateral requirement in Bangladesh is $271.4 \%$ of the loan size; and in Brazil, the interest spread between lending rates and deposit rates is as high as 35.4\%. The model implies that policies that relax the collateral constraint in Bangladesh and reduce the intermediation cost in Brazil would be more effective in increasing GDP and TFP, which is consistent with the inference directly drawn from the tight collateral constraint in Bangladesh and the high 
interest rate spread in Brazil. However, choosing the policy instrument entirely based on descriptive statistics could be misleading because these statistics are endogenously determined in equilibrium. For instance, the model implies that relaxing the collateral constraint rather than reducing the credit entry cost would increase the GDP of Pakistan more, even though the country's credit access ratio is low.

The other three countries analyzed are the Philippines, Kenya, and Zambia, which have relatively balanced financial constraints. It is difficult to tell which financial constraint is most binding simply by looking at the descriptive statistics for the credit access ratio, the collateral-to-loan ratio, and the interest rate spread. By calibrating the model to these countries, we are able to systematically evaluate the potential impacts of different policy instruments, and hence shed light on the real underlying bottleneck. Our model provides a structural framework to systematically study the potential implications of different financial inclusion policies, providing complementary and arguably more accurate evaluations than simple summary statistics.

Finally, to evaluate our model's ability to explain real-world policy intervention, we apply it to the analysis of a large-scale financial liberalization policy implemented in Thailand during the period from 1986 to 1995 . The model is able to explain a large fraction of the cumulative growth in GDP and TFP, and can also generate a hump-shaped income Gini coefficient that resembles the data. Importantly, the model allows us to separately quantify the extent to which relaxing different constraints can drive economic growth and the dynamics of income inequality.

Related Literature. Our paper is related to the literature that uses models of occupational choice and financial frictions to study the aggregate and distributional impacts of financial intermediation (see, e.g., Banerjee and Newman, 1993; Lloyd-Ellis and Bernhardt, 2000; Gine and Townsend, 2004; Cagetti and De Nardi, 2006; Jeong and Townsend, 2007, 2008; Amaral and Quintin, 2010; Buera, Kaboski and Shin, 2011, 2012; Greenwood, Sanchez and 
Wang, 2013; Moll, 2014). In contrast to these studies, our model introduces multiple financial frictions to the occupational choice framework to highlight multiple dimensions of financial inclusion within an economy. The model also uncovers how different frictions interact with each other.

Our paper is particularly related to studies in which multiple financial frictions co-exist and are compared. For example, Albuquerque and Hopenhayn (2004) and Clementi and Hopenhayn (2006) find that moral hazard and limited commitment have different implications for firm dynamics. Abraham and Pavoni (2005) and Doepke and Townsend (2006) illustrate how consumption allocations differ under moral hazard with and without hidden savings versus full information. Ahlin and Townsend (2007) emphasize regional variations in obstacles to trade and financial constraints. Martin and Taddei (2013) study the implications of adverse selection on macroeconomic aggregates and contrast them with those under limited commitment. Karaivanov and Townsend (2014) estimate the financial/information regime in place for households (including those running businesses) in Thailand and find that a financial regime constrained by moral hazard fits the data best in urban areas, while a regime that is more limited by savings is more applicable for rural areas. Relatedly, Paulson, Townsend and Karaivanov (2006) argue that moral hazard best fits the data in the more urban central region of Thailand but not in the more rural northeast. Kinnan (2014) uses a different metric based on the first-order conditions characterizing optimal insurance under moral hazard, limited commitment, and hidden income to distinguish between these regimes in Thai data. Moll, Townsend and Zhorin (2014) develop a general equilibrium framework that encompasses different types of frictions, and examine their interactions. More recently, Nikolov, Schmid and Steri (2018) develop a rich structural corporate model incorporating multiple financial frictions, with the goal of identifying sources of financial constraints using firm-level data. Our paper is different from these studies in that we emphasize the rich interactions among financial constraints and the tradeoffs between different policy instruments.

Our paper is also related to the literature on misallocation (see, e.g., Hsieh and Klenow, 
2009; Banerjee and Moll, 2010; Caselli and Gennaioli, 2013; Midrigan and Xu, 2014; Moll, 2014; Bassetto, Cagetti and De Nardi, 2015) and inequality (see, e.g., Davies, 1982; Huggett, 1996; Aghion and Bolton, 1997; Quadrini, 2000; Castaneda, Diaz-Gimenez and Rios-Rull, 2003; Nardi, 2004; Cagetti and De Nardi, 2006, 2009; Benhabib, Bisin and Zhu, 2011, 2015; De Nardi and Yang, 2016; De Nardi, Giulio and Yang, 2016). Our contribution is to show that policy instruments that target different financial sector frictions have differential impacts on resource allocation and inequality.

\section{Model}

We develop a general equilibrium model of heterogeneous agents with multiple sources of financial frictions to study the equilibrium interactions among different financial constraints.

\subsection{Agents}

Heterogeneity and Demographics. Time is indexed by $t$. The economy is populated by a continuum of agents of measure one and there is no population growth. Agents live indefinitely and are heterogeneous in terms of wealth $b_{t}$ and entrepreneurial productivity $z_{t}$. Wealth $b_{t}$ evolves endogenously, determined by forward-looking savings decisions. Productivity $z_{t}$ follows an exogenous stochastic process. In particular, with probability $\gamma$, agents retain their productivity in the previous period; with probability $1-\gamma$, agents draw a new productivity from a time-invariant Pareto distribution $\mu(z)$ governed by the tail parameter $\theta$. The shocks to productivity can be interpreted as changes in market conditions that affect the profitability of individual skills (see Buera, Kaboski and Shin, 2011).

Preferences. Agents derive utility from consumption $c_{t}$ and have preferences

$$
\mathbb{E}_{t}\left[\sum_{s=t}^{\infty} \beta^{s-t} \frac{c_{s}^{1-\sigma}}{1-\sigma}\right],
$$


where $\beta$ is the discount factor and $\sigma$ is the risk-aversion parameter.

Technology. In any period $t$, agents can choose to be workers or entrepreneurs. Each worker supplies one unit of labor inelasticly and earns the equilibrium wage $w_{t}$. Each entrepreneur operates a technology that uses capital $k_{t}$ and labor $l_{t}$ as inputs to produce output. The profitability of an entrepreneurial business depends on the agent's productivity; specifically, the output $f\left(k_{t}, l_{t}, z_{t}\right)$ is given by

$$
f\left(k_{t}, l_{t}, z_{t}\right)=z_{t}\left(k_{t}^{\alpha} l_{t}^{1-\alpha}\right)^{1-\nu}
$$

where $1-\nu$ is the span-of-control parameter, representing the share of output accruing to variable factors. Out of this, a fraction $\alpha$ goes to capital and $1-\alpha$ goes to labor. Production exhibits diminishing returns to scale, with $\nu>0$. Capital depreciates at rate $\delta$. Our specification of technology follows Buera and Shin (2011), and is also close to Quadrini (2000) and Cagetti and De Nardi (2006) among many others. ${ }^{4}$

\section{$2.2 \quad$ Financial Markets}

The only asset in the economy is capital. This is equivalent to assuming the existence of a perfect technology that can freely transform capital into consumption goods. Perfectly competitive financial intermediaries receive deposits from all agents and lend to entrepreneurs. The deposit interest rate $r_{t}$ is determined endogenously by the capital market clearing condition at time $t$. Following Buera and Shin (2011), we focus on within-period credit for production purposes. We do not allow borrowing for consumption smoothing across periods by imposing $b_{t} \geq 0$. Therefore, only entrepreneurs borrow from intermediaries.

The key distinction of our model is that we introduce and examine three sources of

\footnotetext{
${ }^{4}$ Unlike Quadrini (2000) and Cagetti and De Nardi (2006), we do not model heterogeneous working ability or the corporate sector. We focus on the entrepreneurial sector to demonstrate the interactions among different financial constraints and what important role they might play in policy evaluation. As discussed in Appendix C.2, introducing the corporate sector would affect the response of interest rates and wages to financial inclusion policies, which may consequently have different implications for wealth inequality.
} 
financial frictions in a unified framework. Each source of friction reflects one particular aspect of financial market imperfection. These three types of financial constraints naturally give rise conceptually to three policy instruments, each targeting a specific constraint. The three frictions are described below.

Limited Credit Access. Entrepreneurs incur a fixed credit entry cost $\psi$ to borrow from intermediaries. The modeling of fixed entry costs for obtaining credit follows Greenwood and Jovanovic (1990) and Townsend and Ueda (2006) among others. It captures, for example, various fees associated with financial accounts, the cost of bookkeeping and exchange (transportation), and others (see, e.g., Townsend, 1983).

We assume that an agent lives in a "credit regime" if the agent pays the cost $\psi$ and can borrow, and in a "savings regime" if the agent does not pay $\psi$ and can therefore only save. In equilibrium, the fixed entry cost $\psi$ is more likely to exclude poor entrepreneurs from financial markets, as it amounts to a larger fraction of their wealth.

Collateral Constraint. The credit contract that entrepreneurs receive is subject to a collateral requirement due to limited enforceability of debt contracts. In particular, consider an entrepreneur with wealth $b_{t}$ who approaches financial intermediaries for a loan $x_{t}$ at the competitive equilibrium lending interest rate $r_{t}^{l}$. After obtaining the loan $x_{t}$, the entrepreneur transforms her wealth-on-hand $b_{t}-\psi+x_{t}$ costlessly into capital $k_{t}=b_{t}-\psi+x_{t}$, which is then used as collateral to secure the loan $x_{t}$. The entrepreneur is free to default and walk away with her income and wealth at any time, but if she does, the financial intermediaries will seize the collateral. Following Jermann and Quadrini (2009,2012), we assume that the liquidation value of capital is uncertain at the time of contracting. With probability $1-\xi$ intermediaries recover the full value $k_{t}$, but with probability $\xi$ they recovery nothing. Thus to avoid default, the amount of loan $x_{t}$ that intermediaries are willing to lend is restricted to $x_{t} \leq(1-\xi) k_{t}$. Substituting $x_{t}$, we can derive the entrepreneur's capital constraint in terms 
of her wealth $b_{t}$ :

$$
\xi k_{t} \leq b_{t}-\psi
$$

The single parameter $\xi \in[0,1]$ parsimoniously captures the tightness of the borrowing constraint, with $\xi=1$ corresponding to financial autarky, where all capital must be selffinanced by entrepreneurs with their wealth $b_{t}-\psi$.

Intermediation Inefficiency. We assume that the lending interest rate $r_{t}^{l}$ is higher than the deposit interest rate $r_{t}$ by a margin $\chi$, i.e., $r_{t}^{l}=r_{t}+\chi$. Thus for the loan $x_{t}$, entrepreneurs pay intermediation fees equal to $\chi x_{t}$. The interest rate spread $\chi$ reflects the efficiency of financial intermediation. For example, as noted by Townsend (1983), costly intermediation could arise from the cost of enforcement and monitoring when information is imperfect.

\subsection{Agents' Problem}

We formulate the agent's problem recursively. Denote by $V_{t}\left(b_{t}, z_{t}\right)$ the value function of the agent of type $\left(b_{t}, z_{t}\right)$. Denote by $W_{t}\left(b_{t}, z_{t}\right)$ or $E_{t}\left(b_{t}, z_{t}\right)$ the agent's value if she chooses to be a worker or an entrepreneur at time $t$. The occupation choice is made to maximize utility,

$$
V_{t}\left(b_{t}, z_{t}\right)=\max \left\{W_{t}\left(b_{t}, z_{t}\right), E_{t}\left(b_{t}, z_{t}\right)\right\}
$$

The value function also generally depends on time $t$ because we consider transitional dynamics. For ease of exposition, we denote variables and distributions in steady states by omitting the subscript $t$. The worker's value is given by

$$
\begin{aligned}
W_{t}\left(b_{t}, z_{t}\right) & =\max _{c_{t}} \frac{c_{t}^{1-\sigma}}{1-\sigma}+\beta \mathbb{E}_{t}\left[V_{t+1}\left(b_{t+1}, z_{t+1}\right)\right] \\
\text { s.t. } \quad c_{t}+b_{t+1} & =\left(1+r_{t}\right) b_{t}+w_{t}, \quad \text { with } \quad c_{t}, b_{t+1} \geq 0 .
\end{aligned}
$$

The entrepreneur's value is determined by comparing the cases with and without borrowing 
from financial intermediaries. Denote by $E_{t}^{s}\left(b_{t}, z_{t}\right)$ or $E_{t}^{c}\left(b_{t}, z_{t}\right)$ the entrepreneur's value when capital is financed with savings only or with credit as well. The borrowing decision is made to maximize utility,

$$
E_{t}\left(b_{t}, z_{t}\right)=\max \left\{E_{t}^{s}\left(b_{t}, z_{t}\right), E_{t}^{c}\left(b_{t}, z_{t}\right)\right\}
$$

In the savings regime, the agent finances production herself and the remaining wealth is deposited in financial intermediaries for interest earnings. The value function in the savings regime is

$$
\begin{aligned}
E_{t}^{s}\left(b_{t}, z_{t}\right) & =\max _{c_{t}, k_{t}, l_{t}} \frac{c_{t}^{1-\sigma}}{1-\sigma}+\beta \mathbb{E}_{t}\left[V_{t+1}\left(b_{t+1}, z_{t+1}\right)\right] \\
\text { s.t. } \quad c_{t}+b_{t+1} & =z_{t}\left(k_{t}^{\alpha} l_{t}^{1-\alpha}\right)^{1-\nu}+(1-\delta) k_{t}-w_{t} l_{t}+\left(1+r_{t}\right)\left(b_{t}-k_{t}\right), \\
k_{t} & \leq b_{t} \text { and } c_{t}, k_{t}, l_{t}, b_{t+1} \geq 0 .
\end{aligned}
$$

In the credit regime, the agent takes out loans to finance production. Without loss of generality, we only consider the case in which the agent invests $k_{t}>b_{t}$ in the credit regime, because investing $k_{t} \leq b_{t}$ but paying the credit entry cost is obviously not optimal. Thus, we can write the value function in the credit regime as

$$
\begin{aligned}
E_{t}^{c}\left(b_{t}, z_{t}\right) & =\max _{c_{t}, k_{t}, l_{t}} \frac{c_{t}^{1-\sigma}}{1-\sigma}+\beta \mathbb{E}_{t}\left[V_{t+1}\left(b_{t+1}, z_{t+1}\right)\right] \\
\text { s.t. } \quad c_{t}+b_{t+1} & =z_{t}\left(k_{t}^{\alpha} l_{t}^{1-\alpha}\right)^{1-\nu}+(1-\delta) k_{t}-w_{t} l_{t}-\left(1+r_{t}+\chi\right)\left(k_{t}-b_{t}+\psi\right), \\
\xi k_{t} & \leq b_{t}-\psi \text { and } c_{t}, l_{t}, b_{t+1} \geq 0 \text { and } k_{t}>b_{t} .
\end{aligned}
$$

Panel A of Figure 2 illustrates the choice of occupation for agents with different levels of wealth and productivity. Depending on whether the occupation choice is constrained by wealth, we identify four categories of agents: unconstrained workers, constrained workers, constrained entrepreneurs, and unconstrained entrepreneurs. As shown in the figure, there is a certain level of productivity below which agents will always find working for a wage better than operating a business. These agents are identified as unconstrained workers, because their 

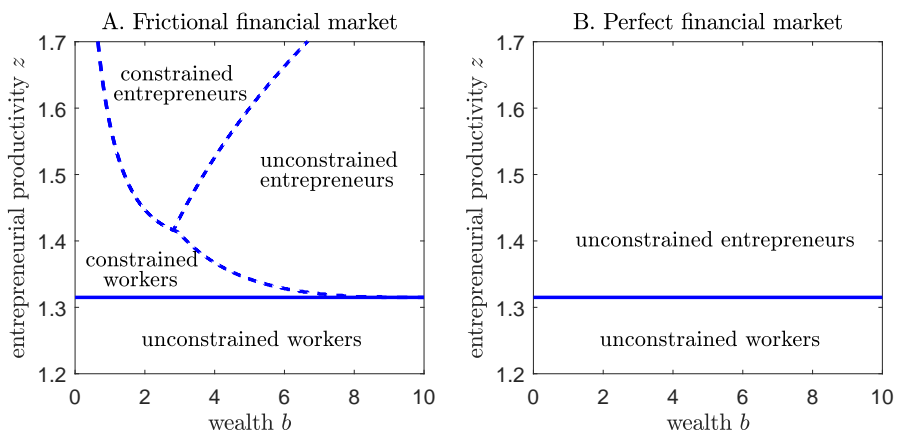

Note: Panel A illustrates the occupation choice in the presence of financial frictions (i.e., $\psi=0.05, \chi=0.05, \xi=0.5$ ). Panel $\mathrm{B}$ illustrates the occupation choice in a perfect financial market (i.e., $\psi=\chi=\xi=0$ ) in partial equilibrium with the same interest rate and wage as panel A. In general equilibrium, when we move from an economy with financial frictions to an economy without financial frictions, the interest rate and wage will also change, which is analyzed in Section 4 . The other parameters for plotting the figure are $r=0.05, w=0.8, \delta=0.06, \nu=0.19, \alpha=0.33$.

Figure 2: Occupation choice with/without financial frictions.

productivity is so low that they will never find it optimal to become entrepreneurs. Above this level of productivity, there are three regions. The left region refers to constrained workers. These agents are productive but do not have sufficient wealth to operate businesses at a profitable scale. The middle region represents constrained entrepreneurs who have sufficient wealth to operate profitable businesses, but their scale of business is constrained. Agents in the right region choose to be entrepreneurs, operating businesses at the unconstrained scale, with the marginal return on capital equal to the marginal cost. Thus, they are classified as unconstrained entrepreneurs.

In the presence of financial market frictions, the decision to become an entrepreneur and the scale of business not only depends on productivity $z_{t}$ but also on wealth $b_{t}$. By contrast, when the financial market is perfect (i.e., $\psi=\chi=\xi=0$ ), panel B of Figure 2 indicates that productive agents always choose to be entrepreneurs and operate their businesses at the unconstrained scale. We formally state this result in Proposition 1.

Proposition 1. In the absence of financial frictions, there exists a threshold of entrepreneurial productivity $\underline{z}_{t}$, and the agent will choose to be an entrepreneur if and only if $z \geq \underline{z}_{t}$. 


\subsection{Competitive Equilibrium}

Denote by $h_{t}(b, z)$ the probability density function (PDF) for the joint distribution of wealth and productivity at the beginning of period $t$. Given an initial distribution $h_{0}(b, z)$, a competitive equilibrium consists of allocations $\left\{c_{t}(b, z), k_{t}(b, z), l_{t}(b, z)\right\}_{t=0}^{\infty}$, sequences of joint distributions of wealth and productivity $\left\{h_{t}(b, z)\right\}_{t=0}^{\infty}$ and prices $\left\{r_{t}, w_{t}\right\}_{t=0}^{\infty}$ such that:

(1) Agents optimally choose the underlying regime, occupation, consumption $c_{t}(b, z)$, capital $k_{t}(b, z)$, and labor $l_{t}(b, z)$ by solving problems (2.4)-(2.8) at all $t \geq 0$.

(2) The capital market clears at all $t \geq 0$,

$$
\iint_{(b, z) \in \Phi_{t}^{C}}\left[k_{t}(b, z)-b+\psi\right] h_{t}(b, z) \mathrm{d} b \mathrm{~d} z=\iint_{(b, z) \notin \Phi_{t}^{E}} b h_{t}(b, z) \mathrm{d} b \mathrm{~d} z+\iint_{(b, z) \in \Phi_{t}^{S}}\left[b-k_{t}(b, z)\right] h_{t}(b, z) \mathrm{d} b \mathrm{~d} z
$$

where $\Phi_{t}^{E}$ is the set of entrepreneurs at time $t ; \Phi_{t}^{S}$ and $\Phi_{t}^{C}$ are the sets of entrepreneurs in the savings and credit regimes, respectively. We have $\Phi_{t}^{E}=\Phi_{t}^{S} \cup \Phi_{t}^{C}$.

(3) The labor market clears at all $t \geq 0$,

$$
\iint_{(b, z) \in \Phi_{t}^{E}} l_{t}(b, z) h_{t}(b, z) \mathrm{d} b \mathrm{~d} z=\iint_{(b, z) \notin \Phi_{t}^{E}} h_{t}(b, z) \mathrm{d} b \mathrm{~d} z .
$$

(4) $\left\{h_{t}(b, z)\right\}_{t=0}^{\infty}$ evolves according to the equilibrium mapping

$$
h_{t+1}\left(b^{\prime}, z^{\prime}\right) \mathrm{d} b \mathrm{~d} z=\gamma d z \int \mathbb{1}_{\left\{b^{*}=b^{\prime}\right\}} h_{t}\left(b, z^{\prime}\right) \mathrm{d} b+(1-\gamma) \mu\left(z^{\prime}\right) d z \iint \mathbb{1}_{\left\{b^{*}=b^{\prime}\right\}} h_{t}(b, z) \mathrm{d} b \mathrm{~d} z,
$$

where $b^{*} \equiv b_{t+1}(b, z)$ is the wealth at $t+1$ implied by the optimal savings decision of agents of type $(b, z) . \mathbb{1}_{\left\{b^{*}=b^{\prime}\right\}}$ is an indicator function which equals one if $b^{*}=b^{\prime}$ and zero otherwise. The left-hand side of equation (2.11) is the probability mass of agents with $\left(b^{\prime}, z^{\prime}\right)$ at $t+1$. The right-hand side sums the probabilities of transition to $\left(b^{\prime}, z^{\prime}\right)$ from any arbitrary $(b, z)$ at $t$. With probability $\gamma$, the agent keeps the current 
Table 1: Calibration and moments in data and model.

\begin{tabular}{lccc}
\hline & Data & Model & Parameter \\
Firms with credit (\%) & 29.9 & 29.5 & $\psi=0.95$ \\
Collateral (\% of loans) & 156.7 & 156.4 & $\xi=0.335$ \\
Interest rate spread (\%) & 4.0 & 4.0 & $\chi=0.04$ \\
Real interest rate (\%) & 6.2 & 6.3 & $\beta=0.88$ \\
Employment share of top 5\% (\%) & 43.7 & 43.7 & $\theta=3.4$ \\
Employment share of top 10\% (\%) & 57.6 & 58.6 & $\gamma=0.89$ \\
Employment share of top 20\% (\%) & 73.2 & 71.5 & \\
Employment share of top 40\% (\%) & 88.8 & 85.3 & \\
Gross savings (\% of GDP) & 44.2 & 41.2 & \\
\hline \hline
\end{tabular}

productivity $z^{\prime}$ and transits to $b^{\prime}$ from $\left(b, z^{\prime}\right)$ if $b^{*}=b^{\prime}$. With probability $1-\gamma$, the agent draws a new productivity, which equals $z^{\prime}$ with probability $\mu\left(z^{\prime}\right) \mathrm{d} z$.

\section{Data and Calibration}

We use data from the World Bank's Enterprise Surveys and World Development Indicators to discipline the model. We calibrate the model by first matching the moments for the Philippines, which serves as our benchmark calibration. The sample contains 1,335 firms interviewed from November 2014 through May 2016. In Section 5.1, we calibrate the model to target moments of other countries and show that it could be used to conduct cross-country analyses.

We set the risk-aversion parameter $\sigma=1.5$ and the span-of-control parameter $\nu=0.19$ following standard practice. The one-year depreciation rate $\delta$ is set to 0.06 . The aggregate income share of capital $\alpha$ is set to 0.33 . The remaining six parameters are calibrated by matching relevant moments in the data as shown in Table 1.

The three key parameters, $\psi, \xi$, and $\chi$, capturing the financial frictions, are calibrated to match the three moments that reflect the country's financial development. These moments are the percentage of firms with access to credit, the collateral-to-loan ratio, and the interest rate spread. ${ }^{5}$ The $4 \%$ interest rate spread directly identifies the parameter $\chi$. For firms

\footnotetext{
${ }^{5}$ Appendix Figure C.1 presents the sensitivity of these moments to each key parameter.
} 
with access to credit, the average collateral as a percentage of loans is $156.7 \%$, indicating that for each unit of credit, the firm has to post 1.57 units of collateral on average. This moment provides information about the tightness of the collateral constraint, governed by the parameter $\xi$. In the Philippines, the fraction of firms with credit access is $29.9 \%$, which identifies the credit entry cost $\psi{ }^{6}$

Buera and Shin (2011) and Moll (2014) show that with persistent productivity, entrepreneurs can accumulate wealth on their own and overcome financial constraints. We thus identify the parameter $\gamma$ by matching the gross savings as a percentage of GDP. ${ }^{7}$ We set the discount factor $\beta$ to match the real interest rate of $6.2 \%$. The parameter $\theta$ governs the distribution of agents' entrepreneurial productivity. A lower $\theta$ implies that the distribution is more right-skewed, and hence top entrepreneurs will employ a larger fraction of labor in the economy. We thus calibrate $\theta$ to match the employment share distribution. Specifically, we use four brackets of employment shares, corresponding to the fraction of labor employed by the top $5 \%, 10 \%, 20 \%$, and $40 \%$ of entrepreneurs ranked in terms of their business income.

\section{Distinguishing the Impact of Policy Instruments}

In this section, we systematically examine the aggregate implications of different financial inclusion policies on GDP and TFP in steady states. We first present formulas to decompose changes in GDP and TFP. Next, we evaluate the aggregate implications of policy instruments and how they interact with each other in equilibrium. Finally, we shed light on the distributional implications of these policies on welfare.

\footnotetext{
${ }^{6}$ The calibrated value of $\psi$ amounts to about $10.4 \%$ of the average wealth of entrepreneurs in the credit regime. Our model requires a high value of $\psi$ in order to rationalize the low credit access ratio in the data. In the literature, Townsend and Ueda (2006) calibrate a fixed entry cost that amounts to one-third of wealth to match the low credit access ratio in Thailand in 1976.

${ }^{7} \mathrm{~A}$ more direct way to estimate $\gamma$ is to use the information on entry and exit rates of entrepreneurship. However, it is difficult to find uniform and high-quality data on business entries and exits for different countries studied in this paper. When applying our model to Thailand in Section 5.2, we use the information on households' business turnovers to calibrate $\gamma$ in a more direct manner.
} 


\subsection{Formulas for GDP and TFP Decomposition}

In our model, financial inclusion is reflected in lower values of the parameters, $\Omega \equiv(\psi, \xi, \chi)$. We decompose the effect of financial inclusion through the extensive and intensive margins. On the one hand, relaxing financial constraints can increase GDP and TFP through the extensive margin by increasing the credit access ratio (i.e., entrepreneurs move from the savings regime to the credit regime). On the other hand, relaxing financial constraints enables entrepreneurs who already have access to credit to scale up their production, boosting GDP and TFP through the intensive margin. In particular, the effect of financial inclusion on GDP and TFP can be decomposed as follows.

Proposition 2. Consider a financial inclusion policy that relaxes the constraints from $\Omega$ to $\Omega^{\prime}$, with $\Omega^{\prime} \leq \Omega$. The increase in steady-state GDP is given by

$$
\begin{aligned}
\operatorname{GDP}_{\Omega^{\prime}}-\operatorname{GDP}_{\Omega}= & \int_{z} \int_{\underline{b}\left(z ; \Omega^{\prime}\right)}^{\underline{b}(z ; \Omega)}\left[y^{C}\left(b, z ; \Omega^{\prime}\right) h\left(b, z ; \Omega^{\prime}\right)-y^{S}(b, z ; \Omega) h(b, z ; \Omega)\right] \mathrm{d} b \mathrm{~d} z \\
& +\int_{z} \int_{\underline{b}(z ; \Omega)}^{\infty}\left[y^{C}\left(b, z ; \Omega^{\prime}\right) h\left(b, z ; \Omega^{\prime}\right)-y^{C}(b, z ; \Omega) h(b, z ; \Omega)\right] \mathrm{d} b \mathrm{~d} z \\
& +\int_{z} \int_{0}^{\underline{b}\left(z ; \Omega^{\prime}\right)}\left[y^{S}\left(b, z ; \Omega^{\prime}\right) h\left(b, z ; \Omega^{\prime}\right)-y^{S}(b, z ; \Omega) h(b, z ; \Omega)\right] \mathrm{d} b \mathrm{~d} z,
\end{aligned}
$$

where $\underline{b}(z ; \Omega)$ denotes the threshold of wealth above which entrepreneurs of productivity $z$ will

choose to access credit in the steady state of the economy with $\Omega$. The variables $y^{S}(b, z ; \Omega)$ and $y^{C}(b, z ; \Omega)$ are entrepreneurs' output net of the deadweight loss arising from financial frictions in the savings and credit regimes, respectively (see Appendix A).

The first term on the right-hand side of equation (4.1) captures the increase in GDP through the extensive margin, because when $\underline{b}\left(z ; \Omega^{\prime}\right)<\underline{b}(z ; \Omega)$, more entrepreneurs will move from the savings regime to the credit regime and they will produce more. The second term captures the increase through the intensive margin, because when $y^{C}\left(b, z ; \Omega^{\prime}\right)>y^{C}(b, z ; \Omega)$, entrepreneurs who are already in the credit regime will expand their scale of production. The third term reflects the general equilibrium effect on entrepreneurs who remain in the savings 
regime after the financial inclusion policy is implemented.

We define the model-implied steady-state $\mathrm{TFP}$ as $\mathrm{TFP}_{\Omega}=Y_{\Omega} /\left(K_{\Omega}^{\alpha} L_{\Omega}^{1-\alpha}\right)$, where $Y_{\Omega}$, $K_{\Omega}$, and $L_{\Omega}$ are steady-state aggregate output, capital, and labor in the economy with $\Omega .{ }^{8}$ By exploring the equivalence between growth accounting by factor and growth accounting by regime, we can decompose the economy's change in steady-state TFP along similar dimensions. ${ }^{9}$

Proposition 3. Consider a financial inclusion policy that relaxes the constraints from $\Omega$ to $\Omega^{\prime}$, with $\Omega^{\prime} \leq \Omega$. The increase in steady-state TFP is given by

$$
\begin{aligned}
\mathrm{TFP}_{\Omega^{\prime}}-\mathrm{TFP}_{\Omega}= & g_{p^{c}}\left[s_{y}^{p}-\alpha s_{k}^{p}-(1-\alpha) s_{l}^{p}\right] \mathrm{TFP}_{\Omega}+\left[s_{y}^{c} g_{\bar{y}^{c}}-\alpha s_{k}^{c} g_{\bar{k}^{c}}-(1-\alpha) s_{l}^{c} g_{\bar{l}^{c}}\right] \mathrm{TFP}_{\Omega} \\
& +\left[s_{y}^{s} g_{\bar{y}^{s}}-\alpha s_{k}^{s} g_{\bar{k}^{s}}-(1-\alpha) s_{l}^{s} g_{\bar{l}^{s}}\right] \mathrm{TFP}_{\Omega},
\end{aligned}
$$

where $s_{y}^{p}, s_{y}^{s}, s_{y}^{c}, s_{k}^{p}, s_{k}^{s}, s_{k}^{c}, s_{l}^{p}, s_{l}^{s}, s_{l}^{c}$ are defined in Appendix B.3. $g_{p^{c}}$ is the percentage change in the fraction of entrepreneurs with credit access after the financial inclusion policy is implemented. $g_{\bar{y}^{s}}, g_{\bar{y}^{c}}, g_{\bar{k}^{s}}, g_{\bar{k}^{c}}, g_{\bar{l}^{s}}$, and $g_{\bar{l}^{c}}$ are the percentage change in the average output, capital, and labor in the savings regime and the credit regime after the financial inclusion policy is implemented.

In equation (4.2), the first term on the right-hand side captures the increase in TFP through the extensive margin, attributed to entrepreneurs who move from the savings regime to the credit regime. The second term captures the increase in TFP through the intensive margin, attributed to entrepreneurs who are already in the credit regime before the financial inclusion policy is implemented. The third term captures the general equilibrium effect from entrepreneurs who remain in the savings regime after the financial inclusion policy is implemented.

\footnotetext{
${ }^{8}$ Moll (2014) shows that when entrepreneurs have constant-return-to-scale production technology, TFP is equal to the average individual productivity weighted by wealth.

${ }^{9}$ Our decomposition is in a similar spirit to the approach of Jeong and Townsend (2007), who decompose the increase in TFP into the occupational shift effect, the financial deepening effect, the capital heterogeneity effect, and sectoral Solow residuals.
} 
Because the extensive and intensive margins benefit different agents, by analyzing by how much different financial inclusion policies increase GDP and TFP through the two margins, we can better understand the implication of these policies on inequality and the distribution of income. In the rest of this section, we use these formulas to quantitatively assess the contribution of the two margins to increases in GDP and TFP, and discuss their link to inequality.

\subsection{Aggregate Implications of Financial Inclusion}

In this section, we analyze the steady-state implications of the three policy instruments in the Philippines. In particular, we vary the value of $\psi, \xi$, or $\chi$, holding the other two parameters at their calibrated values. These counterfactual experiments capture what would happen in the steady state if the government uses a single policy instrument to increase financial inclusion.

In Figure 3, we plot the increase in steady-state GDP (the blue solid lines in panels A, $\mathrm{B}, \mathrm{C}$ ) and TFP (the blue solid lines in panels $\mathrm{D}, \mathrm{E}, \mathrm{F}$ ) when $\psi, \xi$, or $\chi$ is reduced while the other two parameters are held at their calibrated values. For example, panels A and D imply that when the credit entry cost $\psi$ is reduced from 2 to 0 , steady-state GDP and TFP increase by about $12.5 \%$ and $8.2 \%$ respectively; panels B and E show that steady-state GDP and TFP increase by about $71.8 \%$ and $53.3 \%$ respectively when the collateral constraint $\xi$ is lowered from 0.7 to 0 ; and panels $\mathrm{C}$ and $\mathrm{F}$ show that steady-state GDP and TFP increase by about $1.4 \%$ and $0.8 \%$ respectively, when the intermediation cost $\chi$ is lowered from 0.08 to 0 . These counterfactual experiments clearly illustrate that steady-state GDP and TFP respond differently to various financial constraints. In Section 5.1 below, we apply our model to different countries and demonstrate that it can be used to identify the most binding financial constraint in a country.

We use formulas (4.1) and (4.2) to understand the margins through which steady-state GDP and TFP increase after financial constraints are relaxed. The red dashed line shows 

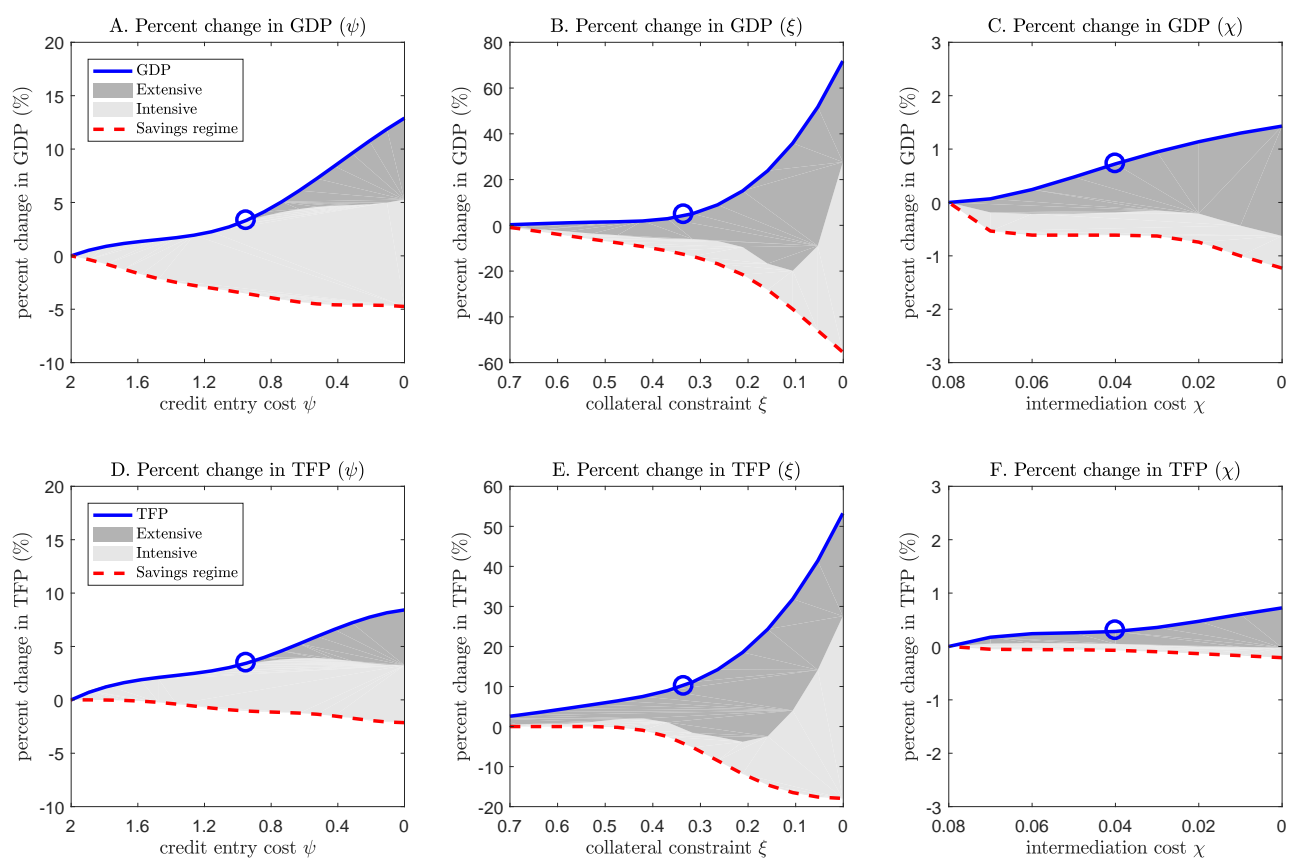

Note: In panels A - C, the blue solid line plots the percentage increase in GDP relative to the benchmark economy associated with the leftmost parameter value on the x-axis (i.e., $\psi=2$ in panel $\mathrm{A}, \xi=0.7$ in panel $\mathrm{B}$, and $\chi=0.08$ in panel $\mathrm{C}$ ). For each parameter value on the x-axis, we use formula (4.1) to decompose the corresponding increase in GDP relative to the benchmark. The red dashed line plots the contribution of the savings regime (the third term in formula 4.1). The height of the light grey area represents the contribution of the intensive margin (the second term in formula 4.1). The height of the dark grey area represents the contribution of the extensive margin (the first term in formula 4.1). In panels $\mathrm{D}-\mathrm{F}$, we perform the same exercise for TFP using formula (4.2). The blue circle in each panel represents the corresponding value under our calibration in Table 1.

Figure 3: Impact of financial inclusion on GDP and TFP in steady states.

that owing to a general equilibrium effect, the savings regime negatively contributes to the overall increase in steady-state GDP and TFP. Intuitively, as financial constraints are relaxed, resources are more efficiently allocated toward more productive entrepreneurs, increasing the demand for capital and labor, which drives up the equilibrium interest rate and wage. Entrepreneurs who remain in the savings regime do not benefit from the relaxed financial constraints. Instead, a higher cost of production leads to their optimally choosing to produce less output. In addition, there is a composition effect. As relatively productive entrepreneurs obtain credit, the average productivity of entrepreneurs in the savings regime will fall, negatively contributing to the overall increase in steady-state TFP. Quantitatively, when $\psi$, $\xi$, and $\chi$ are reduced from their leftmost values on the $\mathrm{x}$-axis to zero, the savings regime contributes to about $-4.9 \%,-55.4 \%$, and $-1.2 \%$ of the increase in steady-state GDP, and $-2.3 \%$, 
$-18.0 \%$, and $-0.2 \%$ of the increase in steady-state TFP, respectively.

The heights of the light and dark grey areas in Figure 3 represent the contributions of the intensive and extensive margins, respectively. Although both margins contribute positively to the increase in steady-state GDP and TFP when financial constraints are relaxed, our simulation suggests that the magnitude of their effects largely depends on the values of $\psi, \xi$, and $\chi$. Specifically, panels $\mathrm{A}$ and $\mathrm{D}$ of Figure 3 show that the intensive margin contributes to a significant portion of the increase in steady-state GDP and TFP. This is because a lower credit entry cost $\psi$ increases pledgeable collateral, allowing entrepreneurs in the credit regime to expand their production. By contrast, our simulation suggests that when $\psi$ is reduced from 2 to 0.9 , the extensive margin has a negligible contribution to the increase in steady-state GDP and TFP. Only when $\psi$ is further reduced to values below 0.9 does the extensive margin start to play a role. Intuitively, this is because high values of $\psi$ lead of to financial exclusion. Unless $\psi$ is sufficiently reduced, most entrepreneurs cannot afford the high credit entry cost. ${ }^{10}$

By contrast, panels B and E show that when the collateral constraint $\xi$ is reduced, both intensive and extensive margins contribute significantly to the increase in steady-state GDP and TFP. Relaxing the collateral constraint allows entrepreneurs with access to credit to borrow more to expand their production, increasing steady-state GDP and TFP through the intensive margin. Moreover, the lower collateral constraint also encourages more entrepreneurs to pay the credit entry cost and enter the credit regime, thereby increasing steady-state GDP and TFP through the extensive margin.

Panels $\mathrm{C}$ and $\mathrm{F}$ show that when the intermediation cost $\chi$ is reduced, most of the increase in steady-state GDP and TFP is attributed to the extensive margin instead of the intensive margin. Intuitively, a lower intermediation cost effectively reduces the user cost of capital, which motivates entrepreneurs to invest more and expand their businesses. However, because the parameter $\xi$ remains unchanged, the scale of business is restricted by the tight collateral

\footnotetext{
${ }^{10}$ As shown in panel A1 of Appendix Figure C.1, the credit access ratio remains low when $\psi$ is greater than 0.9 , and this ratio starts to increase significantly only when $\psi$ is further reduced.
} 
constraint, limiting the effect of reducing $\chi$. On the other hand, a lower intermediation cost encourages more productive, but wealth-constrained entrepreneurs to enter the credit regime, contributing to the increase in steady-state GDP and TFP through the extensive margin.

\subsection{Equilibrium Interactions of Policy Instruments}

Our previous analysis indicates that policy instruments targeting different financial constraints may have differential effects on GDP and TFP. In principle, countries may also adopt more comprehensive policies that alleviate multiple financial frictions at the same time. What would their potential effects on GDP be and through which margin? To what extent does the effect of targeting one financial constraint depend on the tightness of other financial constraints?

In this section, we explore these questions to understand how different constraints interact in equilibrium. We first examine individuals' output and credit access in partial equilibrium to analytically characterize the interaction effect. Next, we use the calibrated model to quantitatively evaluate the interaction effect in general equilibrium. Our findings suggest that it is important for policy makers to identify and alleviate the most binding financial constraint.

Interactions in Partial Equilibrium As discussed in Section 4.1, financial inclusion policies increase GDP through both the extensive margin (by increasing the credit access ratio) and the intensive margin (by allowing entrepreneurs with credit access to scale up their production). Below, we relax multiple constraints simultaneously and study the interaction effect through each margin. For analytical tractability, we focus on a stylized partial-equilibrium example with fixed interest rate $r$, wage $w$, and constant-returns-to-scale production function (i.e., $\nu=0)$.

Proposition 4. (Extensive Margin) Let $\underline{b}(\Omega) \equiv \underline{b}(z ; \Omega)$ be the threshold of wealth above which entrepreneurs of productivity $z$ choose to access credit in the economy with $\Omega$. Consider fixed 
interest rate $r$, wage $w$, and $\nu=0$. We have

i. Tightening (relaxing) each financial constraint reduces (improves) credit access:

$$
\frac{\partial \underline{b}(\Omega)}{\partial \psi}, \quad \frac{\partial \underline{b}(\Omega)}{\partial \xi}, \quad \frac{\partial \underline{b}(\Omega)}{\partial \chi} \geq 0
$$

ii. $\underline{b}(\Omega)$ has submodularity in $\Omega$, suggesting that the effect through the extensive margin of relaxing one constraint is smaller when the other constraints are more relaxed:

$$
\frac{\partial^{2} \underline{b}(\Omega)}{\partial \psi \partial \xi}=\frac{\partial^{2} \underline{b}(\Omega)}{\partial \xi \partial \psi}, \quad \frac{\partial^{2} \underline{b}(\Omega)}{\partial \xi \partial \chi}=\frac{\partial^{2} \underline{b}(\Omega)}{\partial \chi \partial \xi}, \quad \frac{\partial^{2} \underline{b}(\Omega)}{\partial \chi \partial \psi}=\frac{\partial^{2} \underline{b}(\Omega)}{\partial \psi \partial \chi} \geq 0 .
$$

The first-order partial derivatives are positive, indicating that relaxing any constraint (i.e., reducing $\psi, \xi$, or $\chi$ ) unambiguously reduces the threshold of wealth $\underline{b}(\Omega)$. Since a lower $\underline{b}(\Omega)$ means more entrepreneurs will gain access to credit, Proposition 4.i indicates that relaxing these constraints will increase the credit access ratio. The second-order cross partial derivatives are positive, indicating that the impact of relaxing any constraint on $\underline{b}(\Omega)$ would be smaller when the other two constraints are more relaxed (i.e., lower $\psi, \xi$, or $\chi$ ). Therefore, Proposition 4 indicates that the three policy instruments dampen each other's effect through the extensive margin. For example, when the credit entry cost $\psi$ is lower, relaxing the borrowing constraint $\xi$ or reducing the intermediation cost $\chi$ would have a smaller effect on reducing the wealth threshold $\underline{b}(\Omega)$. Intuitively, when the credit entry cost $\psi$ is low, most firms already have access to finance. As such, there is little room for increasing credit access further by relaxing the other two constraints.

Proposition 5. (Intensive Margin) Let $y^{C}(\Omega) \equiv y^{C}(b, z ; \Omega)$ be the net output of entrepreneurs of productivity $z$ and wealth $b$ in the credit regime (see its formula in Appendix A). Consider fixed interest rate $r$, wage $w$, and $\nu=0$. We have

i. Tightening (relaxing) each financial constraint reduces (raises) output:

$$
\frac{\partial y^{C}(\Omega)}{\partial \psi}, \quad \frac{\partial y^{C}(\Omega)}{\partial \xi}, \quad \frac{\partial y^{C}(\Omega)}{\partial \chi} \leq 0
$$


ii. $y^{C}(\Omega)$ has supermodularity, suggesting that the effect through the intensive margin of relaxing one constraint is larger when the other constraints are more relaxed:

$$
\frac{\partial^{2} y^{C}(\Omega)}{\partial \psi \partial \xi}=\frac{\partial^{2} y^{C}(\Omega)}{\partial \xi \partial \psi}, \quad \frac{\partial^{2} y^{C}(\Omega)}{\partial \xi \partial \chi}=\frac{\partial^{2} y^{C}(\Omega)}{\partial \chi \partial \xi}, \quad \frac{\partial^{2} y^{C}(\Omega)}{\partial \chi \partial \psi}=\frac{\partial^{2} y^{C}(\Omega)}{\partial \psi \partial \chi} \geq 0 .
$$

The first-order partial derivatives are negative, indicating that relaxing any constraint (i.e., reducing $\psi, \xi$, or $\chi$ ) unambiguously increases the output $y^{C}(\Omega)$ of entrepreneurs with credit access, increasing GDP through the intensive margin. The second-order cross partial derivatives are positive, indicating that the impact of relaxing any constraint on $y^{C}(\Omega)$ would be larger when the other two constraints are more relaxed (i.e., lower $\psi, \xi$, or $\chi$ ). Therefore, Proposition 5 implies that relaxing any two constraints has complementary effects on output. For example, when the credit entry cost $\psi$ is lower, relaxing the borrowing constraint $\xi$ or reducing the intermediation cost $\chi$ would have a larger effect on increasing $y^{C}(\Omega)$. Intuitively, when the credit entry cost $\psi$ is lower, entrepreneurs are left with more wealth after entering the credit regime, which increases pledgeable capital for borrowing. As a result, relaxing the collateral constraint $\xi$ or reducing the intermediation cost $\chi$ would have a larger effect on output.

Our analytical results reveal that different constraints are complements through the intensive margin and substitutes through the extensive margin. This implies that relaxing multiple constraints simultaneously could, in principle, bring larger or smaller GDP gains than relaxing each constraint separately, depending on whether the overall interaction effect is positive or negative. For example, if the interaction effect through the intensive margin dominates, policy makers should develop a more balanced financial system, because different financial constraints are complements in constraining GDP. In this case, policies that alleviate the most binding financial constraint would be most effective. On the other hand, if the interaction effect through the extensive margin dominates, policy makers should alleviate a single constraint while ignoring all other constraints. 
Quantitative Evaluation. We now use our calibrated model to quantitatively study the interaction effect through the extensive and intensive margins. We present a sequence of counterfactual experiments in general equilibrium where the interest rate, wage, and the distribution of wealth and productivity are endogenously determined in the steady state of each counterfactual experiment. In each experiment, we measure the percentage increase in steady-state GDP after relaxing one financial constraint (i.e., the target constraint) conditional on different values of the second constraint (i.e., the moving constraint), while at the same time keeping the third constraint unchanged. Thus, our experiments essentially measure the interaction effect between the target and the moving constraint. For our three financial constraints $(\psi, \xi, \chi)$, six combinations are possible as presented in Figure 4.

Panel A considers $\psi$ as the target constraint and $\xi$ as the moving constraint. On the y-axis, we plot the percentage increase in steady-state GDP (the blue solid line) resulting from reducing the target constraint $\psi$ from its calibrated value of 0.95 to 0.8 for different values of the moving constraint $\xi$ (from 0.7 to 0 as shown on the $\mathrm{x}$-axis). The dark grey and light grey areas, and the red-dashed line represent the increase in steady-state GDP attributed to the extensive margin, the intensive margin, and the savings regime respectively.

Moving from the left to the right along the x-axis, as the collateral constraint is relaxed (i.e., lowering $\xi$ ), we observe that the intensive-margin effect increases while the extensivemargin effect diminishes, consistent with the implications of Propositions 4 and 5. Moreover, the interaction effect through the intensive margin dominates that through the extensive margin. That is, when we relax the collateral constraint, the (increasing) intensive-margin effect is larger than the (decreasing) extensive-margin effect. As a result, reducing $\psi$ increases steady-state GDP more when the collateral constraint is relaxed (see the upward-sloping blue solid line). Similarly, in panel B, we hold $\psi$ as the target constraint and consider $\chi$ as the moving constraint. Again, moving from the left to the right along the x-axis (i.e., lowering $\chi$ ), the intensive-margin effect increases whereas the extensive-margin effect diminishes. The former dominates the latter, resulting in a larger increase in steady-state GDP from reducing 

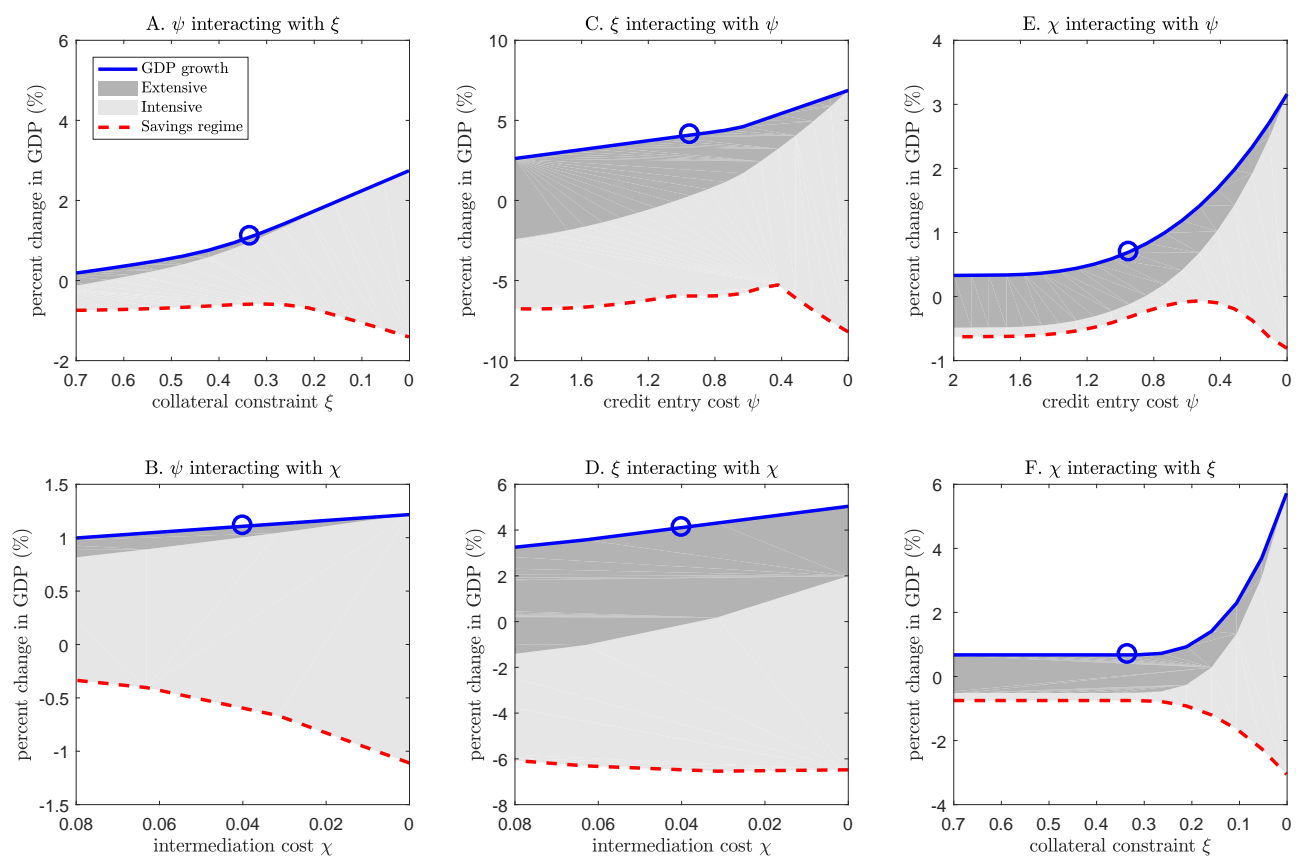

Note: This figure visualizes the interaction effects among financial constraints in general equilibrium with fixed interest rate, wage, and distribution of agents. Panels A and B present the percentage increase in steady-state GDP when $\psi$ is reduced from its calibrated value of 0.95 to 0.8 . Panel A visualizes the interaction effect between $\psi$ and $\xi$ when $\xi$ is varied from 0.7 to 0 while $\chi$ is kept at its calibrated value. For each value of $\xi$, we decompose the increase in GDP (owing to reducing $\psi$ from 0.95 to 0.8 ) into three components according to formula (4.1). The red dashed line plots the contribution of the savings regime (the third term in formula 4.1). The height of the light grey area represents the contribution of the intensive margin (the second term in formula 4.1). The height of the dark grey area represents the contribution of the extensive margin (the first term in formula 4.1). Panel B studies the interaction effect between $\psi$ and $\chi$ when $\chi$ is varied from 0.08 to 0 while $\xi$ is kept at its calibrated value. Panels $\mathrm{C}$ and D present the percentage increase in steady-state GDP when $\xi$ is reduced from its calibrated value of 0.335 to 0.29 , interacting with different values of $\psi$ and $\chi$. Panels $\mathrm{E}$ and $\mathrm{F}$ present the percentage increase in steady-state GDP when $\chi$ is reduced from its calibrated value of 0.04 to 0 , interacting with different values of $\psi$ and $\xi$.

Figure 4: Interaction effects among financial constraints in general equilibrium.

$\psi$. These patterns are also observed in panels $\mathrm{C}$ and $\mathrm{D}$, where we reduce the target constraint $\xi$ from 0.335 to 0.29 , as well as in panels $\mathrm{E}$ and $\mathrm{F}$, where we reduce the target constraint $\chi$ from 0.04 to 0 .

Our results imply that the net effect on GDP is larger when policy makers alleviate multiple financial constraints together than when they relax the financial constraints individually. In other words, effective financial inclusion policies should be designed to develop a well-rounded financial system, as reflected in a high breadth (i.e., high credit access), depth (i.e., relaxed collateral constraints), and efficiency (i.e., low intermediation costs). 

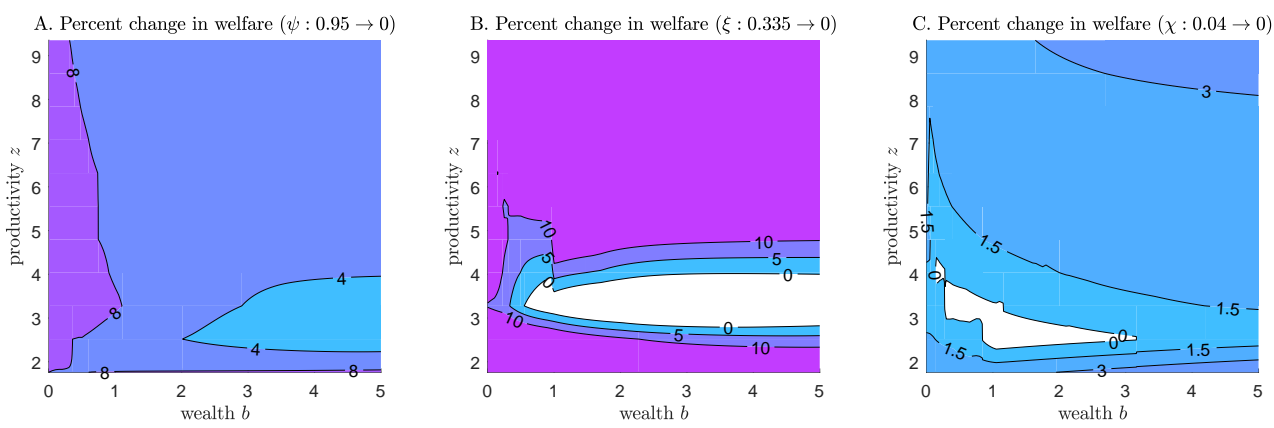

Note: The numbers in panels A - C represent the percentage change in consumption-equivalent welfare in the steady state after financial inclusion policies are implemented relative to that before these policies are implemented. The white area represents the region in which agents experience welfare losses after financial inclusion.

Figure 5: Impact of financial inclusion on welfare in steady states.

\subsection{Distributional Implications of Financial Inclusion}

We now move to the distributional implications of financial inclusion policies in steady states. We conduct three counterfactual experiments for the Philippines. In the first experiment, we reduce the credit entry cost $\psi$ from the calibrated value of 0.95 to 0 . In the second experiment, we assume that borrowing is frictionless by reducing the collateral constraint $\xi$ from the calibrated value of 0.335 to 0 . In the third experiment, we assume perfect financial intermediation by reducing the intermediation cost $\chi$ from the calibrated value of 0.04 to 0 . Figure 5 presents the change in steady-state welfare (consumption-equivalent measure) for agents of different wealth and productivity. ${ }^{11}$

Panel A shows that reducing the credit entry cost $\psi$ increases the steady-state welfare for all agents, but by different magnitudes. Agents in the region enclosed by "4" obtain relatively small welfare gains (less than 4\%). These agents are mostly unconstrained entrepreneurs (see Figure 2) who are wealthy but not productive, operating businesses at small scales and do not demand much external credit. Thus reducing the credit entry cost does not benefit these entrepreneurs much as most of them are currently unconstrained. Agents in the region enclosed by "8" obtain the largest welfare gains (more than 8\%). These agents are currently

\footnotetext{
${ }^{11}$ Note that due to the existence of idiosyncratic productivity shocks, agents who are productive now can be unproductive in the future, and vice versa. Our value functions derived from forward-looking agents already capture the effect from such dynamic changes in individual characteristics. In Appendix C.2, we discuss the implications of financial inclusion on the distribution of income and wealth.
} 
constrained workers, who are productive but poor. A lower credit entry cost allows them to access credit and start businesses, significantly increasing their life-time utility. The agents in the middle region obtain modest welfare gains, between $4 \%$ and $8 \%$. These agents are currently either unconstrained workers who obtain welfare gains due to higher wages, or constrained entrepreneurs who expand their businesses due to a lower credit entry cost.

In contrast to panel $\mathrm{A}$, we find that not everyone gains when the collateral constraint $\xi$ is relaxed or the intermediation cost $\chi$ is reduced. Panel $\mathrm{B}$ shows that when the collateral constraint $\xi$ is relaxed, agents in the (white) region enclosed by " 0 " incur welfare losses in the new steady state. These are the entrepreneurs who are moderately productive and wealthy. Their businesses are operated at the unconstrained scale, and thus further relaxing the collateral constraint does not benefit them much. However, relaxing the collateral constraint results in a general equilibrium effect that increases the cost of production (i.e., the equilibrium interest rate and wage), reducing their profits. Our simulation implies that the biggest winners are the most productive but constrained entrepreneurs and the unconstrained workers, whose welfare increases by more than $10 \%$. The former group benefits from increased scale of production and the latter from the significant increase in the equilibrium wage.

Panel $\mathrm{C}$ shows that when the intermediation cost $\chi$ decreases, agents who are currently moderately productive but poor (in the region enclosed by "0") incur welfare losses in the new steady state. These agents are entrepreneurs who operate their businesses at small scales due to low productivity. They do not demand much credit and receive little benefit from a lower intermediation cost. However, they suffer from a higher production cost due to the rise in the equilibrium interest rate and wage. The agents who obtain the largest welfare gains (more than 3\%) are those in the upper-right region and in the bottom-right region, enclosed by "3". The former group consists of constrained entrepreneurs who borrow the largest amount of credit. Thus, a lower intermediation cost significantly reduces their cost of production. The latter group consists of wealthy workers, who receive significantly more interest earnings from their large amounts of savings when the equilibrium interest rate goes 
up.

\section{Model Applications}

The interaction effects among the three financial constraints suggest that effective financial inclusion policies should be designed to target the most binding constraint. Moreover, policies that are effective in increasing GDP in one country may not be equally effective in

other countries. As one application of the model, we show that it can be used to evaluate and compare the effectiveness of implementing different financial inclusion policies across countries. As another application, we apply our model to the analysis of a large-scale financial liberalization policy in Thailand and evaluate its ability to explain real-world policy intervention.

\subsection{Identifying the Most Binding Constraint}

We consider two groups of countries (see panel A of Table 2). In the first group, we intentionally choose three countries with extreme financial constraints. These countries are Pakistan, Bangladesh, and Brazil. Their financial systems exhibit sharply different characteristics. For example, fewer than $6.7 \%$ of firms in Pakistan have access to credit whereas the figures are $34.1 \%$ and $59.2 \%$ in Bangladesh and Brazil respectively. Among the 139 countries in our sample, only four have a lower percentage of firms with credit than Pakistan (thus, the percentile rank of Pakistan is $5 / 139 \approx 3.6 \%$ ). However, among those firms that have credit access, those in Bangladesh must post collateral that amounts to as much as $271.4 \%$ of the face value of their loans, whereas the figures are $153.4 \%$ and $95.1 \%$ in Pakistan and Brazil respectively. Surprisingly, although firms in Brazil tend to have access to credit and face a more relaxed collateral constraint, the loan interest rate is 35.4 percentage points higher than the deposit rate. By calibrating our model to these countries (see Appendix Table B.1 for parameter values), we can test the model's ability to identify the most binding 
Table 2: Identifying the Most Binding Constraint.

\begin{tabular}{|c|c|c|c|c|c|c|c|c|c|c|c|c|c|c|}
\hline & & & A & ome & ts in $d e$ & lata and & model i & in vario & ous coun & atries & & & & \\
\hline & & & Paki & istan & Bang & sladesh & Bro & azil & The $\mathrm{Ph}$ & iilippines & $\mathrm{Kel}$ & enya & & mbia \\
\hline & & & Data & Model & Data & Model & Data & Model & Data & Model & Data & Model & Data & Model \\
\hline Firms with credit & & & 6.7 & 6.7 & 34.1 & 34.7 & 59.2 & 59.8 & 29.9 & 29.5 & 25.4 & 25.9 & 8.8 & 8.6 \\
\hline Percentile rank ( $h$ & h to low \%) & & 3.6 & & 43.2 & & 85.6 & & 33.8 & & 28.8 & & 5.0 & \\
\hline Collateral (\% of lo & ns) & & 153.4 & 154.0 & 271.4 & 271.7 & 95.1 & 100.4 & 156.7 & 156.4 & 120.8 & 120.8 & 236.6 & 236.4 \\
\hline Percentile rank ( $\mathrm{h}$ & h to low $\%$ ) & & 54.0 & & 3.6 & & 89.9 & & 52.5 & & 80.6 & & 14.4 & \\
\hline Interest rate sprea & $(\%)$ & & 4.8 & 4.7 & 1.9 & 1.9 & 35.4 & 35.4 & 4.0 & 4.0 & 8.5 & 8.5 & 11.8 & 11.8 \\
\hline Percentile rank ( $h$ & h to low \%) & & 51.8 & & 72.7 & & 0.7 & & 56.1 & & 20.9 & & 9.4 & \\
\hline Real interest rate & & & 0.2 & 0.5 & 4.5 & 4.6 & 2.9 & 2.8 & 6.2 & 6.3 & 7.6 & 7.7 & 4.8 & 4.5 \\
\hline Employment share & of Top 5\% & & 65.7 & 52.1 & 55.4 & 50.3 & 63.1 & 66.4 & 43.7 & 43.7 & 54.1 & 53.9 & 41.8 & 35.9 \\
\hline Employment share & of Top $10 \%$ & $(\%)$ & 77.6 & 60.9 & 71.2 & 61.5 & 74.6 & 80.6 & 57.6 & 58.6 & 66.9 & 69.1 & 56.1 & 49.9 \\
\hline Employment share & of Top $20 \%$ & $(\%)$ & 87.6 & 70.2 & 86.2 & 85.8 & 84.7 & 87.1 & 73.2 & 71.5 & 81 & 73.4 & 70.7 & 63.3 \\
\hline Employment share & of Top $40 \%$ & $(\%)$ & 94.7 & 91.4 & 95.2 & 96.6 & 93.1 & 95.9 & 88.8 & 85.3 & 93.2 & 84.9 & 84.7 & 89.0 \\
\hline Gross savings (\% & GDP) & & 21.4 & 20.5 & 21.2 & 20.6 & 23.9 & 28.5 & 44.2 & 41.2 & 15.4 & 14.9 & 35.4 & 29.6 \\
\hline & & $\begin{array}{l}\mathrm{B} \\
\psi\end{array}$ & $\begin{array}{l}\text { Impa } \\
\rightarrow 0\end{array}$ & f fi & ncial i & us & $\begin{array}{c}\text { on GD } \\
\quad \xi-\end{array}$ & $\mathrm{P}, \mathrm{TFF}$ & $\mathrm{P}$ anc & come $\mathrm{Gi}$ & & $\chi \rightarrow 0$ & & \\
\hline & $\operatorname{GDP}(\%)$ & TFF & $\mathrm{P}(\%)$ & Gini & & $\operatorname{GDP}(\%)$ & TFP & $(\%)$ & Gir & GDF & $\%)$ & $\operatorname{TFP}(\%)$ & & Gini \\
\hline $\mathrm{Pa}$ & & & .71 & & & 89.71 & & & & 0. & & 0.01 & & 0.001 \\
\hline ladesh & 8. & & .33 & 0.0 & & 111.92 & 77 . & & -0.124 & 0. & 50 & 0.41 & & 0.002 \\
\hline Brazil & 0. & & .01 & -0.000 & & 0.00 & 0.0 & & 0.000 & 42. & .44 & 38.31 & & 0.056 \\
\hline The Philippines & 9. & & .78 & $-0.04 t$ & & 59.73 & 37. & & -0.083 & 0.7 & 70 & 0.50 & & 0.002 \\
\hline & & & 1.70 & & & 13.77 & 7.8 & & -0.020 & 2. & 41 & 0.91 & & 0.012 \\
\hline Zambia & 10.22 & & .34 & -0.00 & & 81.85 & 47. & & -0.059 & 1.5 & 50 & 1.13 & & 0.002 \\
\hline
\end{tabular}

constraint and quantitatively evaluate the potential gains from relaxing different constraints. In the second group, we choose three countries with relatively balanced financial constraints: the Philippines, Kenya, and Zambia. Kenya's financial system is relatively developed for a country with its level of income and also compared with many other Sub-Saharan African countries. Zambia is a low-income country with an underdeveloped financial system reflected in all three dimensions: a low credit access ratio, a high collateral requirement, and a high interest rate spread. Unlike countries in the first group, it is difficult to see which financial constraint is most binding from a simple eyeball test. Our calibrated model, however, allows us to identify the bottleneck in their financial systems.

Panel B presents the changes in steady-state GDP, TFP and income Gini when the six countries adopt the best-possible financial intermediation technology along a single dimension (i.e., $\psi=0, \xi=0$, or $\chi=0$ ). Regarding the first group of countries, the model implies that the high intermediation cost is the key friction that hinders aggregate production in Brazil. 
Reducing $\chi$ to zero increases Brazil's steady-state GDP and TFP by $42.44 \%$ and $38.31 \%$, while reducing $\psi$ to zero almost has no effect on steady-state GDP and TFP due to the high intermediation cost. The model implies that Bangladesh's most binding financial friction is the tight collateral constraint. If we relax $\xi$ to zero in Bangladesh, steady-state GDP and TFP would increase by $111.92 \%$ and $77.48 \%$ respectively, while reducing either $\psi$ or $\chi$ to zero only increases steady-state GDP by $8.94 \%$ or $0.50 \%$. Regarding Pakistan, steady-state GDP and TFP would increase by $24.96 \%$ and $9.71 \%$ respectively when the credit entry cost $\psi$ goes to zero, while keeping $\xi$ and $\chi$ unchanged. Relaxing the collateral constraint $\xi$ to zero boosts steady-state GDP and TFP by $89.71 \%$ and $55.59 \%$ respectively, while reducing the intermediation cost $\chi$ to zero increases steady-state GDP and TFP by only $0.11 \%$ and $0.01 \%$. Therefore, our model suggests that the most binding financial constraint for Pakistan is the collateral constraint. This differs from our direct inference from the descriptive statistics in Table 2. Although only $6.7 \%$ of firms in Pakistan have access to credit, the credit entry cost is not necessarily the most binding constraint on GDP. ${ }^{12}$

We conduct similar counterfactual experiments for the second group of countries. The last three rows of panel $\mathrm{B}$ indicate that the collateral requirement is the most binding constraint in the Philippines and Zambia whereas the credit entry cost is the most binding constraint in Kenya. In terms of the income inequality, our simulation suggests that reducing the intermediation cost always increases the income Gini and relaxing the collateral constraint always reduces the income Gini. Reducing the credit entry cost lowers the income Gini in all six countries except for Bangladesh. ${ }^{13}$ In Appendix C.5, we study the transitional dynamics after implementing financial inclusion policies. We show that short-run transitional effects may differ from outcomes in long-run steady states, which may be years away. For

\footnotetext{
${ }^{12}$ In fact, as we show in Appendix Figure C.1, the credit access ratio is an endogenous variable determined by all three constraints, not simply the credit entry cost. Thus, the low credit access ratio could be largely attributed to the tight collateral constraint in Pakistan rather than the high credit entry cost. On the other hand, our model suggests that reducing the credit entry cost is more effective at boosting GDP in Pakistan than in Bangladesh. This suggests that the credit entry cost is indeed a more binding constraint in Pakistan than in Bangladesh.

${ }^{13}$ In Appendix C.4, we shed light on the margins through which steady-state GDP and TFP increase in these countries.
} 
example, the short-run interest rate could rise and overshoot the target, resulting in high borrowing costs. Similarly, reducing the cost of intermediation increases GDP and widens income inequality, but the short-run effect on GDP could be smaller whereas that on income inequality is larger. Such intertemporal tradeoffs may raise concerns for policy makers or lead to time-inconsistent behavior.

\subsection{Application: Policy Evaluation in Thailand}

Between 1986-1996, Thailand's economy underwent deep structural changes, including the liberalization of its financial sector and the economic integration with global financial and product markets. A series of financial liberalization policies were rapidly adopted with the intention to develop a highly functional financial system with efficient financial institutions through the market mechanism.

Before these financial policies were adopted, the prime lending rate to small- and mediumsized companies differed substantially from the commercial bank's deposit rate. The interest rate spread, measured as the difference between the prime lending rate and the deposit rate, decreased from about $8 \%$ in 1986 to about $2 \%$ by the end of 1995 (see panel A of Appendix Figure C.6).

Moreover, the competitive market environment created after the implementation of these policies gave the financial institutions strong incentives to expand their bank branch networks (see panels B and C of Appendix Figure C.6), which improves the access to credit for Thai households.

Third, the Thai government also enacted policies to further open up the capital account in the late 1980s and early 1990s. As reviewed in Alba, Hernandez and Klingebiel (1999), during 1986 the tax impediments to portfolio inflows were reduced, in particular for purchasing Thai mutual funds, with the aim of fostering the development of Bangkok as a regional financial center. This capital account liberalization resulted in a surge in private capital inflows and rapid credit growth (see panel D of Appendix Figure C.6). 
Model-based Evaluation As a quantitative exercise, we take these policy shifts as given and evaluate the distinct roles played by these policies on GDP, TFP, and income inequality using our model. We solve the model's transitional dynamics using the algorithm in Appendix D. The three parameters, $\psi_{t}, \xi_{t}$, and $\chi_{t}$, governing the degree of financial frictions are allowed to vary from 1986 to 1995, to capture the financial inclusion policies implemented during this period. ${ }^{14}$ In particular, we calibrate the path of intermediation costs $\chi_{t}$ by directly fitting the average annualized quarterly interest rate spread in each year. We calibrate the initial credit entry cost $\psi_{t}$ in 1986 so that $10 \%$ of households have access to credit at the beginning of the simulation, as in the data. We assume that the value of $\psi_{t}$ decreases by the same amount in each year until it vanishes in 1996. We do not have reliable data to calibrate the tightness of the collateral constraint in 1986. Because the public development bank in Thailand had much fewer branches than commercial banks, loans were mostly made by commercial banks which were quite stringent in lending (see Assuncao, Mityakov and Townsend, 2012). We thus set a high initial value of $\xi_{t}$ in 1986 and allow it to decrease by the same amount in each year until 1996. The value of $\xi_{t}$ in 1996 is calibrated to match the median loan-to-collateral ratio in the 1997 Townsend Thai annual survey.

In addition, we introduce net international capital flows to the model, which increases the aggregate supply of capital (i.e., the right-hand side of equation 2.9) by an amount equal to $\varsigma_{t} \mathrm{GDP}_{t}$, where $\varsigma_{t}$ is chosen to match the yearly ratio of net capital inflows to GDP. The capital inflows during this period effectively lower the borrowing cost, thus playing a role similar to lowering intermediation cost, for entrepreneurs by increasing the supply of credit. All other parameters are calibrated according to Appendix C.7 and their values are fixed in our analysis.

Over 1986-1995, GDP more than doubled in Thailand whereas the model can generate about 93.5\% cumulative growth (see the blue solid line in panel A of Figure 6), suggesting that other forces like technology adoption and human capital accumulation were also at

\footnotetext{
${ }^{14}$ But their values are fixed after 1996 so that we can attain a steady state at which backward induction is applied to solve the transitional dynamics.
} 

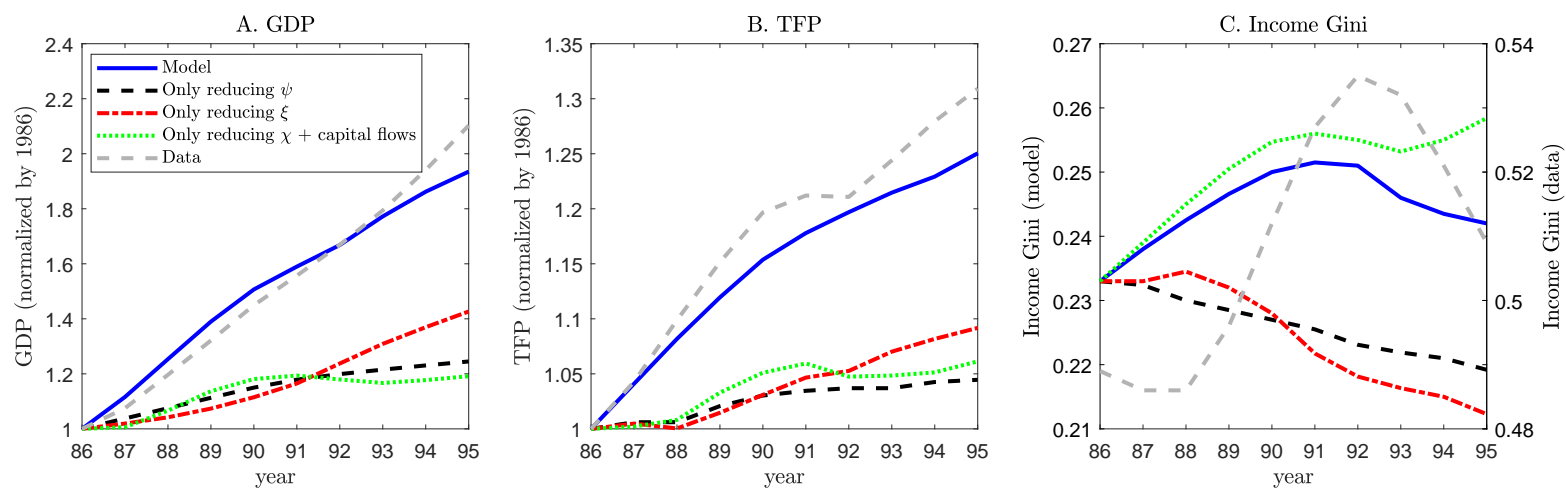

Figure 6: Model-based evaluation of GDP, TFP, and income Gini in Thailand 1986-1996.

work. The model also generates a smaller increase in TFP than the data (see the blue solid line in panel B). The income Gini is much lower in the model due to the lack of worker heterogeneity, however, the model is able to capture the hump-shaped dynamics of income inequality (see the blue solid line in panel C). ${ }^{15}$ Using the model, we run three counterfactual experiments to evaluate the relative contribution of reducing the credit entry cost, relaxing the collateral constraint and cutting the cost of credit (i.e., the downward trend in $\chi_{t}$ and the surge in capital inflows). In each counterfactual experiment, we allow $\psi_{t}, \xi_{t}$, or $\chi_{t}$ (plus $\left.\varsigma_{t}\right)$ to vary over time while keeping the other two parameters fixed at their values in 1986. Our simulations imply that if only the collateral constraint is relaxed, GDP increases by about $42.7 \%$ and TFP by $9.2 \%$ (the red dash-dotted lines in panels A and B). Reducing the credit entry cost alone increases GDP by about $24.5 \%$ and TFP by about $4.5 \%$ (the black dashed lines in panels $\mathrm{A}$ and B), whereas cutting the cost of credit increases GDP by about $19.1 \%$ and TFP by $6.1 \%$ (the green dotted lines in panels A and B). Moreover, the lower cost of credit results in a higher Gini coefficient of earnings whereas the lower credit entry cost and relaxed collateral constraint reduce income inequality. It is the joint effect of the three policies that generates the hump-shaped income Gini dynamics (see panel C).

\footnotetext{
${ }^{15}$ Jeong and Townsend (2008) show that the standard occupation choice model does not generate a high income Gini due to the lack of worker heterogeneity. Cagetti and De Nardi (2006) introduce heterogeneity in both working ability and entrepreneurial ability, and they calibrate the variance of the former to match the Gini coefficient of earnings. Cagetti and De Nardi (2008) provide a comprehensive review on the issue of wealth inequality. They emphasize that it is even more difficult for models to generate the observed degree of wealth concentration from observed income inequality.
} 


\section{Conclusion}

In this paper, we develop a tractable general equilibrium model with heterogeneous agents to study how different financial constraints interact in equilibrium. Our model highlights three different dimensions of a financial system: breadth, depth, and efficiency. These dimensions reflect different sources of financial frictions whose tightness can be captured by three indicators, the credit access ratio, the loan-to-collateral ratio, and the interest rate spread.

Our analytical and quantitative analyses indicate that the three financial constraints should be jointly analyzed due to their rich interactions in equilibrium. The quantitative as well as qualitative implications of financial inclusion on GDP, TFP, and the distribution of income not only depend on which constraint is alleviated, but also on the extent to which other constraints are binding. Analytically, we show that relaxing these constraints increases GDP through both the extensive margin and the intensive margin. However, the interaction between different constraints tends to dampen the effect through the extensive margin and amplify the effect through the intensive margin. Quantitatively, we find that the interaction effect through the intensive margin dominates, indicating that more effective financial inclusion policies should be designed in a balanced manner.

Our model provides insights into financial inclusion policies. The main value of our model lies in clarifying the tradeoff among different policy instruments and in distinguishing their impacts on various macro and micro variables in both steady states and transitions. The financial frictions incorporated in our model are not meant to be exhaustive, but our intention is to suggest an approach that might be applied to more complete and realistic models.

\section{References}

Abraham, Arpad, and Nicola Pavoni. 2005. "The Efficient Allocation of Consumption under Moral Hazard and Hidden Access to the Credit Market." Journal of the European Economic Association, 3(23): $370-381$.

Aghion, Philippe, and Patrick Bolton. 1997. "A Theory of Trickle-Down Growth and Development." Review of Economic Studies, 64(2): 151-72.

Aguirregabiria, Victor, Robert Clark, and Hui Wang. 2017. "The Geographic Flow of Bank Funding and Access to Credit: Branch Networks and Local-Market Competition." 
Ahlin, Christian, and Robert M. Townsend. 2007. "Using Repayment Data to Test Across Models of Joint Liability Lending." Economic Journal, 117(517): 11-51.

Alba, Pedro, Leonardo Hernandez, and Daniela Klingebiel. 1999. "Financial Liberalization and the Capital Account: Thailand 1988-1997." The World Bank Manuscript.

Albuquerque, Rui, and Hugo A. Hopenhayn. 2004. "Optimal Lending Contracts and Firm Dynamics." Review of Economic Studies, 71(2): 285-315.

Alem, Mauro, and Robert M. Townsend. 2013. "An Evaluation of Financial Institutions: Impact on Consumption and Investment Using Panel Data and the Theory of Risk-Bearing." Annals Issue of the Journal of Econometrics in Honor of Bill Barnett, , (forthcoming).

Amaral, Pedro S., and Erwan Quintin. 2010. "Limited Enforcement, Financial Intermediation, And Economic Development: A Quantitative Assessment." International Economic Review, 51(3): 785-811.

Assuncao, Juliano, Sergey Mityakov, and Robert M. Townsend. 2012. "Ownership matters: the geographical dynamics of a public development bank and private sector commercial banks." Working Paper.

Banerjee, Abhijit V, and Andrew F Newman. 1993. "Occupational Choice and the Process of Development." Journal of Political Economy, 101(2): 274-98.

Banerjee, Abhijit V., and Benjamin Moll. 2010. "Why Does Misallocation Persist?" American Economic Journal: Macroeconomics, 2(1): 189-206.

Bassetto, Marco, Marco Cagetti, and Mariacristina De Nardi. 2015. "Credit Crunches and Credit Allocation in a Model of Entrepreneurship." Review of Economic Dynamics, 18(1): 53-76.

Benhabib, Jess, Alberto Bisin, and Shenghao Zhu. 2011. "The Distribution of Wealth and Fiscal Policy in Economies With Finitely Lived Agents." Econometrica, 79(1): 123-157.

Benhabib, Jess, Alberto Bisin, and Shenghao Zhu. 2015. "The wealth distribution in Bewley economies with capital income risk." Journal of Economic Theory, 159(PA): 489-515.

Buera, Francisco J., and Yongseok Shin. 2011. "Self-insurance vs. self-financing: A welfare analysis of the persistence of shocks." Journal of Economic Theory, 146(3): 845-862.

Buera, Francisco J., and Yongseok Shin. 2013. "Financial Frictions and the Persistence of History: A Quantitative Exploration." Journal of Political Economy, 121(2): 221 - 272.

Buera, Francisco J., Joseph P. Kaboski, and Yongseok Shin. 2011. "Finance and Development: A Tale of Two Sectors." American Economic Review, 101(5): 1964-2002.

Buera, Francisco J., Joseph P. Kaboski, and Yongseok Shin. 2012. "The Macroeconomics of Microfinance." National Bureau of Economic Research, Inc NBER Working Papers 17905.

Burgess, Robin, and Rohini Pande. 2005. "Do Rural Banks Matter? Evidence from the Indian Social Banking Experiment." American Economic Review, 95(3): 780-795.

Cagetti, Marco, and Mariacristina De Nardi. 2006. "Entrepreneurship, Frictions, and Wealth." Journal of Political Economy, 114(5): 835-870.

Cagetti, Marco, and Mariacristina De Nardi. 2008. "Wealth Inequality: Data And Models." Macroeconomic Dynamics, 12(S2): 285-313.

Cagetti, Marco, and Mariacristina De Nardi. 2009. "Estate Taxation, Entrepreneurship, and Wealth." American Economic Review, 99(1): 85-111.

Caselli, Francesco, and Nicola Gennaioli. 2013. "Dynastic Management." Economic Inquiry, 51(1): 971996.

Castaneda, Ana, Javier Diaz-Gimenez, and Jose-Victor Rios-Rull. 2003. "Accounting for the U.S. Earnings and Wealth Inequality." Journal of Political Economy, 111(4): 818-857.

Celerier, Claire, and Adrien Matray. 2017. "Bank Branch Supply and the Unbanked Phenomenon."

Clementi, Gina Luca, and Hugo A Hopenhayn. 2006. "A Theory of Financing Constraints and Firm Dynamics." The Quarterly Journal of Economics, 121(1): 229-265.

Davies, James B. 1982. "The Relative Impact of Inheritance and Other Factors on Economic Inequality." The Quarterly Journal of Economics, 97(3): 471-98.

De Nardi, Mariacristina, and Fang Yang. 2016. "Wealth inequality, family background, and estate taxation." Journal of Monetary Economics, 77(C): 130-145.

De Nardi, Mariacristina, Fella Giulio, and Fang Yang. 2016. "Piketty's Book and Macro Models of Wealth Inequality." Chicago Fed Letter.

Doepke, Matthias, and Robert M. Townsend. 2006. "Dynamic Mechanism Design with Hidden Income and Hidden Actions." Journal of Economic Theory, 126(1): 235-285.

Gilje, Erik P., Elena Loutskina, and Philip E. Strahan. 2016. "Exporting Liquidity: Branch Banking and Financial Integration." Journal of Finance, 71(3): 1159-1184.

Gine, Xavier, and Robert M. Townsend. 2004. "Evaluation of financial liberalization: a general equilibrium model with constrained occupation choice." Journal of Development Economics, 74(2): 269307. 
Greenwood, Jeremy, and Boyan Jovanovic. 1990. "Financial Development, Growth, and the Distribution of Income." Journal of Political Economy, 98(5): 1076-1107.

Greenwood, Jeremy, Juan M. Sanchez, and Cheng Wang. 2010. "Financing Development: The Role of Information Costs." American Economic Review, 100(4): 1875-91.

Greenwood, Jeremy, Juan Sanchez, and Cheng Wang. 2013. "Quantifying the Impact of Financial Development on Economic Development." Review of Economic Dynamics, 16(1): 194-215.

Hsieh, Chang-Tai, and Peter J. Klenow. 2009. "Misallocation and Manufacturing TFP in China and India." The Quarterly Journal of Economics, 124(4): 1403-1448.

Huggett, Mark. 1996. "Wealth Distribution in Life-cycle Economies." Journal of Monetary Economics, 38(3): 469-494.

Jeong, Hyeok, and Robert M. Townsend. 2008. "Growth And Inequality: Model Evaluation Based On An Estimation-Calibration Strategy." Macroeconomic Dynamics, 12(S2): 231-284.

Jeong, Hyeok, and Robert Townsend. 2007. "Sources of TFP growth: occupational choice and financial deepening." Economic Theory, 32(1): 179-221.

Jermann, Urban, and Vincenzo Quadrini. 2009. "Financial Innovations and Macroeconomic Volatility." Working Papers.

Jermann, Urban, and Vincenzo Quadrini. 2012. "Macroeconomic Effects of Financial Shocks." American Economic Review, 102(1): 238-271.

Jermann, Urban J., and Vincenzo Quadrini. 2007. "Stock market boom and the productivity gains of the 1990s." Journal of Monetary Economics, 54(2): 413-432.

Karaivanov, Alexander, and Robert M. Townsend. 2014. "Dynamic Financial Constraints: Distinguishing Mechanism Design From Exogenously Incomplete Regimes." Econometrica, 82(3): 887-959.

Kinnan, Cynthia. 2014. "Distinguishing Barriers to Insurance in Thai Villages." Northwestern University Working Papers 1276.

Lloyd-Ellis, Huw, and Dan Bernhardt. 2000. "Enterprise, Inequality and Economic Development." Review of Economic Studies, 67(1): 147-68.

Martin, Alberto, and Filippo Taddei. 2013. "International Capital Flows and Credit Market Imperfections: A Tale of Two Frictions." Journal of International Economics, 89(2): 441-452.

Midrigan, Virgiliu, and Daniel Yi Xu. 2014. "Finance and Misallocation: Evidence from Plant-Level Data." American Economic Review, 104(2): 422-58.

Moll, Benjamin. 2014. "Productivity Losses from Financial Frictions: Can Self-Financing Undo Capital Misallocation?" American Economic Review, , (forthcoming).

Moll, Benjamin, Robert M. Townsend, and Victor Zhorin. 2014. "Economic Development and the Equilibrium Interaction of Financial Frictions." Working Papers.

Nardi, Mariacristina De. 2004. "Wealth Inequality and Intergenerational Links." Review of Economic Studies, 71(3): 743-768.

Nguyen, Hoai-Luu Q. 2017. "Are Credit Markets Still Local? Evidence from Bank Branch Closings."

Nikolov, Boris, Lukas Schmid, and Roberto Steri. 2018. "The Sources of Financing Constraints." Working Papers.

Okuda, Hidenobu, and Fumiharu Mieno. 1999. "What Happened to Thai Commercial Banks in the Pre-Asian Crisis Period: Microeconomic Analysis of Thai Banking Industry." Hitotsubashi Journal of Economics, 40(2): 97-121.

Paulson, Anna L., Robert M. Townsend, and Alexander Karaivanov. 2006. "Distinguishing Limited Liability from Moral Hazard in a Model of Entrepreneurship." Journal of Political Economy, 114(1): 100144.

Paweenawat, Archawa, and Robert M. Townsend. 2014. "Villages as Small Open Economies: Disentangling Real and Financial Factors." Department of Economics, MIT Working paper 04/104.

Quadrini, Vincenzo. 2000. "Entrepreneurship, Saving and Social Mobility." Review of Economic Dynamics, 3(1): 1-40.

Samphantharak, Krislert, and Robert M. Townsend. 2009. Households as Corporate Firms. Cambridge University Press.

Townsend, Robert. 1983. "Financial Structure and Economic Activity." American Economic Review, 73: 895-911.

Townsend, Robert M., and Kenichi Ueda. 2006. "Financial Deepening, Inequality, and Growth: A Model-Based Quantitative Evaluation." Review of Economic Studies, 73(1): 251-293.

Townsend, Robert M., and Kenichi Ueda. 2010. "Welfare Gains From Financial Liberalization." International Economic Review, 51(3): 553-597. 


\section{Appendix}

\section{Online Appendix (Not for Publication)}

\section{A GDP Formula}

Consider the steady state of an economy with constraint parameters $\Omega \equiv(\psi, \xi, \chi)$. The income $I(b, z)$ for each agent of wealth $b$ and productivity $z$ is equal to the sum of her wage (or business profit) and interest earnings. The amount of each component depends on her occupation and credit access. In particular,

$$
\begin{aligned}
& I(b, z ; \Omega)= \\
& \begin{cases}w+r b, & \text { workers; } \\
z\left(k^{\alpha} l^{1-\alpha}\right)^{1-\nu}-\delta k-w l+r\left(b-k_{t}\right), & \text { entrepreneurs in the savings regime; } \\
z\left(k^{\alpha} l^{1-\alpha}\right)^{1-\nu}-\delta k-w l-\psi-(r+\chi)(k-b+\psi), & \text { entrepreneurs in the credit regime, }\end{cases}
\end{aligned}
$$

where $k$ and $l$ are short for $k(b, z ; \Omega)$ and $l(b, z ; \Omega)$.

According to the income approach, the economy's GDP is equal to the total national income plus depreciation

$$
\operatorname{GDP}_{\Omega}=\iint_{(b, z) \in \Phi} I(b, z ; \Omega) h(b, z ; \Omega) \mathrm{d} b \mathrm{~d} z+\iint_{(b, z) \in \Phi^{E}} \delta k h(b, z ; \Omega) \mathrm{d} b \mathrm{~d} z .
$$

We can rewrite equation (A.2) as the sum of workers' and entrepreneurs' income

$$
\begin{aligned}
\operatorname{GDP}_{\Omega} & =\iint_{(b, z) \in \Phi} I(b, z ; \Omega) h(b, z ; \Omega) \mathrm{d} b \mathrm{~d} z+\iint_{(b, z) \in \Phi^{E}} \delta k(b, z ; \Omega) h(b, z ; \Omega) \mathrm{d} b \mathrm{~d} z \\
& =\iint_{(b, z) \notin \Phi^{E}} I(b, z ; \Omega) h(b, z ; \Omega) \mathrm{d} b \mathrm{~d} z+\iint_{(b, z) \in \Phi^{E}}[I(b, z ; \Omega)+\delta k(b, z ; \Omega)] h(b, z ; \Omega) \mathrm{d} b \mathrm{~d} z .
\end{aligned}
$$


Substituting equation (A.1) into equation (A.3) yields

$$
\begin{aligned}
& \operatorname{GDP}_{\Omega}=\iint_{(b, z) \notin \Phi^{E}}(w+r b) h(b, z ; \Omega) \mathrm{d} b \mathrm{~d} z \\
& +\iint_{(b, z) \in \Phi^{S}}\left[z\left(k(b, z ; \Omega)^{\alpha} l(b, z ; \Omega)^{1-\alpha}\right)^{1-\nu}-w l(b, z ; \Omega)+r(b-k(b, z ; \Omega))\right] h(b, z ; \Omega) \mathrm{d} b \mathrm{~d} z \\
& +\iiint_{(b, z) \in \Phi^{C}}\left[z\left(k(b, z ; \Omega)^{\alpha} l(b, z ; \Omega)^{1-\alpha}\right)^{1-\nu}-w l(b, z ; \Omega)-\psi-(r+\chi)(k(b, z ; \Omega)-b+\psi)\right] h(b, z ; \Omega) \mathrm{d} b \mathrm{~d} z .
\end{aligned}
$$

Taking out the terms with wage $w$ and interest rate $r$, equation (A.4) is rewritten as

$$
\begin{aligned}
\operatorname{GDP}_{\Omega}= & w\left[\iint_{(b, z) \notin \Phi^{E}} h(b, z ; \Omega) \mathrm{d} b \mathrm{~d} z-\iint_{(b, z) \in \Phi^{E}} l(b, z ; \Omega) h(b, z ; \Omega) \mathrm{d} b \mathrm{~d} z\right] \\
& +r\left[\iint_{(b, z) \notin \Phi^{E}} b h(b, z ; \Omega) \mathrm{d} b \mathrm{~d} z+\iint_{(b, z) \in \Phi^{S}}[b-k(b, z ; \Omega)] h(b, z ; \Omega) \mathrm{d} b \mathrm{~d} z\right. \\
& \left.-\iint_{(b, z) \in \Phi^{C}}[k(b, z ; \Omega)-b+\psi] h(b, z ; \Omega) \mathrm{d} b \mathrm{~d} z\right] \\
& +\iint_{(b, z) \in \Phi^{S}} z\left[k(b, z ; \Omega)^{\alpha} l(b, z ; \Omega)^{1-\alpha}\right]^{1-\nu} h(b, z ; \Omega) \mathrm{d} b \mathrm{~d} z \\
& +\iint_{(b, z) \in \Phi^{C}}\left[z\left(k(b, z ; \Omega)^{\alpha} l(b, z ; \Omega)^{1-\alpha}\right)^{1-\nu}-\psi-\chi(k(b, z ; \Omega)-b+\psi)\right] h(b, z ; \Omega) \mathrm{d} b \mathrm{~d} z .
\end{aligned}
$$

The labor and capital market clearing conditions (2.9-2.10) imply that the first two terms on the right-hand side of equation (A.5) are zero, and thus we have

$$
\begin{aligned}
\operatorname{GDP}_{\Omega}= & \iint_{(b, z) \in \Phi^{S}} z\left[k(b, z ; \Omega)^{\alpha} l(b, z ; \Omega)^{1-\alpha}\right]^{1-\nu} h(b, z ; \Omega) \mathrm{d} b \mathrm{~d} z \\
& +\iint_{(b, z) \in \Phi^{C}}\left[z\left(k(b, z ; \Omega)^{\alpha} l(b, z ; \Omega)^{1-\alpha}\right)^{1-\nu}-\psi-\chi(k(b, z ; \Omega)-b+\psi)\right] h(b, z ; \Omega) \mathrm{d} b \mathrm{~d} z \\
= & \iint_{(b, z) \in \Phi^{S}} y^{S}(b, z ; \Omega) h(b, z ; \Omega) \mathrm{d} b \mathrm{~d} z+\iiint_{(b, z) \in \Phi^{C}} y^{C}(b, z ; \Omega) h(b, z ; \Omega) \mathrm{d} b \mathrm{~d} z
\end{aligned}
$$


where $y^{S}(b, z ; \Omega)$ and $y^{C}(b, z ; \Omega)$ are entrepreneurs' steady-state output net of the deadweight loss arising from financial frictions in the savings and credit regimes:

$$
\begin{aligned}
& y^{S}(b, z ; \Omega)=z\left(k^{\alpha} l^{1-\alpha}\right)^{1-\nu}, \\
& y^{C}(b, z ; \Omega)=z\left(k^{\alpha} l^{1-\alpha}\right)^{1-\nu}-\chi(k-b+\psi)-\psi .
\end{aligned}
$$

\section{B Proofs}

\section{B.1 Proof of Proposition 1}

Consider the entrepreneur's problem, where labor is a freely adjustable input. Taking the first-order condition with respect to $l_{t}$, we can derive the optimal labor demand as a function of capital $k_{t}$ and productivity $z_{t}$

$$
l_{t}\left(z_{t}, k_{t}\right)=\left[\frac{(1-\alpha)(1-\nu) z_{t} k_{t}^{\alpha(1-\nu)}}{w_{t}}\right]^{\frac{1}{\nu+\alpha(1-\nu)}}
$$

Because there is no uncertainty within each period, maximizing utility is equivalent to maximizing the end-of-period wealth $\tilde{b}_{t}$, defined by $\tilde{b}_{t}=c_{t}+b_{t+1}$. Substituting the optimal labor demand (B.1) into the entrepreneur's budget constraint yields

$$
\begin{aligned}
\tilde{b}_{t}\left(b_{t}, z_{t}, k_{t}\right) & =z_{t}\left(k_{t}^{\alpha} l_{t}^{1-\alpha}\right)^{1-\nu}+(1-\delta) k_{t}-w_{t} l_{t}+\left(1+r_{t}\right)\left(b_{t}-k_{t}\right) \\
& =\left[\frac{(1-\alpha)(1-\nu) z_{t}}{w_{t}}\right]^{\frac{1}{\nu+\alpha(1-\nu)}} k_{t}^{\frac{\alpha(1-\nu)}{\nu+\alpha(1-\nu)}} \frac{\nu+\alpha(1-\nu)}{(1-\nu)(1-\alpha)} w_{t}+(1-\delta) k_{t}+\left(1+r_{t}\right)\left(b_{t}-k_{t}\right) .
\end{aligned}
$$

In the absence of financial frictions, capital $k_{t}$ is optimally chosen to maximize $\tilde{b}_{t}$. By taking the first-order condition with respect to $k_{t}$, we derive the optimal (unconstrained) capital demand $k_{t}^{u}$ :

$$
k_{t}^{u}\left(z_{t}\right)=\left[\frac{\alpha w_{t}}{(1-\alpha)\left(r_{t}+\delta\right)}\right]^{\frac{\nu+\alpha(1-\nu)}{\nu}}\left[\frac{(1-\alpha)(1-\nu) z_{t}}{w_{t}}\right]^{\frac{1}{\nu}} .
$$

Substituting equation (B.3) into equation (B.2) yields the maximal end-of-period wealth $\tilde{b}_{t}^{e}$ for an entrepreneur:

$$
\tilde{b}_{t}^{e}\left(b_{t}, z_{t}\right)=\left(1+r_{t}\right) b_{t}+z_{t}^{\frac{1}{\nu}} \nu\left[\frac{\alpha w_{t}}{(1-\alpha)\left(r_{t}+\delta\right)}\right]^{\frac{\alpha(1-\nu)}{\nu}}\left[\frac{(1-\alpha)(1-\nu)}{w_{t}}\right]^{\frac{1-\nu}{\nu}}
$$


The end-of-period wealth for a worker is $\tilde{b}_{t}^{w}\left(b_{t}\right)=\left(1+r_{t}\right) b_{t}+w_{t}$. Since $\tilde{b}_{t}^{e}\left(b_{t}, z_{t}\right)$ increases with $z_{t}$, the threshold of entrepreneurial productivity $\underline{z}_{t}$ at time $t$ is given by $\tilde{b}_{t}^{w}\left(b_{t}\right)=\tilde{b}_{t}^{e}\left(b_{t}, \underline{z}_{t}\right)$,

$$
\underline{z}_{t}=\frac{\left(r_{t}+\delta\right)^{\alpha(1-\nu)} w_{t}^{1-\alpha(1-\nu)}}{\nu^{\nu}\left[\alpha^{\alpha}(1-\alpha)^{1-\alpha}(1-\nu)\right]^{1-\nu}}
$$

\section{B.2 Proof of Proposition 2}

According to equation (A.6) and the definition of $\underline{b}(z ; \Omega)$, the steady-state GDP can be written as

$$
\mathrm{GDP}_{\Omega}=\int_{z} \int_{0}^{\underline{\underline{b}}(z ; \Omega)} y^{S}(b, z ; \Omega) h(b, z ; \Omega) \mathrm{d} b \mathrm{~d} z+\int_{z} \int_{\underline{b}(z ; \Omega)}^{\infty} y^{C}(b, z ; \Omega) h(b, z ; \Omega) \mathrm{d} b \mathrm{~d} z .
$$

Thus,

$$
\begin{aligned}
\operatorname{GDP}_{\Omega^{\prime}}-\operatorname{GDP}_{\Omega}= & \int_{z} \int_{0}^{\underline{b}\left(z ; \Omega^{\prime}\right)} y^{S}\left(b, z ; \Omega^{\prime}\right) h\left(b, z ; \Omega^{\prime}\right) \mathrm{d} b \mathrm{~d} z+\int_{z} \int_{\underline{b}\left(z ; \Omega^{\prime}\right)}^{\infty} y^{C}\left(b, z ; \Omega^{\prime}\right) h\left(b, z ; \Omega^{\prime}\right) \mathrm{d} b \mathrm{~d} z \\
& -\int_{z} \int_{0}^{\underline{b}(z ; \Omega)} y^{S}(b, z ; \Omega) h(b, z ; \Omega) \mathrm{d} b \mathrm{~d} z-\int_{z} \int_{\underline{b}(z ; \Omega)}^{\infty} y^{C}(b, z ; \Omega) h(b, z ; \Omega) \mathrm{d} b \mathrm{~d} z .
\end{aligned}
$$

When $\Omega^{\prime} \leq \Omega$, we have $\underline{b}\left(z ; \Omega^{\prime}\right) \leq \underline{b}(z ; \Omega)$ for all $z \geq 0$, and thus

$$
\begin{aligned}
\operatorname{GDP}_{\Omega^{\prime}}-\operatorname{GDP}_{\Omega}= & \int_{z} \int_{\underline{b}\left(z ; \Omega^{\prime}\right)}^{\underline{b}(z ; \Omega)}\left[y^{C}\left(b, z ; \Omega^{\prime}\right) h\left(b, z ; \Omega^{\prime}\right)-y^{S}(b, z ; \Omega) h(b, z ; \Omega)\right] \mathrm{d} b \mathrm{~d} z \\
& +\int_{z} \int_{\underline{b}(z ; \Omega)}^{\infty}\left[y^{C}\left(b, z ; \Omega^{\prime}\right) h\left(b, z ; \Omega^{\prime}\right)-y^{C}(b, z ; \Omega) h(b, z ; \Omega)\right] \mathrm{d} b \mathrm{~d} z \\
& +\int_{z} \int_{0}^{\underline{b}\left(z ; \Omega^{\prime}\right)}\left[y^{S}\left(b, z ; \Omega^{\prime}\right) h\left(b, z ; \Omega^{\prime}\right)-y^{S}(b, z ; \Omega) h(b, z ; \Omega)\right] \mathrm{d} b \mathrm{~d} z .
\end{aligned}
$$

\section{B.3 Proof of Proposition 3}

Growth Accounting by Factor. Rewrite the formula of TFP as

$$
Y_{\Omega}=\operatorname{TFP}_{\Omega} K_{\Omega}^{\alpha} L_{\Omega}^{1-\alpha}
$$

Taking the logarithm of both sides of equation (B.9) yields

$$
\log \left(Y_{\Omega}\right)=\log \left(\mathrm{TFP}_{\Omega}\right)+\alpha \log \left(K_{\Omega}\right)+(1-\alpha) \log \left(L_{\Omega}\right)
$$


Moving from the steady-state economy with $\Omega$ to the steady-state economy with $\Omega^{\prime}$, we have a similar expression:

$$
\log \left(Y_{\Omega^{\prime}}\right)=\log \left(\mathrm{TFP}_{\Omega^{\prime}}\right)+\alpha \log \left(K_{\Omega^{\prime}}\right)+(1-\alpha) \log \left(L_{\Omega^{\prime}}\right)
$$

Taking the difference of $\log \left(Y_{\Omega}\right)$ and $\log \left(Y_{\Omega^{\prime}}\right)$ using equations (B.10) and (B.11) yields

$$
\log \left(Y_{\Omega^{\prime}} / Y_{\Omega}\right)=\log \left(\mathrm{TFP}_{\Omega^{\prime}} / \mathrm{TFP}_{\Omega}\right)+\alpha \log \left(K_{\Omega^{\prime}} / K_{\Omega}\right)+(1-\alpha) \log \left(L_{\Omega^{\prime}} / L_{\Omega}\right)
$$

Equation (B.12) can be approximated by first difference,

$$
\frac{Y_{\Omega^{\prime}}-Y_{\Omega}}{Y_{\Omega}}=\frac{\operatorname{TFP}_{\Omega^{\prime}}-\mathrm{TFP}_{\Omega}}{\operatorname{TFP}_{\Omega}}+\alpha \frac{K_{\Omega^{\prime}}-K_{\Omega}}{K_{\Omega}}+(1-\alpha) \frac{L_{\Omega^{\prime}}-L_{\Omega}}{L_{\Omega}}
$$

Let $g_{x}=\left(x_{\Omega^{\prime}}-x_{\Omega}\right) / x_{\Omega}$ denote the percentage change in the value of variable $x$ when the economy moves from $\Omega$ to $\Omega^{\prime}$. Thus equation (B.13) can be written as

$$
g_{Y}=g_{\mathrm{TFP}}+\alpha g_{K}+(1-\alpha) g_{L}
$$

Since the economy consists of two regimes, aggregate capital is equal to the sum of capital employed by entrepreneurs living in the two regimes. Denote by $\bar{k}_{\Omega}^{s}$ the average capital employed by entrepreneurs in the savings regime of the steady-state economy with $\Omega$. By definition, we have

$$
\bar{k}_{\Omega}^{s} \iint_{(b, z) \in \Phi^{S}} h(b, z ; \Omega) \mathrm{d} b \mathrm{~d} z=\iint_{(b, z) \in \Phi^{S}} k(b, z ; \Omega) h(b, z ; \Omega) \mathrm{d} b \mathrm{~d} z .
$$

Denote by $\bar{k}_{\Omega}^{c}$ the average capital employed by entrepreneurs in the credit regime of the steady-state economy with $\Omega$. By definition, we have

$$
\bar{k}_{\Omega}^{c} \iint_{(b, z) \in \Phi^{C}} h(b, z ; \Omega) \mathrm{d} b \mathrm{~d} z=\iint_{(b, z) \in \Phi^{C}} k(b, z ; \Omega) h(b, z ; \Omega) \mathrm{d} b \mathrm{~d} z .
$$

Denote by $E_{\Omega}$ the percentage of agents who choose to be entrepreneurs. By definition, we have

$$
E_{\Omega}=\iint_{(b, z) \in \Phi^{E}} h(b, z ; \Omega) \mathrm{d} b \mathrm{~d} z .
$$

Denote by $p_{\Omega}^{c}$ the percentage of entrepreneurs living in the credit regime. Note that 
$\Phi_{t}^{E}=\Phi_{t}^{S} \cup \Phi_{t}^{C}$, thus we have

$$
\begin{aligned}
p_{\Omega}^{c} E_{\Omega} & =\iint_{(b, z) \in \Phi^{C}} h(b, z ; \Omega) \mathrm{d} b \mathrm{~d} z, \\
\left(1-p_{\Omega}^{c}\right) E_{\Omega} & =\iint_{(b, z) \in \Phi^{S}} h(b, z ; \Omega) \mathrm{d} b \mathrm{~d} z .
\end{aligned}
$$

Thus, the aggregate capital is

$$
\begin{aligned}
K_{\Omega}= & \iint_{(b, z) \in \Phi^{E}} k(b, z ; \Omega) h(b, z ; \Omega) \mathrm{d} b \mathrm{~d} z \\
& =\iint_{(b, z) \in \Phi^{S}} k(b, z ; \Omega) h(b, z ; \Omega) \mathrm{d} b \mathrm{~d} z+\iint_{(b, z) \in \Phi^{C}} k(b, z ; \Omega) h(b, z ; \Omega) \mathrm{d} b \mathrm{~d} z \\
& =\bar{k}_{\Omega}^{s} \iint_{(b, z) \in \Phi^{S}} h(b, z ; \Omega) \mathrm{d} b \mathrm{~d} z+\bar{k}_{\Omega}^{c} \iint_{(b, z) \in \Phi^{C}} h(b, z ; \Omega) \mathrm{d} b \mathrm{~d} z \\
& =E_{\Omega}\left(1-p_{\Omega}^{c}\right) \bar{k}_{\Omega}^{s}+E_{\Omega} p_{\Omega}^{c} \bar{k}_{\Omega}^{c} \\
& =E_{\Omega} \bar{k}_{\Omega}
\end{aligned}
$$

where $\bar{k}_{\Omega}=\left(1-p_{\Omega}^{c}\right) \bar{k}_{\Omega}^{s}+p_{\Omega}^{c} \bar{k}_{\Omega}^{c}$ represents the average capital per entrepreneur.

Moving from the steady-state economy with $\Omega$ to the steady-state economy with $\Omega^{\prime}$, using an approximation similar to equations (B.12-B.13), the percentage change in aggregate capital can be written as

$$
g_{K}=g_{E}+g_{\bar{k}}
$$

where $g_{\bar{k}}$ is given by

$$
\begin{aligned}
g_{\bar{k}} \bar{k}_{\Omega} & =\bar{k}_{\Omega^{\prime}}-\bar{k}_{\Omega} \\
& =\left(1-p_{\Omega^{\prime}}^{c}\right) \bar{k}_{\Omega^{\prime}}^{s}+p_{\Omega^{\prime}}^{c} \bar{k}_{\Omega^{\prime}}^{c}-\left(1-p_{\Omega}^{c}\right) \bar{k}_{\Omega}^{s}-p_{\Omega}^{c} \bar{k}_{\Omega}^{c} \\
& =\left(1-p_{\Omega}^{c}\right)\left(\bar{k}_{\Omega^{\prime}}^{s}-\bar{k}_{\Omega}^{s}\right)-\left(1-p_{\Omega}^{c}\right) \bar{k}_{\Omega^{\prime}}^{s}+\left(1-p_{\Omega^{\prime}}^{c}\right) \bar{k}_{\Omega^{\prime}}^{s}+p_{\Omega}^{c}\left(\bar{k}_{\Omega^{\prime}}^{c}-\bar{k}_{\Omega}^{c}\right)-p_{\Omega}^{c} \bar{k}_{\Omega^{\prime}}^{c}+p_{\Omega^{\prime}}^{c} \bar{k}_{\Omega^{\prime}}^{c} \\
& =\left(1-p_{\Omega}^{c}\right)\left(\bar{k}_{\Omega^{\prime}}^{s}-\bar{k}_{\Omega}^{s}\right)-\left(p_{\Omega^{\prime}}^{c}-p_{\Omega}^{c}\right) \bar{k}_{\Omega^{\prime}}^{s}+p_{\Omega}^{c}\left(\bar{k}_{\Omega^{\prime}}^{c}-\bar{k}_{\Omega}^{c}\right)+\left(p_{\Omega^{\prime}}^{c}-p_{\Omega}^{c}\right) \bar{k}_{\Omega^{\prime}}^{c} \\
& =\left(1-p_{\Omega}^{c}\right)\left(\bar{k}_{\Omega^{\prime}}^{s}-\bar{k}_{\Omega}^{s}\right)+p_{\Omega}^{c}\left(\bar{k}_{\Omega^{\prime}}^{c}-\bar{k}_{\Omega}^{c}\right)+\left(p_{\Omega^{\prime}}^{c}-p_{\Omega}^{c}\right)\left(\bar{k}_{\Omega^{\prime}}^{c}-\bar{k}_{\Omega^{\prime}}^{s}\right) .
\end{aligned}
$$


Moreover, $g_{\bar{k}}$ can also be derived as

$$
\begin{aligned}
g_{\bar{k}} \bar{k}_{\Omega} & =\bar{k}_{\Omega^{\prime}}-\bar{k}_{\Omega} \\
& =\left(1-p_{\Omega^{\prime}}^{c}\right) \bar{k}_{\Omega^{\prime}}^{s}+p_{\Omega^{\prime}}^{c} \bar{k}_{\Omega^{\prime}}^{c}-\left(1-p_{\Omega}^{c}\right) \bar{k}_{\Omega}^{s}-p_{\Omega}^{c} \bar{k}_{\Omega}^{c} \\
& =\left(1-p_{\Omega^{\prime}}^{c}\right)\left(\bar{k}_{\Omega^{\prime}}^{s}-\bar{k}_{\Omega}^{s}\right)+\left(1-p_{\Omega^{\prime}}^{c}\right) \bar{k}_{\Omega}^{s}-\left(1-p_{\Omega}^{c}\right) \bar{k}_{\Omega}^{s}+p_{\Omega^{\prime}}^{c}\left(\bar{k}_{\Omega^{\prime}}^{c}-\bar{k}_{\Omega}^{c}\right)+p_{\Omega^{\prime}}^{c} \bar{k}_{\Omega}^{c}-p_{\Omega}^{c} \bar{k}_{\Omega}^{c} \\
& =\left(1-p_{\Omega^{\prime}}^{c}\left(\bar{k}_{\Omega^{\prime}}^{s}-\bar{k}_{\Omega}^{s}\right)-\left(p_{\Omega^{\prime}}^{c}-p_{\Omega}^{c}\right) \bar{k}_{\Omega}^{s}+p_{\Omega^{\prime}}^{c}\left(\bar{k}_{\Omega^{\prime}}^{c}-\bar{k}_{\Omega}^{c}\right)+\left(p_{\Omega^{\prime}}^{c}-p_{\Omega}^{c}\right) \bar{k}_{\Omega}^{c}\right. \\
& =\left(1-p_{\Omega^{\prime}}^{c}\right)\left(\bar{k}_{\Omega^{\prime}}^{s}-\bar{k}_{\Omega}^{s}\right)+p_{\Omega^{\prime}}^{c}\left(\bar{k}_{\Omega^{\prime}}^{c}-\bar{k}_{\Omega}^{c}\right)+\left(p_{\Omega^{\prime}}^{c}-p_{\Omega}^{c}\right)\left(\bar{k}_{\Omega}^{c}-\bar{k}_{\Omega}^{s}\right) .
\end{aligned}
$$

Combining equations (B.22) and (B.23) yields

$$
\begin{aligned}
g_{\bar{k}}= & \frac{\left(1-p_{\Omega}^{c}\right)\left(\bar{k}_{\Omega^{\prime}}^{s}-\bar{k}_{\Omega}^{s}\right)}{2 \bar{k}_{\Omega}}+\frac{\left(1-p_{\Omega^{\prime}}^{c}\right)\left(\bar{k}_{\Omega^{\prime}}^{s}-\bar{k}_{\Omega}^{s}\right)}{2 \bar{k}_{\Omega}}+\frac{p_{\Omega}^{c}\left(\bar{k}_{\Omega^{\prime}}^{c}-\bar{k}_{\Omega}^{c}\right)}{2 \bar{k}_{\Omega}}+\frac{p_{\Omega^{\prime}}^{c}\left(\bar{k}_{\Omega^{\prime}}^{c}-\bar{k}_{\Omega}^{c}\right)}{2 \bar{k}_{\Omega}} \\
& +\frac{\left(p_{\Omega^{\prime}}^{c}-p_{\Omega}^{c}\right)\left(\bar{k}_{\Omega^{\prime}}^{c}-\bar{k}_{\Omega^{\prime}}^{s}\right)}{2 \bar{k}_{\Omega}}+\frac{\left(p_{\Omega^{\prime}}^{c}-p_{\Omega}^{c}\right)\left(\bar{k}_{\Omega}^{c}-\bar{k}_{\Omega}^{s}\right)}{2 \bar{k}_{\Omega}} \\
= & {\left[\frac{\left(1-p_{\Omega}^{c}\right) \bar{k}_{\Omega}^{s}}{2 \bar{k}_{\Omega}}+\frac{\left(1-p_{\Omega^{\prime}}^{c}\right)}{2 \bar{k}_{\Omega}^{s}}\right] \frac{\bar{k}_{\Omega^{\prime}}^{s}-\bar{k}_{\Omega}^{s}}{\bar{k}_{\Omega}^{s}}+\left[\frac{p_{\Omega}^{c} \bar{k}_{\Omega}^{c}}{2 \bar{k}_{\Omega}}+\frac{p_{\Omega^{\prime}}^{c} \bar{k}_{\Omega}^{c}}{2 \bar{k}_{\Omega}}\right] \frac{\bar{k}_{\Omega^{\prime}}^{c}-\bar{k}_{\Omega}^{c}}{\bar{k}_{\Omega}^{c}} } \\
& +\left[\frac{p_{\Omega}^{c}\left(\bar{k}_{\Omega^{\prime}}^{c}-\bar{k}_{\Omega^{\prime}}^{s}\right)}{2 \bar{k}_{\Omega}}+\frac{p_{\Omega}^{c}\left(\bar{k}_{\Omega}^{c}-\bar{k}_{\Omega}^{s}\right)}{2 \bar{k}_{\Omega}}\right] \frac{p_{\Omega^{\prime}}^{c}-p_{\Omega}^{c}}{p_{\Omega}^{c}} \\
= & {\left[\frac{E_{\Omega}\left(1-p_{\Omega}^{c}\right) \bar{k}_{\Omega}^{s}}{2 K_{\Omega}}+\frac{E_{\Omega}\left(1-p_{\Omega^{\prime}}^{c}\right) \bar{k}_{\Omega}^{s}}{2 K_{\Omega}}\right] g_{\bar{k}^{s}}+\left[\frac{E_{\Omega} p_{\Omega}^{c} \bar{k}_{\Omega}^{c}}{2 K_{\Omega}}+\frac{E_{\Omega} p_{\Omega^{\prime}}^{c} \bar{k}_{\Omega}^{c}}{2 K_{\Omega}}\right] g_{\bar{k}^{c}} } \\
& +\left[\frac{E_{\Omega} p_{\Omega}^{c}\left(\bar{k}_{\Omega^{\prime}}^{c}-\bar{k}_{\Omega^{\prime}}^{s}\right)}{2 K_{\Omega}}+\frac{E_{\Omega} p_{\Omega}^{c}\left(\bar{k}_{\Omega}^{c}-\bar{k}_{\Omega}^{s}\right)}{2 K_{\Omega}}\right] g_{p^{c}} \\
= & s_{k}^{s} g_{\bar{k}^{s}}^{s}+s_{k}^{c} g_{\bar{k}^{c}}+s_{k}^{p} g_{p^{c}},
\end{aligned}
$$

where $s_{k}^{s}, s_{k}^{c}$, and $s_{k}^{p}$ are given by

$$
\begin{aligned}
& s_{k}^{s}=\frac{E_{\Omega}\left(1-p_{\Omega}^{c}\right) \bar{k}_{\Omega}^{s}}{2 K_{\Omega}}+\frac{E_{\Omega}\left(1-p_{\Omega^{\prime}}^{c}\right) \bar{k}_{\Omega}^{s}}{2 K_{\Omega}}, \\
& s_{k}^{c}=\frac{E_{\Omega} p_{\Omega}^{c} \bar{k}_{\Omega}^{c}}{2 K_{\Omega}}+\frac{E_{\Omega} p_{\Omega^{\prime}}^{c} \bar{k}_{\Omega}^{c}}{2 K_{\Omega}}, \\
& s_{k}^{p}=\frac{E_{\Omega} p_{\Omega}^{c}\left(\bar{k}_{\Omega^{\prime}}^{c}-\bar{k}_{\Omega^{\prime}}^{s}\right)}{2 K_{\Omega}}+\frac{E_{\Omega} p_{\Omega}^{c}\left(\bar{k}_{\Omega}^{c}-\bar{k}_{\Omega}^{s}\right)}{2 K_{\Omega}} .
\end{aligned}
$$

Substituting equation (B.24) into equation (B.21) yields

$$
g_{K}=g_{E}+s_{k}^{s} g_{\bar{k}^{s}}+s_{k}^{c} g_{\bar{k}^{c}}+s_{k}^{p} g_{p^{c}} .
$$


Similarly, we derive the percentage change in aggregate labor as

$$
g_{L}=g_{E}+s_{l}^{s} g_{\bar{l}}^{s}+s_{l}^{c} g_{\bar{l}^{c}}+s_{l}^{p} g_{p^{c}}
$$

where $s_{l}^{s}, s_{l}^{c}$, and $s_{l}^{p}$ are given by

$$
\begin{aligned}
& s_{l}^{s}=\frac{E_{\Omega}\left(1-p_{\Omega}^{c}\right) \bar{l}_{\Omega}^{s}}{2 L_{\Omega}}+\frac{E_{\Omega}\left(1-p_{\Omega^{\prime}}^{c}\right) \bar{l}_{\Omega}^{s}}{2 L_{\Omega}}, \\
& s_{l}^{c}=\frac{E_{\Omega} p_{\Omega}^{c} \bar{l}_{\Omega}^{c}}{2 L_{\Omega}}+\frac{E_{\Omega} p_{\Omega^{\prime}}^{c} \bar{l}_{\Omega}^{c}}{2 L_{\Omega}}, \\
& s_{l}^{p}=\frac{E_{\Omega} p_{\Omega}^{c}\left(\bar{l}_{\Omega^{\prime}}^{c}-\bar{l}_{\Omega^{\prime}}^{s}\right)}{2 L_{\Omega}}+\frac{E_{\Omega} p_{\Omega}^{c}\left(\bar{l}_{\Omega}^{c}-\bar{l}_{\Omega}^{s}\right)}{2 L_{\Omega}} .
\end{aligned}
$$

Substituting equations (B.28-B.29) into equation (B.14) yields

$$
g_{Y}=g_{\mathrm{TFP}}+g_{E}+\alpha\left(s_{k}^{s} g_{\bar{k}^{s}}+s_{k}^{c} g_{\bar{k}^{c}}+s_{k}^{p} g_{p^{c}}\right)+(1-\alpha)\left(s_{l}^{s} g_{\bar{l}^{s}}+s_{l}^{c} g_{\bar{l}^{c}}+s_{l}^{p} g_{p^{c}}\right)
$$

Growth Accounting by Regime. The economy's aggregate output $Y_{\Omega}$ is equal to the sum of the output of all regimes,

$$
Y_{\Omega}=E_{\Omega}\left(1-p_{\Omega}^{c}\right) \bar{y}_{\Omega}^{s}+E_{\Omega} p_{\Omega}^{c} \bar{y}_{\Omega}^{c}
$$

where $\bar{y}_{\Omega}^{s}$ and $\bar{y}_{\Omega}^{c}$ are the average output produced by entrepreneurs in the savings and credit regimes. By definition, we have

$$
\begin{aligned}
& \bar{y}_{\Omega}^{s} \iint_{(b, z) \in \Phi^{S}} h(b, z ; \Omega) \mathrm{d} b \mathrm{~d} z=\iint_{(b, z) \in \Phi^{S}} z\left[k(b, z ; \Omega)^{\alpha} l(b, z ; \Omega)^{1-\alpha}\right]^{1-\nu} h(b, z ; \Omega) \mathrm{d} b \mathrm{~d} z, \\
& \bar{y}_{\Omega}^{c} \iint_{(b, z) \in \Phi^{C}} h(b, z ; \Omega) \mathrm{d} b \mathrm{~d} z=\iint_{(b, z) \in \Phi^{C}} z\left[k(b, z ; \Omega)^{\alpha} l(b, z ; \Omega)^{1-\alpha}\right]^{1-\nu} h(b, z ; \Omega) \mathrm{d} b \mathrm{~d} z .
\end{aligned}
$$

Similar to equation (B.28) the percentage change in aggregate output when moving from the steady-state economy with $\Omega$ to the steady-state economy with $\Omega^{\prime}$ can be expressed as

$$
g_{Y}=g_{E}+s_{y}^{s} g_{\bar{y}^{s}}+s_{y}^{c} g_{\bar{y}^{c}}+s_{y}^{p} g_{p^{c}}
$$


where $s_{y}^{s}, s_{y}^{c}$, and $s_{y}^{p}$ are given by

$$
\begin{aligned}
s_{y}^{s} & =\frac{E_{\Omega}\left(1-p_{\Omega}^{c}\right) \bar{y}_{\Omega}^{s}}{2 Y_{\Omega}}+\frac{E_{\Omega}\left(1-p_{\Omega^{\prime}}^{c}\right) \bar{y}_{\Omega}^{s}}{2 Y_{\Omega}}, \\
s_{y}^{c} & =\frac{E_{\Omega} p_{\Omega}^{c} \bar{y}_{\Omega}^{c}}{2 Y_{\Omega}}+\frac{E_{\Omega} p_{\Omega^{\prime}}^{c} \bar{y}_{\Omega}^{c}}{2 Y_{\Omega}}, \\
s_{y}^{p} & =\frac{E_{\Omega} p_{\Omega}^{c}\left(\bar{y}_{\Omega^{\prime}}^{c}-\bar{y}_{\Omega^{\prime}}^{s}\right)}{2 Y_{\Omega}}+\frac{E_{\Omega} p_{\Omega}^{c}\left(\bar{y}_{\Omega}^{c}-\bar{y}_{\Omega}^{s}\right)}{2 Y_{\Omega}} .
\end{aligned}
$$

TFP Decomposition. Combining equations (B.33) and (B.37) yields

$$
\begin{aligned}
g_{\mathrm{TFP}}= & g_{p^{c}}\left[s_{y}^{p}-\alpha s_{k}^{p}-(1-\alpha) s_{l}^{p}\right]+s_{y}^{c} g_{\bar{y}^{c}}-\alpha s_{k}^{c} g_{\bar{k}^{c}}-(1-\alpha) s_{l}^{c} g_{\bar{l}^{c}} \\
& +s_{y}^{s} g_{\bar{y}^{s}}-\alpha s_{k}^{s} g_{\bar{k}^{s}}-(1-\alpha) s_{l}^{s} g_{\bar{l}^{s}} .
\end{aligned}
$$

Thus,

$$
\begin{aligned}
\operatorname{TFP}_{\Omega^{\prime}}-\operatorname{TFP}_{\Omega}= & g_{p^{c}}\left[s_{y}^{p}-\alpha s_{k}^{p}-(1-\alpha) s_{l}^{p}\right] \operatorname{TFP}_{\Omega}+\left[s_{y}^{c} g_{\bar{y}^{c}}-\alpha s_{k}^{c} g_{\bar{k}^{c}}-(1-\alpha) s_{l}^{c} g_{\bar{l}^{c}}\right] \operatorname{TFP}_{\Omega} \\
& +\left[s_{y}^{s} g_{\bar{y}^{s}}-\alpha s_{k}^{s} g_{\bar{k}^{s}}-(1-\alpha) s_{l}^{s} g_{\bar{l}^{s}}\right] \mathrm{TFP}_{\Omega} .
\end{aligned}
$$

\section{B.4 Proof of Proposition 4}

Consider an entrepreneur of $(b, z)$. Since labor supply is not subject to the collateral constraint, the optimal labor supply $l$ is linear in $k$

$$
l(z, k)=\left[\frac{(1-\alpha) z}{w}\right]^{\frac{1}{\alpha}} k .
$$

Substituting out $l(z, k)$, we derive output as a linear function of $k$,

$$
f(k, z)=z k^{\alpha} l^{1-\alpha}=z\left[\frac{(1-\alpha) z}{w}\right]^{\frac{1-\alpha}{\alpha}} k .
$$

With constant returns to scale, optimal capital demand has a bang-bang solution. If the agent chooses to be an entrepreneur, then $k=b$ in the savings regime and $k=(b-\psi) / \xi$ in the credit regime. Given $z$ and $b$, the entrepreneur's utility is increasing in current consumption $c$ and the future value $V\left(z^{\prime}, b^{\prime}\right)$, which increases with the next-period wealth $b^{\prime}$ for every realization of the next-period productivity $z^{\prime}$. Therefore, the optimal borrowing decision is determined to maximize the end-of-period wealth $\tilde{b}^{e}=c+b^{\prime}$.

Substituting equation (B.44) into the budget constraint in problems (2.7) and (2.8), we 
derive the end-of-period wealth in the savings regime as

$$
\begin{aligned}
\tilde{b}^{e, s}(b, z) & =z k^{\alpha} l^{1-\alpha}+(1-\delta) k-w l+(1+r)(b-k) \\
& =z\left[\frac{(1-\alpha) z}{w}\right]^{\frac{1-\alpha}{\alpha}} b+(1-\delta) b-w\left[\frac{(1-\alpha) z}{w}\right]^{\frac{1}{\alpha}} b,
\end{aligned}
$$

and the end-of-period wealth in the credit regime as

$$
\begin{aligned}
\tilde{b}^{e, c}(b, z)= & z k^{\alpha} l^{1-\alpha}+(1-\delta) k-w l-(1+r+\chi)(k-b+\psi) \\
= & z\left[\frac{(1-\alpha) z}{w}\right]^{\frac{1-\alpha}{\alpha}} k+(1-\delta) k-w\left[\frac{(1-\alpha) z}{w}\right]^{\frac{1}{\alpha}} k-(1+r+\chi)(k-b+\psi) \\
= & z\left[\frac{(1-\alpha) z}{w}\right]^{\frac{1-\alpha}{\alpha}} \frac{b-\psi}{\xi}+\frac{(1-\delta)(b-\psi)}{\xi}-w\left[\frac{(1-\alpha) z}{w}\right]^{\frac{1}{\alpha}} \frac{b-\psi}{\xi} \\
& -(1+r+\chi)\left(\frac{b-\psi}{\xi}-b+\psi\right) .
\end{aligned}
$$

The threshold of wealth $\underline{b}(z ; \Omega)$ is determined by $\tilde{b}^{e, s}(\underline{b}, z)=\tilde{b}^{e, c}(\underline{b}, z)$ :

$$
\underline{b}(z ; \Omega)=\frac{\psi}{1-\xi}+\frac{\psi}{1-\xi} \frac{(1+r+\chi) \xi}{z\left[\frac{(1-\alpha) z}{w}\right]^{\frac{1-\alpha}{\alpha}}-w\left[\frac{(1-\alpha) z}{w}\right]^{\frac{1}{\alpha}}-\delta-r-\chi} .
$$

Taking the first-order partial derivative, we derive the effect through the extensive margin from relaxing each financial constraint separately:

$$
\begin{gathered}
\frac{\partial \underline{b}}{\partial \psi}=\frac{1}{1-\xi}+\frac{1}{1-\xi} \frac{(1+r+\chi) \xi}{z\left[\frac{(1-\alpha) z}{w}\right]^{\frac{1-\alpha}{\alpha}}-w\left[\frac{(1-\alpha) z}{w}\right]^{\frac{1}{\alpha}}-\delta-r-\chi} \geq 0 ; \\
\frac{\partial \underline{b}}{\partial \xi}=\frac{\psi}{(1-\xi)^{2}}+\frac{\psi}{(1-\xi)^{2}} \frac{1+r+\chi}{z\left[\frac{(1-\alpha) z}{w}\right]^{\frac{1-\alpha}{\alpha}}-w\left[\frac{(1-\alpha) z}{w}\right]^{\frac{1}{\alpha}}-\delta-r-\chi} \geq 0 ; \\
\frac{\partial \underline{b}}{\partial \chi}=\frac{\psi \xi}{1-\xi} \frac{z\left[\frac{(1-\alpha) z}{w}\right]^{\frac{1-\alpha}{\alpha}}-w\left[\frac{(1-\alpha) z}{w}\right]^{\frac{1}{\alpha}}+1-\delta}{\left[z\left[\frac{(1-\alpha) z}{w}\right]^{\frac{1-\alpha}{\alpha}}-w\left[\frac{(1-\alpha) z}{w}\right]^{\frac{1}{\alpha}}-\delta-r-\chi\right]^{2} \geq 0 .}
\end{gathered}
$$

Taking the second-order cross-partial derivative, we derive the interaction effect through 
the extensive margin from relaxing two financial constraints jointly:

$$
\begin{aligned}
& \frac{\partial^{2} \underline{b}}{\partial \psi \partial \xi}=\frac{\partial^{2} \underline{b}}{\partial \xi \partial \psi}=\frac{1}{(1-\xi)^{2}}+\frac{1}{(1-\xi)^{2}} \frac{1+r_{t}+\chi}{z\left[\frac{(1-\alpha) z}{w}\right]^{\frac{1-\alpha}{\alpha}}-w\left[\frac{(1-\alpha) z}{w}\right]^{\frac{1}{\alpha}}-\delta-r-\chi} \geq 0 ; \\
& \frac{\partial^{2} \underline{b}}{\partial \xi \partial \chi}=\frac{\partial^{2} \underline{b}}{\partial \chi \partial \xi}=\frac{\psi}{(1-\xi)^{2}} \frac{z\left[\frac{(1-\alpha) z}{w}\right]^{\frac{1-\alpha}{\alpha}}-w\left[\frac{(1-\alpha) z}{w}\right]^{\frac{1}{\alpha}}+1-\delta}{\left[z\left[\frac{(1-\alpha) z}{w}\right]^{\frac{1-\alpha}{\alpha}}-w\left[\frac{(1-\alpha) z}{w}\right]^{\frac{1}{\alpha}}-\delta-r-\chi\right]^{2}} \geq 0 \\
& \frac{\partial^{2} \underline{b}}{\partial \chi \partial \psi}=\frac{\partial^{2} \underline{b}}{\partial \psi \partial \chi}=\frac{\xi}{1-\xi} \frac{z\left[\frac{(1-\alpha) z}{w}\right]^{\frac{1-\alpha}{\alpha}}-w\left[\frac{(1-\alpha) z}{w}\right]^{\frac{1}{\alpha}}+1-\delta}{\left.z\left[\frac{(1-\alpha) z}{w}\right]^{\frac{1-\alpha}{\alpha}}-w\left[\frac{(1-\alpha) z}{w}\right]^{\frac{1}{\alpha}}-\delta-r-\chi\right]^{2}} \geq 0
\end{aligned}
$$

\section{B.5 Proof of Proposition 5}

Substituting the optimal labor demand (B.43) and $k=(b-\psi) / \xi$ into equation (A.8) yields

$$
y^{C}(b, z ; \Omega)=\left[z\left[\frac{(1-\alpha) z}{w}\right]^{\frac{1-\alpha}{\alpha}}-\chi\right] \frac{b-\psi}{\xi}+\chi(b-\psi)-\psi
$$

Taking the first-order partial derivative, we derive the effect through the intensive margin from relaxing each financial constraint separately:

$$
\begin{gathered}
\frac{\partial y^{C}}{\partial \psi}=-\left[z\left[\frac{(1-\alpha) z}{w}\right]^{\frac{1-\alpha}{\alpha}}-\chi\right] \frac{1}{\xi}-\chi-1 \leq 0 ; \\
\frac{\partial y^{C}}{\partial \xi}=-\left[z\left[\frac{(1-\alpha) z}{w}\right]^{\frac{1-\alpha}{\alpha}}-\chi\right] \frac{b-\psi}{\xi^{2}} \leq 0 ; \\
\frac{\partial y^{C}}{\partial \chi}=-\frac{(1-\xi)(b-\psi)}{\xi} \leq 0 .
\end{gathered}
$$

Taking the second-order cross-partial derivative, we derive the interaction effect through 
Table B.1: Calibrated parameters fox six countries.

\begin{tabular}{ccccccc}
\hline Parameters & Pakistan & Bangladesh & Brazil & The Philippines & Kenya & Zambia \\
$\psi$ & 2.86 & 0.80 & 0.09 & 0.95 & 2.00 & 1.49 \\
$\xi$ & 0.315 & 0.568 & 0.001 & 0.335 & 0.165 & 0.520 \\
$\chi$ & 0.048 & 0.019 & 0.354 & 0.040 & 0.085 & 0.118 \\
$\beta$ & 0.79 & 0.89 & 0.97 & 0.88 & 0.89 & 0.66 \\
$\theta$ & 3.0 & 3.2 & 3.1 & 3.4 & 3.2 & 3.4 \\
$\gamma$ & 0.77 & 0.78 & 0.80 & 0.89 & 0.74 & 0.85 \\
\hline \hline
\end{tabular}

the intensive margin from relaxing two financial constraints jointly:

$$
\begin{gathered}
\frac{\partial^{2} y^{C}}{\partial \psi \partial \xi}=\frac{\partial^{2} y^{C}}{\partial \xi \partial \psi}=\left[z\left[\frac{(1-\alpha) z}{w}\right]^{\frac{1-\alpha}{\alpha}}-\chi\right] \frac{1}{\xi^{2}} \geq 0 \\
\frac{\partial^{2} y^{C}}{\partial \xi \partial \chi}=\frac{\partial^{2} y^{C}}{\partial \chi \partial \xi}=\frac{b-\psi}{\xi^{2}} \geq 0 \\
\frac{\partial^{2} y^{C}}{\partial \chi \partial \psi}=\frac{\partial^{2} y^{C}}{\partial \psi \partial \chi}=\frac{1-\xi}{\xi} \geq 0
\end{gathered}
$$

\section{Supplementary Information on Model Analysis}

\section{C.1 Financial Characteristics and Equilibrium Prices}

Our calibration uses the credit access ratio, the collateral-to-loan ratio, and the interest rate spread to determine the three key parameters $\psi, \xi$, and $\chi$. Figure C.1 illustrates how these moments are jointly determined by the three parameters. As shown in panels A1, B1, and $\mathrm{C} 1$, reducing the credit entry cost $\psi$, relaxing the collateral constraint $\xi$, and reducing the intermediation cost $\chi$ all lead to a higher credit access ratio and more inclusion. However, as we have discussed in Section 2, these financial frictions are meant to capture different types of constraints. Particularly, the parameter $\psi$ captures an ex-ante friction in obtaining credit access, but not the ex-post terms of loan contracts within the credit regime. Thus, a lower $\psi$ increases the credit access ratio but has a negligible effect on the collateral-to-loan ratio and the interest rate spread (panels A2 and A3). The other two parameters, $\xi$ and $\chi$, capture ex-post frictions within the credit regime. Thus, a lower $\xi$ and a lower $\chi$ imply a lower collateral-to-loan ratio (panel B2) and a lower interest rate spread (panel C3), respectively. Better terms of loan contracts motivate entrepreneurs to access credit by paying the credit entry $\operatorname{cost} \psi$. Thus, even if $\psi$ remains unchanged, the credit access ratio increases due to lower $\xi$ and $\chi$. 

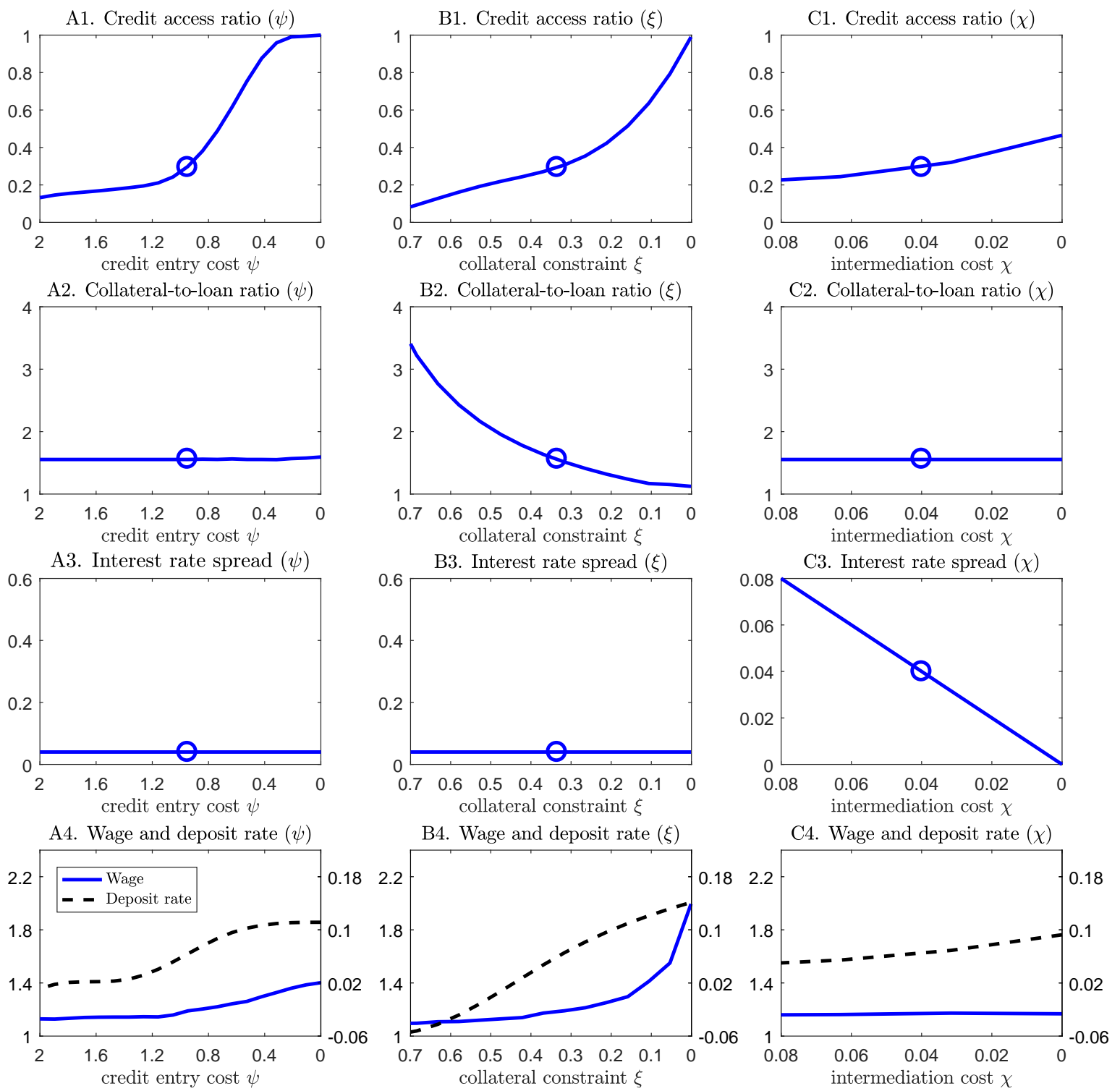

Note: Panels A1, B1, and C1 plot the steady-state fraction of entrepreneurs with access to credit when $\psi$, $\xi$, or $\chi$ is reduced while the other two parameters are held at their calibrated values. Panels A2, B2, and C2 plot the average steady-state collateral-to-loan ratio, $k / x$. Panels A3, B3, and $\mathrm{C} 3$ plot the interest rate spread $\chi$ between the deposit rate $r$ and the lending rate $r^{l}$. In panels $\mathrm{A} 4, \mathrm{~B} 4$, and $\mathrm{C} 4$, the left $\mathrm{y}$-axis refers to the steady-state wage (the blue solid line); and the right y-axis refers to the steady-state deposit rate (the black dashed line). The blue circle in each panel represents the corresponding value under our calibration in Table 1.

Figure C.1: Financial characteristics and equilibrium prices.

\section{C.2 The Distribution of Income and Wealth}

In panels A1, B1, and C1 of Figure C.2, we plot the steady-state income Gini when $\psi$, $\xi$, or $\chi$ is reduced while holding the other two parameters at their calibrated values.

Panel A1 of Figure C.2 indicates that the steady-state income Gini increases before 
declining when the credit entry cost $\psi$ is reduced from 2 to 0 . We obtain this inverted $\mathrm{U}$ curve due to reasons mentioned for Figure 3. For high values of $\psi$, reducing the credit entry cost does not generate a significant effect through the extensive margin and GDP increases mainly through the intensive margin. However, entrepreneurs in the credit regime already earn more than others. Thus, a policy change that further increases their income leads to higher income inequality. When $\psi$ is further lowered, the effect through the extensive margin starts to dominate as more entrepreneurs in the savings regime enter the credit regime. The improved credit access for these entrepreneurs not only increases their income but also generates significant upward pressure on the equilibrium wage, thereby reducing income inequality.

We can also see the rich dynamics of different income groups in panel A2, which plots the share of total income for the top $10 \%$ and the bottom $50 \%$ of the steady-state income distribution, and for the middle class. The top $10 \%$ mainly consist of wealthy and productive entrepreneurs within the credit regime, whose income share (the blue solid line) displays a shape similar to the income Gini. The bottom $50 \%$ consist of workers, whose income share (the black dashed line) displays a U shape, opposite to the top 10\%. The middle class (the red dash-dotted line) mainly consists of productive, but less wealthy entrepreneurs plus some rich workers with high interest income. Clearly, the main driver for the turning point (at $\psi=1.1$ ) of the steady-state income Gini curve is the rise of the middle class due to improved credit access. The dramatic expansion of the middle class's businesses results in a wage takeoff (panel A4 of Figure C.1), which increases the income share of the bottom $50 \%$ and lowers that of the top $10 \%$.

Panel B1 shows that the steady-state income Gini also increases before declining when the collateral constraint $\xi$ is relaxed. Similar to the turning point in the previous experiment, the turning point in the experiments of $\xi$ also coincides with the value of $\xi$ at which the equilibrium wage takes off (panel B4 of Figure C.1). As shown in panel B2, the main driver for the wage takeoff is the middle class who expands production due to relaxed collateral requirements. By contrast, our simulation indicates that reducing the intermediation cost $\chi$ always leads to higher income inequality (panel C1). Panel C2 shows that there is a slight increase in the steady-state income share of the top $10 \%$ (the blue solid line) and a slight decrease in that of the bottom 50\% (the black dashed line). The middle class's steady-state income share is barely changed (the red dash-dotted line) and as a result, the equilibrium wage stays put (panel C4 of Figure C.1).

In panels A3, B3, and C3, we plot the share of total wealth for the top $10 \%$ and the bottom $50 \%$ of the steady-state wealth distribution, and the middle class. The composition of each wealth group is similar to that of the corresponding income group. The steady-state 

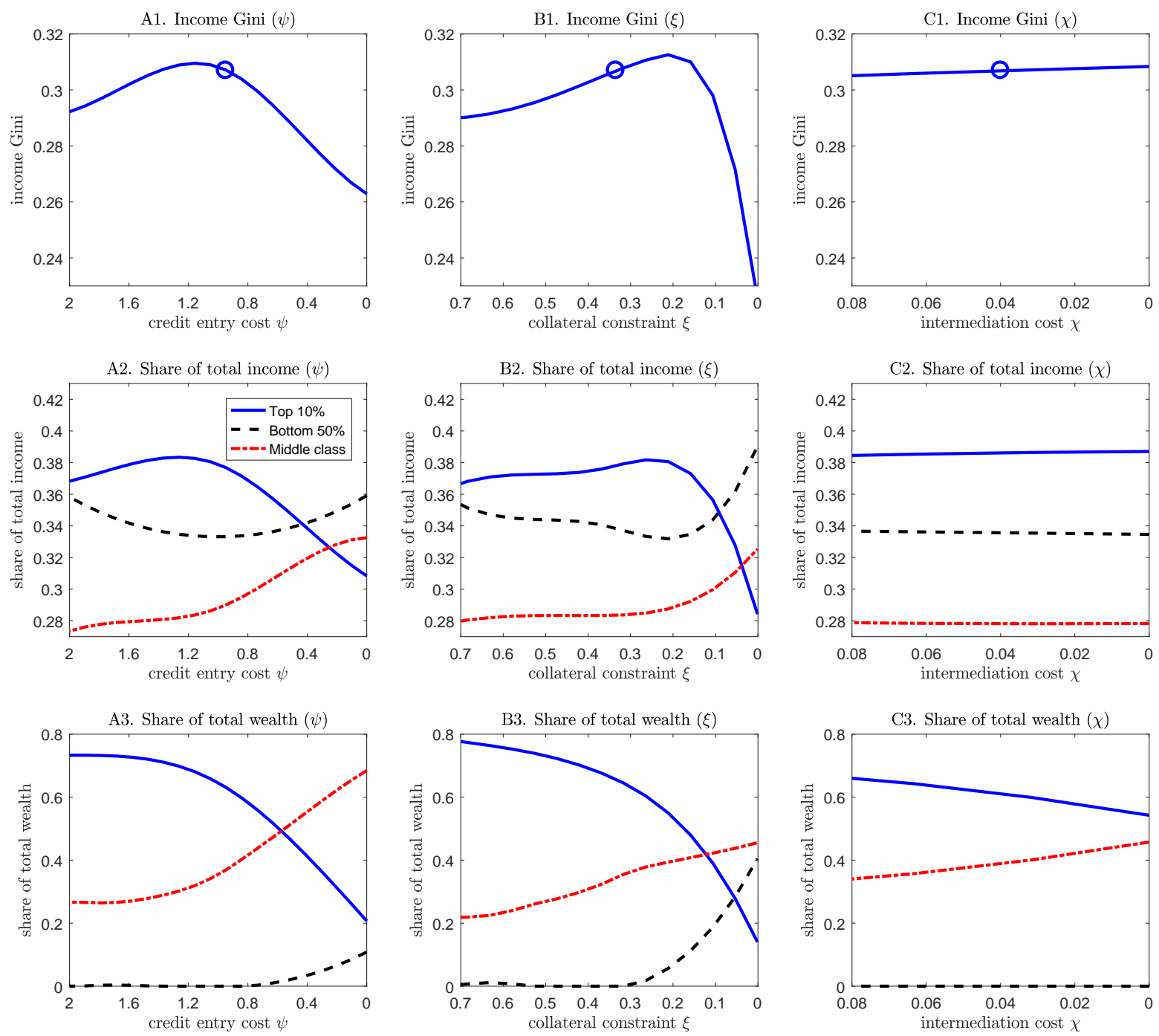

Note: In panels A1, B1, and C1, we plot the steady-state income Gini when $\psi, \xi$, or $\chi$ is reduced while holding the other two parameters at their calibrated values. In panels A2, B2, and C2, we plot the share of total income for the top $10 \%$ and the bottom $50 \%$ of the steady-state income distribution, and the middle class. In panels A3, B3, and C3, we plot the share of total wealth for the top $10 \%$ and the bottom $50 \%$ of the steady-state wealth distribution, and the middle class. The middle class refers to people whose income/wealth is below the $10 \%$ threshold and above the $50 \%$ threshold. The blue circle in each panel represents the corresponding value under our calibration in Table 1.

Figure C.2: Impact of financial inclusion on the distribution of income and wealth.

wealth share of the top $10 \%$ always decreases after any one of the three financial constraints is relaxed. This is because when financial constraints are relaxed, credit effectively becomes cheaper and more accessible. Thus, in steady states, wealthy and productive entrepreneurs do not need to accumulate as much wealth to operate their businesses at the unconstrained scale (Figure 2). Therefore, they reduce savings, leading to a lower wealth share of the top 
$10 \%$ and a higher wealth share of the rest.

Our results on wealth inequality seem to be contradict the work of Cagetti and De Nardi (2006), who show that when financial constraints become more stringent, both the wealth share of entrepreneurs and wealth inequality decrease. We obtain a different implication on wealth inequality because of the different sensitivity of the endogenous interest rate to financial constraints. Specifically, tightening the financial constraints lowers the equilibrium interest rate in our model whereas it increases the equilibrium interest rate in the model of Cagetti and De Nardi (2006). A lower interest rate dampens the incentive for workers to save, resulting in a lower share of wealth for workers and higher wealth inequality. By contrast, a higher interest rate motivates workers to save, which increases their share of total wealth, resulting in lower wealth inequality.

The key reason why our interest rate responds negatively to a tighter financial constraint is because we do not model the corporate sector. In our model, a tighter financial constraint exacerbates the misallocation of entrepreneurial productivity (see, e.g., Moll, 2014, for insightful discussions), which lowers the economy's TFP. A lower TFP reduces the marginal product of capital, which in turn lowers the interest rate. This negative effect on the interest rate through the endogenous TFP channel dominates the positive effect on interest rate caused by a lower aggregate capital (and higher aggregate labor), leading to a lower equilibrium interest rate. By contrast, in the model of Cagetti and De Nardi (2006), the economy's TFP is a weighted average of the productivity of the corporate sector and the endogenous aggregate productivity of the entrepreneurial sector. Since the productivity of the corporate sector is a constant, introducing the corporate sector dampens the response of TFP to tightened financial constraints. In other words, the negative effect on the interest rate through the endogenous TFP channel is weaker in their model. Based on their calibration, the negative effect through the endogenous TFP channel is dominated by the positive effect through lower aggregate capital (and higher aggregate labor), and thus the interest rate responds positively to a tighter financial constraint (see Table 7 of Cagetti and De Nardi, 2006).

We find that our results are consistent with the findings of Quadrini (2000), whose model also has a corporate sector. In particular, Table XII of Quadrini (2000) reports that when the economy is moving from one with zero intermediation cost to one with intermediation cost (i.e., the baseline economy), the wealth share of the top 1\%, $5 \%, 10 \%, 20 \%$, and $30 \%$ will increase and the wealth Gini will also increase. This seems to suggest that in a model with both the corporate sector and the entrepreneurial sector, the response of the equilibrium interest rate to financial constraints largely depends on the calibration, and in particular, the relative importance of the two sectors in determining the economy's TFP. 


\section{C.3 Interactions in Partial Equilibrium}

In this appendix, we conduct similar counterfactual experiments to the ones in Figure 4 to study the interaction effect in partial equilibrium. Specifically, in these experiments, the interest rate, the wage, and the distribution of agents are fixed at their steady-state values of our calibrated economy.

Comparing the general-equilibrium simulation results (Figure 4) with those of the partial equilibrium (Figure C.3), two differences stand out. First, the increase in steady-state GDP owing to relaxing financial constraints is smaller in general equilibrium (the blue solid line) because of the increase in the equilibrium interest rate and wage. Second, the savings regime negatively contributes to the increase in steady-state GDP in all counterfactual experiments of general equilibrium whereas the contribution of the savings regime to the increase in steady-state GDP is always zero in partial equilibrium. However, our main finding in general equilibrium, that the interaction effect through the intensive margin dominates that through the extensive margin, remains robust.
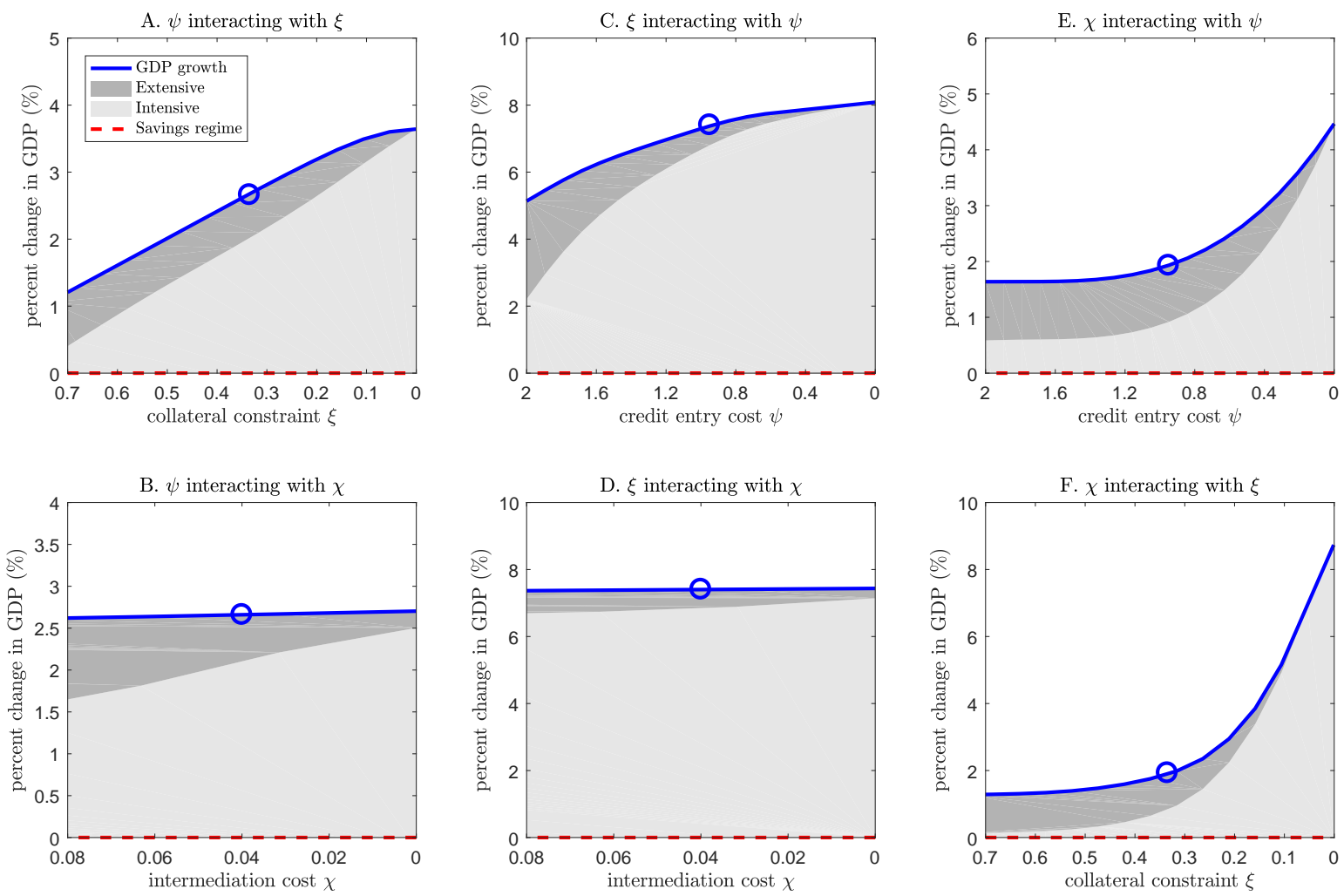

Note: This figure visualizes the interaction effects among financial constraints in partial equilibrium. The descriptions of each panel are similar to those in Figure 4.

Figure C.3: Interaction effects among financial constraints in partial equilibrium. 


\section{C.4 Decomposition of the Increase in GDP and TFP}

We use formulas (4.1) and (4.2) to understand the margins through which steady-state GDP and TFP increase after relaxing various forms of financial constraints. Tables C.2 and C.3 present the decomposition of the increase in steady-state GDP and TFP for all six countries. For each country, we conduct three experiments: (1) the general equilibrium where the deposit rate and wage are endogenously determined in the new steady state; (2) the partial equilibrium where the deposit rate and wage are fixed at their values in the initial steady state before various forms of financial constraints are relaxed; and (3) the small-open-economy experiment where the interest rate is fixed at its value in the initial steady state but wage is endogenously determined in the new steady state. The third experiment is useful because several of these countries have fairly open capital accounts, and are not well represented by a closed-economy model. Moreover, the third experiment allows us to understand the relative importance of the interest rate and wage movement in driving the difference between the results of general equilibrium and those of partial equilibrium.

The following conclusions can be drawn from our analyses: (1) The increase in steady-state GDP and TFP caused by reducing the collateral constraint $\xi$ to zero is mainly attributed to the intensive margin; (2) depending on country characteristics, the increase in steady-state GDP and TFP caused by reducing the credit entry cost $\psi$ to zero could be mainly attributed to the extensive margin (Pakistan, the Philippines, Kenya, and Zambia) or the intensive margin (Bangladesh); (3) reducing the intermediation cost to zero usually has a smaller effect on steady-state GDP and TFP except for Brazil. In Brazil, the large increase in steady-state GDP and TFP from reducing the intermediation cost is mostly attributed to the intensive margin; (4) the savings regime always negatively contributes to the increase in steady-state GDP and TFP, because relaxing any financial constraint would motivate more productive entrepreneurs to move from the savings regime to the credit regime; (5) the most binding constraints identified in partial equilibrium are the same as those in general equilibrium, although the increase in steady-state GDP and TFP is larger; (6) the small-open-economy experiment suggests that in most cases, both the endogenous movement in the interest rate and wage should be considered when analyzing the steady-state increase GDP and TFP in general equilibrium.

\section{C.5 Transitional Dynamics of Financial Inclusion}

In this appendix, we study the transitional dynamics after implementing financial inclusion policies. Starting from the calibrated steady state of each country, we consider an unexpected shock that occurs in year 5 , which permanently reduces one of the financial constraint 
Table C.2: Decomposing the increase in steady-state GDP due to financial inclusion.

\begin{tabular}{|c|c|c|c|c|c|c|c|c|c|c|}
\hline & & \multicolumn{3}{|c|}{ General Equilibrium } & \multicolumn{3}{|c|}{ Partial Equilibrium } & \multicolumn{3}{|c|}{ Fixed Deposit Rate } \\
\hline & & $\psi \rightarrow 0$ & $\xi \rightarrow 0$ & $\chi \rightarrow 0$ & $\psi \rightarrow 0$ & $\xi \rightarrow 0$ & $\chi \rightarrow 0$ & $\psi \rightarrow 0$ & $\xi \rightarrow 0$ & $\chi \rightarrow 0$ \\
\hline & Extensive margin $(\%)$ & 15.70 & 13.34 & 0.01 & 284.08 & 361.97 & 0.03 & 146.96 & 211.20 & 0.02 \\
\hline \multirow[t]{4}{*}{ Pakistan } & Intensive margin (\%) & 15.20 & 128.02 & 0.11 & 41.68 & 833.26 & 0.18 & 25.74 & 618.83 & 0.14 \\
\hline & Savings regime $(\%)$ & -5.94 & -51.65 & -0.01 & 0.00 & 0.00 & 0.00 & -2.17 & -33.65 & 0.00 \\
\hline & Total $(\%)$ & 24.96 & 89.71 & 0.11 & 325.76 & 1195.23 & 0.21 & 170.53 & 796.38 & 0.16 \\
\hline & Extensive margin (\%) & 3.67 & 41.34 & 0.12 & 55.68 & 61.53 & 0.18 & 27.44 & 49.78 & 0.15 \\
\hline \multirow[t]{4}{*}{ Bangladesh } & Intensive margin (\%) & 6.90 & 127.46 & 0.39 & 158.76 & 1487.82 & 0.54 & 70.91 & 917.90 & 0.49 \\
\hline & Savings regime $(\%)$ & -1.63 & -56.87 & -0.01 & 0.00 & 0.00 & 0.00 & -0.79 & -24.55 & 0.00 \\
\hline & Total $(\%)$ & 8.94 & 111.92 & 0.50 & 214.45 & 1549.35 & 0.72 & 97.56 & 943.13 & 0.64 \\
\hline & Extensive margin $(\%)$ & 0.01 & 0.00 & 4.25 & 0.32 & 0.00 & 74.44 & 0.22 & 0.00 & 37.51 \\
\hline \multirow[t]{4}{*}{ Brazil } & Intensive margin (\%) & 0.01 & 0.00 & 38.66 & 0.20 & 0.00 & 494.04 & 0.15 & 0.00 & 279.88 \\
\hline & Savings regime $(\%)$ & 0.00 & 0.00 & -0.47 & 0.00 & 0.00 & 0.00 & 0.00 & 0.00 & -0.19 \\
\hline & Total $(\%)$ & 0.02 & 0.00 & 42.44 & 0.53 & 0.00 & 568.49 & 0.37 & 0.00 & 317.20 \\
\hline & Extensive margin $(\%)$ & 7.53 & 34.61 & 1.09 & 30.78 & 54.28 & 1.28 & 17.29 & 46.12 & 1.24 \\
\hline \multirow[t]{4}{*}{ The Philippines } & Intensive margin (\%) & 2.76 & 73.81 & 0.23 & 7.18 & 649.66 & 0.65 & 4.94 & 348.06 & 0.59 \\
\hline & Savings regime $(\%)$ & -1.04 & -48.69 & -0.62 & 0.00 & 0.00 & 0.00 & -0.47 & -15.73 & -0.07 \\
\hline & Total $(\%)$ & 9.25 & 59.73 & 0.70 & 37.96 & 703.94 & 1.93 & 21.76 & 378.45 & 1.76 \\
\hline & Extensive margin $(\%)$ & 13.34 & 3.61 & 1.47 & 43.86 & 5.61 & 12.80 & 31.75 & 4.77 & 7.98 \\
\hline \multirow[t]{4}{*}{ Kenya } & Intensive margin (\%) & 10.22 & 18.51 & 0.97 & 38.89 & 51.36 & 1.56 & 24.79 & 33.62 & 1.36 \\
\hline & Savings regime $(\%)$ & -2.54 & -8.35 & -0.03 & 0.00 & 0.00 & 0.00 & -1.06 & -4.38 & -0.01 \\
\hline & Total $(\%)$ & 21.01 & 13.77 & 2.41 & 82.76 & 56.97 & 14.36 & 55.48 & 34.01 & 9.33 \\
\hline & Extensive margin $(\%)$ & 14.59 & 13.45 & 1.90 & 32.88 & 247.04 & 3.62 & 21.45 & 135.7 & 2.27 \\
\hline \multirow[t]{3}{*}{ Zambia } & Intensive margin (\%) & 6.49 & 117.45 & 1.26 & 13.13 & 963.18 & 2.17 & 10.19 & 682.82 & 1.54 \\
\hline & Savings regime $(\%)$ & -10.86 & -49.05 & -1.66 & 0.00 & 0.00 & 0.00 & -3.66 & -17.20 & -0.79 \\
\hline & Total (\%) & 10.22 & 81.85 & 1.50 & 46.01 & 1210.22 & 5.79 & 27.98 & 801.32 & 3.02 \\
\hline
\end{tabular}

parameters (i.e., $\psi, \xi$, or $\chi$ ) to zero. Figures C.4 and C.5 plot the transitional dynamics of GDP, TFP, the income Gini coefficient, interest rate, and wage.

Across the six countries, GDP, TFP, and the income Gini coefficient converge to their new steady-state values in about $10-20$ years. Transition is gradual because reallocation of capital is intermediated through imperfect financial markets (see, e.g., Jermann and Quadrini, 2007; Buera and Shin, 2011). For the simulated path of transitional dynamics in each country, we observe overshooting in the equilibrium interest rate; that is, the interest rate in the short run is higher than that in the long run after financial inclusion (panels A4, B4, and C4 of Figures C.4 and C.5) There is no overshooting of the equilibrium wage. In all six countries, and across the three different financial inclusion policies, the equilibrium wage surges in year 5 , reflecting the immediate increase in demand for workers when constraints are relaxed. Moreover, the equilibrium wage steadily increases thereafter to reach its new steady-state value due to the gradual accumulation and reallocation of capital (panels A5, B5, and C5 of Figures C.4 and C.5).

GDP increases substantially in year 5 and more gradually thereafter (panels A1, B1, and 
Table C.3: Decomposing the increase in steady-state TFP due to financial inclusion.

\begin{tabular}{|c|c|c|c|c|c|c|c|c|c|c|}
\hline & & \multicolumn{3}{|c|}{ General Equilibrium } & \multicolumn{3}{|c|}{ Partial Equilibrium } & \multicolumn{3}{|c|}{ Fixed Deposit Rate } \\
\hline & & $\psi \rightarrow 0$ & $\xi \rightarrow 0$ & $\chi \rightarrow 0$ & $\psi \rightarrow 0$ & $\xi \rightarrow 0$ & $\chi \rightarrow 0$ & $\psi \rightarrow 0$ & $\xi \rightarrow 0$ & $\chi \rightarrow 0$ \\
\hline & Extensive margin $(\%)$ & 20.75 & 13.76 & 0.00 & 22.06 & 23.05 & 0.00 & 21.33 & 19.54 & 0.00 \\
\hline \multirow[t]{4}{*}{ Pakistan } & Intensive margin (\%) & 4.23 & 54.38 & 0.01 & 11.18 & 68.20 & 0.03 & 8.76 & 65.04 & 0.02 \\
\hline & Savings regime $(\%)$ & -15.27 & -12.55 & 0.00 & 0.00 & 0.00 & 0.00 & -8.34 & -5.45 & 0.00 \\
\hline & Total $(\%)$ & 9.71 & 55.59 & 0.01 & 33.24 & 91.25 & 0.03 & 21.75 & 79.13 & 0.02 \\
\hline & Extensive margin (\%) & 2.34 & 22.19 & 0.42 & 9.15 & 26.79 & 0.45 & 7.21 & 24.13 & 0.44 \\
\hline \multirow[t]{4}{*}{ Bangladesh } & Intensive margin (\%) & 4.21 & 89.34 & 0.06 & 17.19 & 100.50 & 0.10 & 12.69 & 94.38 & 0.07 \\
\hline & Savings regime $(\%)$ & -4.22 & -34.05 & -0.07 & 0.00 & 0.00 & 0.00 & -1.59 & -13.07 & -0.03 \\
\hline & Total $(\%)$ & 2.33 & 77.48 & 0.41 & 26.34 & 127.29 & 0.55 & 18.31 & 105.44 & 0.48 \\
\hline & Extensive margin $(\%)$ & 0.00 & 0.00 & 15.17 & 0.16 & 0.00 & 18.01 & 0.09 & 0.00 & 16.95 \\
\hline \multirow[t]{4}{*}{ Brazil } & Intensive margin (\%) & 0.01 & 0.00 & 23.78 & 0.11 & 0.00 & 49.55 & 0.09 & 0.00 & 38.08 \\
\hline & Savings regime (\%) & 0.00 & 0.00 & -0.64 & 0.00 & 0.00 & 0.00 & 0.00 & 0.00 & -0.31 \\
\hline & Total $(\%)$ & 0.01 & 0.00 & 38.31 & 0.27 & 0.00 & 67.56 & 0.18 & 0.00 & 54.72 \\
\hline & Extensive margin (\%) & 4.74 & 15.01 & 0.49 & 6.47 & 17.92 & 0.97 & 5.55 & 17.07 & 0.94 \\
\hline \multirow[t]{4}{*}{ The Philippines } & Intensive margin (\%) & 1.21 & 39.32 & 0.13 & 1.38 & 77.12 & 0.55 & 1.30 & 61.52 & 0.50 \\
\hline & Savings regime $(\%)$ & -1.17 & -16.91 & -0.12 & 0.00 & 0.00 & 0.00 & -0.38 & -6.40 & -0.01 \\
\hline & Total $(\%)$ & 4.78 & 37.42 & 0.50 & 7.85 & 95.04 & 1.52 & 6.47 & 72.19 & 1.43 \\
\hline & Extensive margin $(\%)$ & 8.37 & 2.59 & 0.77 & 11.02 & 3.53 & 3.89 & 9.63 & 2.66 & 2.22 \\
\hline \multirow[t]{4}{*}{ Kenya } & Intensive margin (\%) & 6.84 & 8.92 & 0.41 & 9.18 & 11.25 & 0.58 & 7.83 & 9.06 & 0.53 \\
\hline & Savings regime $(\%)$ & -3.51 & -3.68 & -0.27 & 0.00 & 0.00 & 0.00 & -2.01 & -1.69 & -0.18 \\
\hline & Total $(\%)$ & 11.70 & 7.83 & 0.91 & 20.20 & 14.78 & 4.47 & 15.45 & 10.03 & 2.57 \\
\hline & Extensive margin $(\%)$ & 5.53 & 9.45 & 0.91 & 6.37 & 33.35 & 1.44 & 6.01 & 20.35 & 1.18 \\
\hline \multirow[t]{3}{*}{ Zambia } & Intensive margin (\%) & 2.71 & 44.98 & 0.59 & 3.40 & 79.30 & 1.28 & 3.06 & 71.57 & 0.93 \\
\hline & Savings regime $(\%)$ & -2.90 & -6.67 & -0.37 & 0.00 & 0.00 & 0.00 & -1.25 & -2.79 & -0.15 \\
\hline & Total $(\%)$ & 5.34 & 47.76 & 1.13 & 9.77 & 112.65 & 2.72 & 7.82 & 89.13 & 1.96 \\
\hline
\end{tabular}

Note: When performing the decomposition of the savings regime in partial equilibrium, we focus on agents that are in the savings regime both before and after financial inclusion for consistency with our GDP decomposition in partial equilibrium.

C1 of Figures C.4 and C.5). The positive effect of financial inclusion on GDP is larger in the long run than in the short run. Intuitively, this is because it takes time for entrepreneurs to accumulate wealth to fully reap the gains from financial inclusion policies. This intuition is closely related to the finding of Moll (2014), who shows that the negative welfare effect of financial frictions is larger in the short run than in the long run as entrepreneurs can accumulate capital to alleviate constraints.

In terms of TFP, we find that reducing the credit entry cost $\psi$ to zero generates overshooting in the short-run dynamics (panel A2 of Figures C.4 and C.5) in all six countries, although the overshooting may happen with a lag in some countries (see the red dash-dotted line for Zambia in panel A2 of Figure C.5). By contrast, relaxing the collateral constraint $\xi$ to zero does not generate an overshooting effect (panel B2 of Figures C.4 and C.5). In all six countries, TFP surges in year 5 before plateauing to reach its new steady-state value. Reducing the intermediation cost generates an overshooting effect in all six countries except for Brazil (panel C2 of Figures C.4 and C.5), although the magnitude of overshooting is small 

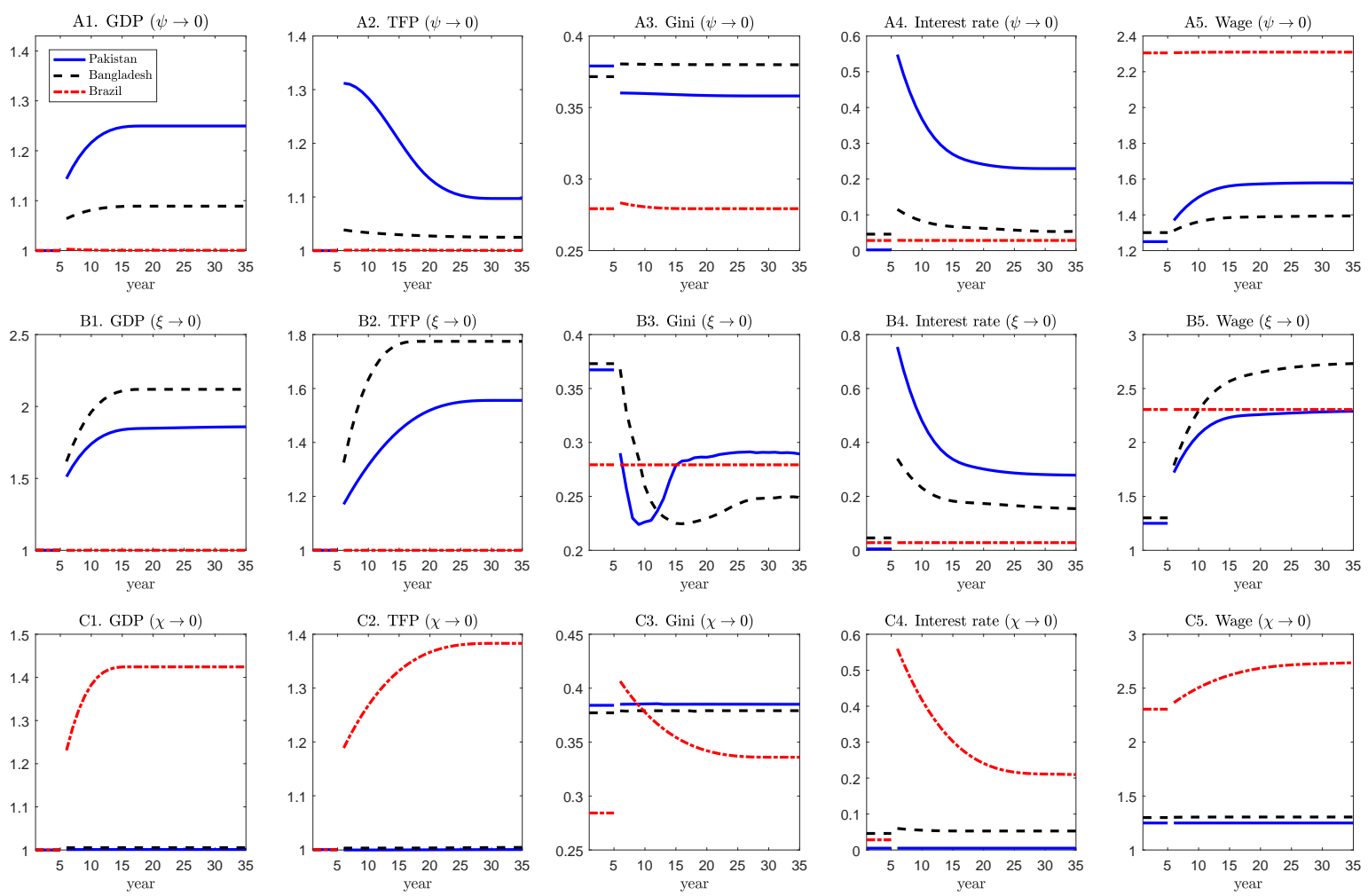

Note: In all experiments, we start with the steady state of the calibrated economy in year 1 , and consider an unexpected shock in year 5, which reduces one of the financial constraint parameters (i.e., $\psi$, $\xi$, or $\chi$ ) to zero permanently. Panels A1-A5, B1-B5, and C1-C5 plot the model-implied transitional dynamics of GDP, TFP, the income Gini coefficient, interest rate, and wage for reducing $\psi, \xi$, and $\chi$ to zero, respectively.

Figure C.4: Transitional dynamics for Pakistan, Bangladesh, and Brazil.

due to the relatively small long-run effect on TFP in these countries. Brazil's TFP displays different dynamics because its high intermediation cost is the most binding constraint, which is not the case in other countries.

In terms of income inequality, we find that reducing the credit entry cost $\psi$ may lead to a higher or a lower long-run Gini coefficient, depending on the country (panel A3 of Figures C.4 and C.5). Relaxing the collateral constraint $\xi$ results in a lower Gini coefficient in the long run, and overshooting occurs in the short run (panel B3 of Figures C.4 and C.5). Reducing the intermediation cost $\chi$ leads to a higher Gini coefficient in the long run (panel C3 of Figures C.4 and C.5). In Brazil, reducing the intermediation cost leads to higher GDP and income inequality. However, the effect on GDP is smaller in the short run than in the long run whereas the opposite is true for income inequality (see the red dash-dotted line in panel C3 of Figure C.4).

Overall, our simulation indicates that the short-run implications of reducing different 

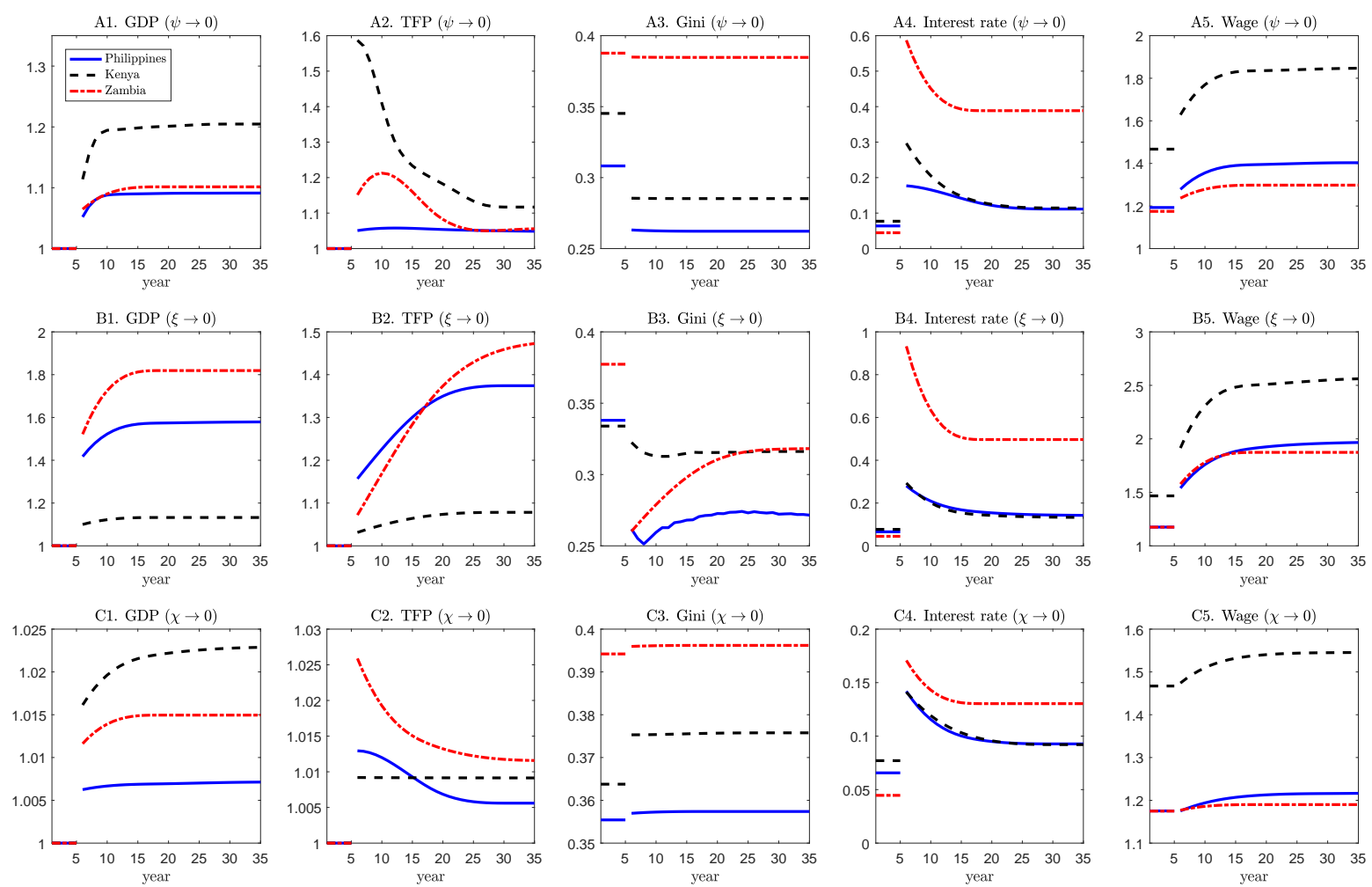

Note: The descriptions of each experiment are similar to those in Figure C.4.

Figure C.5: Transitional dynamics for the Philippines, Kenya, and Zambia.

financial constraints on GDP, TFP, income inequality, and the equilibrium interest rate and wage could be very different than their long-run effects. Such intertemporal tradeoffs may raise concerns for policy makers depending on their objectives. For the same financial inclusion policy, the transitional dynamics in different countries share many common features. However, the dynamics also exhibit some degree of heterogeneity, depending on the characteristics of a country's financial system.

Welfare Gains during Economic Transitions. To understand the welfare implications of financial liberalization, we use the model to compute the welfare gains along the transition paths.

Suppose financial inclusion policies are implemented unexpectedly in year $t=t^{\prime}$ in a steady-state economy of financial characteristics $\Omega$ (as in above experiments). These policies change the financial characteristics permanently to $\Omega^{\prime}$ for all $t \geq t^{\prime}$ (similar to our experiments in Figures C.4 and C.5). By varying $t^{\prime}$ from $-\infty$ to 0 , we can capture an economy that is $-t^{\prime}$ years after the implementation of financial inclusion policies from the perspective of year 
$t=0$. For example, in year $t=0$, the economy has already reached the steady state of $\Omega^{\prime}$ if $t^{\prime}=-\infty$; the economy is 10 years after financial liberalization and is still in transition if $t^{\prime}=-10$; and the economy has just started financial liberalization if $t^{\prime}=0$. Therefore, by considering different values of $t^{\prime} \leq 0$, we can calculate welfare gains from financial inclusion policies at any point in time along the transition path.

Our welfare calculation is based on the consumption-equivalent measure. Denote by $\left\{c_{t}\right\}_{t=0}^{\infty}$ the consumption path of a generic agent for $t \geq 0$ in an economy where financial inclusion policies were implemented at $t^{\prime} \leq 0$. Denote by $\left\{\bar{c}_{t}\right\}_{t=0}^{\infty}$ the consumption path of a generic agent in an otherwise identical economy in which financial inclusion policies were not implemented, namely, this economy stays at the original steady state with $\Omega$. The conditional welfare gain $\omega(b, z)$ for type- $(b, z)$ is defined as

$$
\mathbb{E}_{0}\left[\sum_{t=0}^{\infty} \beta^{t} u\left([1+\omega(b, z)] \bar{c}_{t}\right)\right]=\mathbb{E}_{0}\left[\sum_{t=0}^{\infty} \beta^{t-t^{\prime}} u\left(c_{t}\right)\right]
$$

Because $u\left(c_{t}\right)=c_{t}^{1-\sigma} /(1-\sigma)$, we can exploit the homogeneity of the utility function and the equation above becomes

$$
[1+\omega(b, z)]^{1-\sigma} V(b, z ; \Omega)=V_{0}\left(b, z ; \Omega^{\prime}, t^{\prime}\right)
$$

where $V(b, z ; \Omega)$ represents the value function in the steady state of the pre-financial-inclusion economy with $\Omega$; and $V_{0}\left(b, z ; \Omega^{\prime}, t^{\prime}\right)$ represents the value function at $t=0$ in the economy with $\Omega^{\prime}$ whose financial inclusion policies are implemented at $t^{\prime} \leq 0$. The conditional welfare gain is

$$
\omega\left(b, z \mid \Omega^{\prime}, t^{\prime}\right)=\left[\frac{V_{0}\left(b, z ; \Omega^{\prime}, t^{\prime}\right)}{V(b, z ; \Omega)}\right]^{\frac{1}{1-\sigma}}-1 .
$$

We consider a utilitarian social welfare function, which gives the welfare change of the whole economy as follows:

$$
\omega\left(\Omega^{\prime}, t^{\prime}\right)=\left[\frac{\iint V_{0}\left(b, z ; \Omega^{\prime}, t^{\prime}\right) h_{0}\left(b, z ; \Omega^{\prime}, t^{\prime}\right) \mathrm{d} b \mathrm{~d} z}{\iint V(b, z ; \Omega) h(b, z ; \Omega) \mathrm{d} b \mathrm{~d} z}\right]^{\frac{1}{1-\sigma}}-1
$$

In Table C.4, we report $\omega\left(\Omega^{\prime}, t^{\prime}\right)$ for $t^{\prime}=0, t^{\prime}=-10$, and $t^{\prime}=-\infty$, corresponding to the welfare gains immediately after financial inclusion, 10 years after financial inclusion, and in the new steady state after financial liberalization. It is shown that the welfare gains from financial inclusion policies are about 20 - 40\% larger in the long-run steady state than in the short run, immediately after implementing these policies. Moreover, most of the welfare gains are realized in the first 10 years. This is because the productive but poor agents would 
Table C.4: Welfare gains during transitions.

\begin{tabular}{lccccccccc}
\hline & \multicolumn{3}{c}{$\psi \rightarrow 0$} & \multicolumn{3}{c}{$\xi \rightarrow 0$} & \multicolumn{3}{c}{$\chi \rightarrow 0$} \\
\hline & $t^{\prime}=0$ & $t^{\prime}=-10$ & $t^{\prime}=-\infty$ & $t^{\prime}=0$ & $t^{\prime}=-10$ & $t^{\prime}=-\infty$ & $t^{\prime}=0$ & $t^{\prime}=-10$ & $t^{\prime}=-\infty$ \\
Pakistan (\%) & 4.85 & 7.40 & 7.96 & 16.39 & 23.68 & 25.95 & 0.67 & 1.80 & 2.06 \\
Bangladesh (\%) & 2.08 & 2.90 & 3.12 & 39.50 & 61.54 & 62.22 & 0.19 & 0.28 & 0.94 \\
Brazil (\%) & 0.79 & 0.79 & 0.80 & 0.00 & 0.00 & 0.000 & 45.59 & 62.15 & 70.46 \\
The Philippines (\%) & 3.95 & 4.98 & 5.29 & 17.39 & 22.65 & 25.10 & 1.17 & 2.05 & 2.50 \\
Kenya (\%) & 3.87 & 4.68 & 4.94 & 14.78 & 18.86 & 20.35 & 3.88 & 6.73 & 8.22 \\
Zambia (\%) & 2.70 & 4.27 & 4.36 & 13.73 & 20.61 & 20.85 & 0.49 & 1.18 & 1.27 \\
\hline \hline
\end{tabular}

enjoy benefits of the financial inclusion policies only in the distant future, after accumulating enough capital to make it worthwhile for themselves to utilize financial services. By contrast, a steady-state on-off comparison implicitly assumes that the allocation of capital across agents has been sufficiently made more efficient so that productive agents can better use financial services immediately after a policy change. As emphasized by Townsend and Ueda (2010), transitional dynamics create more complex effects than in a simple on-off experiment.

\section{C.6 Comparison with Models with a Single Constraint}

A unique feature of our model is that it incorporates three different sources of financial frictions. Each source of friction reflects one particular aspect of financial market imperfection. By modeling all of them in the same framework, we can not only better match the data on financial system characteristics, but also study how these constraints interact in equilibrium and thus offer richer policy implications. In this appendix section, we take our lead calibration, the Philippines, as an example to illustrate how the quantitative performance of our model differs from existing models with only one constraint.

In the macro-development literature, for example, the seminar work of Greenwood and Jovanovic (1990) introduces the idea of a fixed entry cost, and Townsend and Ueda (2006) take a quantitative version of their model seriously to the data. Buera, Kaboski and Shin (2011) and Buera and Shin (2013) focus on the collateral constraint. Greenwood, Sanchez and Wang $(2010,2013)$ quantify the importance of the intermediation cost. By modifying our model with one single constraint, we can capture the main feature of existing models. In particular, we consider the following three special cases of our model. In the first case, we fix $\xi=\chi=0$ and calibrate $\psi$ to match the country's ratio of private credit to GDP, following the standard in the literature. In the second case, we fix $\psi=\chi=0$ and calibrate $\xi$ to match the country's ratio of private credit to GDP. In the third case, we fix $\xi=\chi=0$ and calibrate $\psi$ to match the country's ratio of private credit to GDP. The other parameters are calibrated similarly as described in Section 3. We then compare these models' implications with those of 
Table C.5: Calibration and moments in data and different versions of our model.

\begin{tabular}{lccccc}
\hline & Data & Baseline Model & Model 1 (only $\psi$ ) & Model 2 (only $\xi$ ) & Model 3 (only $\chi$ ) \\
Private credit-to-GDP (\%) & 41.7 & 27.8 & 41.7 & 41.7 & 41.6 \\
Firms with credit (\%) & 29.9 & 29.5 & 18.8 & 100.0 & 66.8 \\
Collateral (\% of loans) & 156.7 & 156.4 & 100.5 & 176.5 & 100.8 \\
Interest rate spread (\%) & 4.0 & 4.0 & 0.0 & 0.0 & 34.0 \\
\hline \hline
\end{tabular}

our baseline model. When calibrating the baseline model, we follow the calibration in Section 3 by targeting the percentage of firms with credit, the collateral-to-loan ratio, and the interest rate spread; and we treat the country's ratio of private credit to GDP as a non-targeted moment.

Table C.5 reports the implied financial characteristics of these four different models. It is shown that our baseline model with all three frictions implies a private credit-to-GDP ratio that is lower than the data. The other three models are calibrated to match the credit-to-GDP ratio. However, they do not match the country's other characteristics.

Specifically, the first model with only credit entry cost $\psi$ implies that only $18.8 \%$ of the firms have access to credit compared to $29.9 \%$ in the data. Moreover, targeting the credit-to-GDP ratio requires a calibration of $\psi=4.9$, which is about $24.6 \%$ of the average wealth of entrepreneurs in the credit regime. If the model were calibrated to target the $18.8 \%$ credit access, it would imply a credit-to-GDP ratio equal to $112 \%$, which is much larger than the value in data. The collateral-to-loan ratio and interest rate spread are not matched well due to the lack of collateral constraint and intermediation costs. The second model with only collateral constraints implies that every entrepreneur has access to credit due to the absence of credit entry cost. The third model with only intermediation costs also implies that a large fraction of entrepreneurs would obtain credit access once it is calibrated to match the credit-to-GDP ratio. Moreover, the interest rate spread implied by the model is $34 \%$, which is also much higher than the value in the data. ${ }^{16}$

We further evaluate the quantitative implications of these models on GDP, TFP, and inequality, by moving from the calibrated value of financial frictions to an economy with a perfect financial market. That is, in our baseline model, because we have three constraints governed by three parameters, we set all three parameters $\psi=\xi=\chi=0$ to obtain a perfect financial market. In the first model, the only financial constraint is the positive credit entry $\operatorname{cost} \psi$, and so we set $\psi=0$ to obtain a perfect financial market; in the second model, the only financial constraint is the collateral constraint governed by parameter $\xi$, and so we set $\xi=0$; and in the third model, the only financial constraint is the positive intermediation

\footnotetext{
${ }^{16}$ In the literature, the models emphasizing intermediation costs choose to target the interest rate spread, instead of the credit-to-GDP ratio.
} 
Table C.6: GDP, TFP, and inequality implied by different models.

\begin{tabular}{lcccc}
\hline & Baseline Model & Model 1 (only $\psi)$ & Model 2 (only $\xi)$ & Model 3 (only $\chi$ ) \\
GDP (\%) & 135.2 & 109.0 & 123.8 & 79.5 \\
TFP (\%) & 73.9 & 55.3 & 67.2 & 42.4 \\
Gini & -0.092 & -0.068 & -0.070 & -0.048 \\
\hline \hline
\end{tabular}

cost $\chi$, and so we set $\chi=0$.

Table C.6 shows that our baseline model implies the highest increase in GDP and TFP and the largest decrease in the Gini coefficient of income once the economy's financial frictions are removed. For example, the baseline model implies an increase in GDP by $135.2 \%$ whereas the first model, which only focuses on the credit entry cost, implies an increase in GDP by $109.0 \%$.

Further, the baseline model allows us to separately evaluate how relaxing different constraints contributes differently to GDP, TFP, and income inequality. For example, in panel B of Table 2, we can see that for the Philippines, reducing the credit entry cost increases GDP by $9.25 \%$, whereas relaxing the collateral constraint increases GDP by $59.73 \%$ and reducing the intermediation cost increases GDP by $0.70 \%$. Therefore, if our goal is only to evaluate the effect from alleviating one particular constraint, e.g., the credit entry cost, our baseline model would imply a smaller effect (i.e., 9.25\%) than that implied by the first model (i.e., 109.0\%), which only focuses on the credit entry cost. This result is perhaps not surprising. Given that these models only focus on one specific financial constraint, they tend to attribute the overall effect of financial inclusion to the relaxation of one particular constraint.

Moreover, comparing the baseline model's implication in Table C.6 to its implication in panel B of Table 2 where we remove each financial constraint separately, we find that removing all constraints simultaneously increases GDP by $135.2 \%$, which is much larger than the sum of the increases in GDP from removing the constraints individually, i.e., $9.25 \%+59.73 \%+0.70 \%=69.68 \%$. This is consistent with our analysis in Section 4.3 , which suggests that the interaction effect of different constraints through the intensive margin dominates that through the extensive margin, leading to an overall positive interaction effect on GDP. In other words, our baseline model implies that removing one particular financial constraint would have a much smaller impact on GDP than removing all three financial constraints together. By modeling all three constraints in a unified framework, our model can help policy makers to better evaluate and understand different sources of financial frictions, and hence to design more relevant financial inclusion policies. 


\section{C.7 Calibration to Thailand}
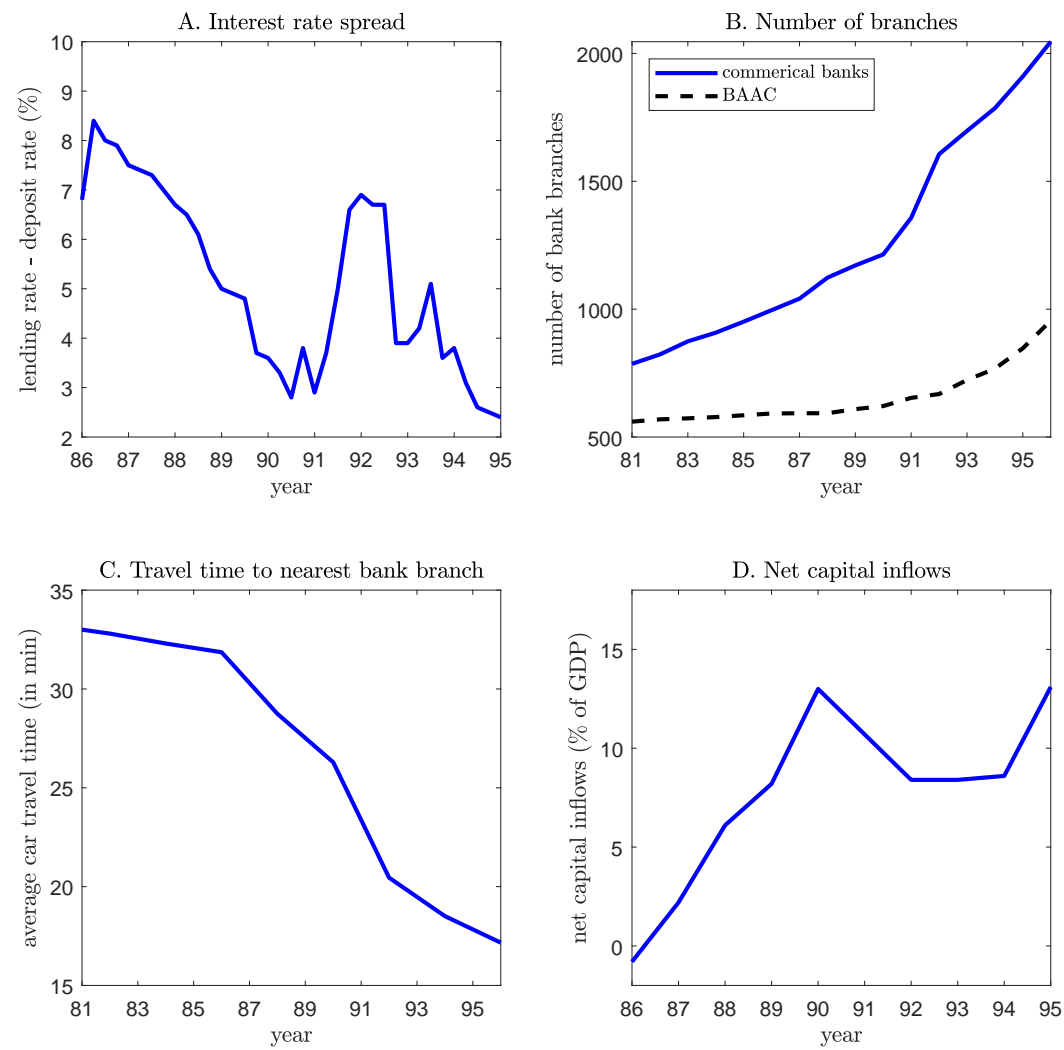

Note: Panel A plots the trend of interest rate spread (prime lending rate minus deposit rate) between 1986-1995. Data are from various issues of Financial Institutions and Markets in Thailand, published by the Bank of Thailand. Financial policies led to the expansion of business operations of banks. As of 1987, Thailand's formal financial system consisted of commercial banks, finance companies, credit financier companies, government savings banks, private and government insurance companies, and a number of sectorally and functionally specialized financial institutions. The central players in the Thai financial system are commercial banks which absorb $80.9 \%$ of deposits and account for $73.1 \%$ of total financial system assets. The second largest players are specialized government banks, known as Bank for Agriculture and Agricultural Cooperatives (BAAC), capturing $9.5 \%$ of total financial system deposits and $14.2 \%$ of total financial system assets. The competitive market environment created after financial liberalization gave the financial institutions strong incentives to expand their business operations. Panel B presents the number of branches operated by commercial banks and BAAC in different locations over the period 1981-1996. The number of commercial bank branches had been steadily increasing since the late $80 \mathrm{~s}$, and more than doubled by the end of 1996. Importantly, a substantial number of branches were opened in different locations to explore underdeveloped areas, thereby leading to a significant decrease in the car-travel time to the nearest bank branch (panel C). Panel D plots capital flows between 1980 and 1995. Data are from Alba, Hernandez and Klingebiel (1999, Figure 2) and the Bank of Thailand. The Bank of Thailand includes nonbank and bank capital flows. The former includes foreign direct investment, portfolio capital, nonresident baht accounts, trade credits, and syndicated borrowing by domestic corporates from overseas financial institutions. The bank flows are resident banks borrowing from overseas sources.

Figure C.6: Access to formal finance in Thailand, 1981-1996.

In this appendix, we provide details on calibrating the model to evaluate the Thai economy in Section 5.2. Since our focus is on evaluating the financial liberalization policies from 1986 to 1995 , we allow the key parameters $\psi_{t}, \xi_{t}$, and $\chi_{t}$ governing credit access in Thailand to be potentially time-varying. Their values are fixed after 1996 so that we can attain a steady 
Table C.7: Calibration of policy reform parameters in Thailand

\begin{tabular}{lcccccccccc}
\hline \hline & 86 & 87 & 88 & 89 & 90 & 91 & 92 & 93 & 94 & 95 \\
\hline$\chi_{t}(\%)$ & 8.00 & 7.70 & 6.88 & 5.35 & 3.85 & 3.30 & 6.30 & 4.68 & 3.90 & 2.40 \\
$\varsigma_{t}(\%)$ & -0.80 & 2.20 & 6.10 & 8.20 & 13.00 & 10.70 & 8.40 & 8.40 & 8.60 & 13.10 \\
$\psi_{t}$ & 0.72 & 0.64 & 0.56 & 0.48 & 0.40 & 0.32 & 0.24 & 0.16 & 0.08 & 0 \\
$\xi_{t}$ & 0.9 & 0.82 & 0.74 & 0.66 & 0.58 & 0.51 & 0.43 & 0.35 & 0.27 & 0.19 \\
\hline \hline
\end{tabular}

state at which backward induction is applied to solve the transitional dynamics. In particular, the parameter $\chi_{t}$ is calibrated to match the average annualized quarterly interest rate spread in each year (see panel A of Figure C.6) from 1986 to 1995. We introduce net international capital flows to the model, which increases the aggregate supply of capital by an amount equal to $\varsigma_{t} \mathrm{GDP}_{t}$. We calibrate $\varsigma_{t}$ year by year according to panel D of Figure C.6. The capital market clearing condition in equation (2.9) is modified as follows:

$$
\begin{array}{r}
\iint_{(b, z) \in \Phi_{t}^{C}}\left[k_{t}(b, z)-b+\psi_{t}\right] h_{t}(b, z) \mathrm{d} b \mathrm{~d} z=\iint_{(b, z) \notin \Phi_{t}^{E}} b h_{t}(b, z) \mathrm{d} b \mathrm{~d} z+\iint_{(b, z) \in \Phi_{t}^{S}}\left[b-k_{t}(b, z)\right] h_{t}(b, z) \mathrm{d} b \mathrm{~d} z \\
+\varsigma_{t}\left[\iint_{(b, z) \in \Phi_{t}^{S}} y_{t}^{S}(b, z) h_{t}(b, z) \mathrm{d} b \mathrm{~d} z+\iint_{(b, z) \in \Phi_{t}^{C}} y_{t}^{C}(b, z) h_{t}(b, z) \mathrm{d} b \mathrm{~d} z\right], \quad(C .5)
\end{array}
$$

where $y_{t}^{S}(b, z)$ and $y_{t}^{C}(b, z)$ are defined according to Appendix A:

$$
\begin{aligned}
& y_{t}^{S}(b, z)=z\left(k_{t}(b, z)^{\alpha} l_{t}(b, z)^{1-\alpha}\right)^{1-\nu}, \\
& y_{t}^{C}(b, z)=z\left(k_{t}(b, z)^{\alpha} l_{t}(b, z)^{1-\alpha}\right)^{1-\nu}-\chi_{t}\left(k_{t}(b, z)-b+\psi_{t}\right)-\psi_{t} .
\end{aligned}
$$

We calibrate the initial credit entry cost $\psi_{t}$ to be 0.72 in 1986 so that $10 \%$ of households have access to credit at the beginning of the simulation, as in the data. We assume that the value of $\psi_{t}$ decreases by the same amount in each year until it vanishes in 1996 . We do not have reliable data to calibrate the tightness of the collateral constraint in 1986. Because the public development bank in Thailand had much fewer branches than commercial banks, the loans were mostly made by commercial banks which were quite stringent in lending (see Assuncao, Mityakov and Townsend, 2012). We thus set the initial $\xi_{t}$ in 1986 to a high value, 0.9. We allow it to decrease by the same amount in each year until it reaches 0.19 in 1996, which allows the model to match the median loan-to-collateral ratio in the 1997 Townsend Thai annual survey. The values of these policy reform parameters are tabulated in Table C.7.

The other parameters are calibrated as follows. We set the risk aversion parameter to $\sigma=1.5$. We set $\alpha=0.33$ and $\nu=0.16$ according to the estimate of Paweenawat and Townsend 
(2014) using the Townsend Thai data. In the Townsend Thai data, households' production activities are classified into four types depending on the sector: business, cultivation, fish and shrimp, or livestock. Cultivation activity is the most labor-intensive, while fish and shrimp activity is the least labor-intensive. Our calibration relies on the average estimates of the four activities weighted by the number of observations. The one-year depreciation rate $\delta$ is set to 0.08 according to the estimate of Samphantharak and Townsend (2009). We calibrate the annual discount factor $\beta=0.85$ to match the real interest of $11.5 \%$ in Thailand in 1986 . We calculate the parameter $\theta=3.7$ to match the fraction of labor force $(72.2 \%)$ employed by the top $20 \%$ of firms (sorted by total employment) in the World Bank's Enterprise Surveys of Thailand.

The 1997 Townsend Thai annual survey has 10,602 respondents reporting the number of years that household members have been involved in the current business. This provides information to identify the persistence parameter $\gamma$ governing the probability of a change in productivity. We calibrate the value of $\gamma$ to 0.72 , which allows us to capture the cumulative distribution of the number of years that households have maintained in their current businesses (see Figure C.7).

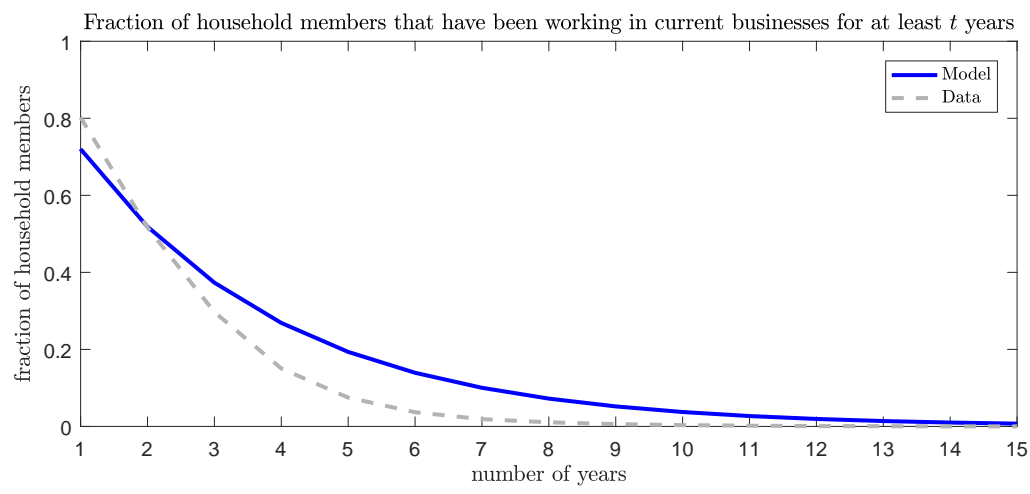

Figure C.7: Calibrating the persistence parameter $\gamma$ of entrepreneurial productivity.

\section{Numerical Algorithm}

We allow wealth $b$ to vary from 0 to 5 , and verify that further increasing wealth does not affect the simulation results. To ensure accuracy, we use 1,000 grids with equal length to discretize the support of wealth when approximating the value functions. We use 100,000 grids to discretize the support of wealth when running simulations. The values between wealth grids are approximated by linear interpolation. We allow productivity $z$ to vary from 1 to the value corresponding to $99.95 \%$ of the cumulative distribution function. We use 50 
grids with equal length to discretize the support of productivity. We use the golden-section search method to find the optimal decision rules. The advantage of the golden-section search method is that it is robust to the choice of initial values because convergence is guaranteed. The numerical algorithm is implemented with parallel computing using $\mathrm{C}++$ and OpenMP.

\section{Computing the Steady State.}

(0) Start from some arbitrary distribution $h_{0}(b, z)$.

(1) Guess the wage in the steady state, $w$.

(2) Guess the interest rate in the steady state, $r$.

(3) Given the interest rate $r$ and wage $w$, solve the agent's problem (2.4-2.8) and obtain optimal policies $c(b, z ; w, r), k(b, z ; w, r)$, and $l(b, z ; w, r)$ as well as the set of agents who choose to be entrepreneurs $\Phi^{E}(w, r)$ and the set of entrepreneurs who choose to enter the credit regime $\Phi^{C}(w, r)$.

(4) Forward simulate the model by $T$ periods using the optimal policy functions. We set $T=100$, which is long enough to ensure that the economy reaches the steady state. Calculate the steady-state joint distribution of wealth and productivity $h_{T}(b, z)$ according to equation (2.11).

(5) Check the capital market clearing condition (2.9) in period $T$. If there is excess capital demand (supply), choose a new interest rate $r$ that is greater (smaller) than $r$ and return to step (3). We use bi-section search to form the new guess.

(6) Check the labor market clearing condition (2.10) in period $T$. If there is excess labor demand (supply), choose a new wage $w$ that is greater (smaller) than $w$ and return to step (2).

\section{Computing the Transitional Dynamics.}

(0) Solve the steady-state distribution before implementing the financial inclusion policy $h^{\text {pre }}(b, z)$, and the steady-state distribution after implementing the financial inclusion policy $h^{\text {post }}(b, z)$.

(1) Start from the steady-state distribution before implementing the financial inclusion policy, i.e., $h_{0}(b, z)=h^{\text {pre }}(b, z)$. 
(2) Guess the wage path $\left\{w_{t}\right\}_{t=0}^{T}$, where $T$ is set long enough to ensure that the economy can reach the steady state after implementing the financial inclusion policy.

(3) Guess the interest rate path $\left\{r_{t}\right\}_{t=0}^{T}$.

(4) Taking the wage path $\left\{w_{t}\right\}_{t=0}^{T}$ and interest rate path $\left\{r_{t}\right\}_{t=0}^{T}$ as given, solve the agent's problem (2.4-2.8) for $t=T, \ldots, 0$ using backward induction, starting from $t=T$. We obtain optimal policies $\left\{c_{t}(b, z ; w, r), k_{t}(b, z ; w, r), l_{t}(b, z ; w, r)\right\}_{t=0}^{T}$ as well as the set of agents who choose to be entrepreneurs $\left\{\Phi_{t}^{E}(w, r)\right\}_{t=0}^{T}$ and the set of entrepreneurs who choose to enter the credit regime $\left\{\Phi_{t}^{C}(w, r)\right\}_{t=0}^{T}$.

(5) Forward simulate the model by $T$ periods using the optimal policy functions, starting from $t=0$. Calculate the joint distribution of wealth and productivity $\left\{h_{t}(b, z)\right\}_{t=0}^{T}$ according to equation (2.11).

(6) For each $t=0,1, \ldots, T$, holding $h_{t}(b, z)$ and $w_{t}$ constant, find the implied interest rate $\tilde{r}_{t}$ that clears the capital market (2.9).

(7) Calculate $\operatorname{diff}_{r}=\max \left\{\left|r_{t}-\tilde{r}_{t}\right|\right.$, for $\left.t=0,1, \ldots, T\right\}$. If $\operatorname{diff}_{r}>10^{-5}$, replace $r_{t}$ with $\left(r_{t}+\tilde{r}_{t}\right) / 2$ for $t=0,1, \ldots, T$ and return to step (4).

(8) For each $t=0,1, \ldots, T$, holding $h_{t}(b, z)$ and $r_{t}$ constant, find the implied wage $\tilde{w}_{t}$ that clears the labor market (2.10).

(9) Calculate $\operatorname{diff}_{w}=\max \left\{\left|w_{t}-\tilde{w}_{t}\right|\right.$, for $\left.t=0,1, \ldots, T\right\}$. If $\operatorname{diff}_{w}>10^{-5}$, replace $w_{t}$ with $\left(w_{t}+\tilde{w}_{t}\right) / 2$ for $t=0,1, \ldots, T$ and return to step $(3)$. 